\title{
Comparison of MAGIC and DIATOM Paleolimnological Model Hindcasts of Lakewater Acidification in the Adirondack Region of New York
}
T. J. Sullivan
B. J. Cosby
J. A. Bernert
D. F. Charles
E. A. Jenne
A. R. Selle
J. M. Eilers

March 1991

Prepared for the U.S. Department of Energy under Contract DE-AC06-76RLO 1830

Pacific Northwest Laboratory

Operated for the U.S. Department of Energy

by Battelle Memorial Institute 


\title{
DISCLAIMER
}

This report was prepared as an account of work sponsored by an agency of the United States Government. Neither the United States Government nor any agency thereof, nor Battelle Memorial Institute, nor any of their employees, makes any warranty, expressed or implied, or assumes any legal liability or responsibility for the accuracy, completeness, or usefulness of any information, apparatus, product, or process disclosed, or represents that its use would not infringe privately owned rights. Reference herein to any specific commercial product, process, or service by trade name, trademark, manufacturer, or otherwise does not necessarily constitute or imply its endorsement, recommendation, or favoring by the United States Government or any agency thereof, or Battelle Memorial institute. The views and opinions of authors expressed herein do not necessarily state or reflect those of the United States Government or any agency thereof.

\author{
PACIFIC NORTHWEST LABORATORY \\ operated by \\ BATTELLE MEMORIAL INSTITUTE \\ for the \\ UNITED STATES DEPARTMENT OF ENERGY \\ under Contract DE-ACO6-76RLO 1830
}

Printed in the United States of America

Available to DOE and DOE contractors from the

Office of Scientific and Technical Information, P.O. Box 62, Oak Ridge, TN 37831; prices available from (615) 576-8401. FTS 626-840t.

Available to the public from the National Technical Information Service, U.S. Department of Commerce, 5285 Port Royal Rd., Springfield, VA 22161. 
PNL-7487

UC -603

COMPARISON OF MAGIC AND DIATOM PALEOLIMNOLOGICAL MODEL HINDCASTS OF LAKEWATER ACIDIFICATION IN THE ADIRONDACX REGION OF NEW YORK

T. J. Sullivan(a)

J. A. Bernert(a)

B. J. Cosby(b)

E. A. Jenne

J. M. Eilers(a)

D. F. Charles(c)

A. R. Selle(d)

March 1991

Prepared for

the U.S. Department of Energy

under Contract DE-AC06-76RLO 1830

Pacific Northwest Laboratory

Richland, Washington 99352

(a) E\&S Environmental Chemistry, P.0. Box 609, Corvallis, OR 97339.

(b) School of Forestry and Environmental Sciences, Duke University, Durham, NC 27706.

(c) Department of Biology, Indiana University, c/o U.S. Environmental Protection Agency, Environmental Research Labortory

200 S.W. 35th St., Corvallis, OR 97333

(d) NSI Technology Services Corporation, c/o U.S. Environmental Protection Agency, Environmental Research Laboratory 200 S.W. 35th St., Corvallis, OR 97333. 


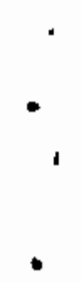

I •

,

.

. 


\section{PREFACE}

This research was funded primarily by the U.S. Department of Energy (DOE) with additional support from the U.S. Environmental Protection Agency (EPA). Because the research reported here draws upon many National Acid Precipitation Assessment (NAPAP) studies that are being completed coincident with the present work, the authors find it necessary to cite many sources that are either in press, in review, or unpublished. This research has not been subjected to Agency review and no official endorsement is implied. The authors wish to thank Walter Warnick of DOE and Dixon Landers of EPA for their encouragement and support, Robert Turner and Craig Brandt of Oak Ridge National Laboratory for assistance in data analysis, S. S. Dixit and B. F. Cumming of Queen's University for providing unpublished data; and E. C. Krug of the Illinois State Hater Survey for his detailed critique of the report. This research would not have been possible without the considerable efforts of Robbins Church and coworkers in the Direct Delayed Response Project and of John Smol and coworkers in the PIRLA-II project. 
. 
$\underline{\text { ABSTRACT }}$

Thirty-three lakes that had been statistically selected as part of the U.S. Environmental Protection Agency's Eastern Lake Survey and Direct Delayed Response Project (DDRP) were used to compare the MAGIC (watershed) and Diatom (paleolimnological) models. The study lakes represented a well-defined group of Adirondack lakes, each larger than 4 ha in area and having acidneutralizing capacity (ANC) $<400 \mu \mathrm{eq} \mathrm{L}^{-1}$. The study first compared current and pre-industrial (before 1850) $\mathrm{pH}$ and ANC estimates from Diatom and MAGIC as they were calibrated in the preceding Paleocological Investigation of Recent Lake Acidification (PIRLA) and ODRP studies, respectively. Initially, the comparison of hindcasts of pre-industrial chemistry was confounded by seasonal and methodological differences in lake chemistry data used in calibration of the models. Although certain differences proved to be of little significance for comparison, MAGIC did predict significantly higher pre-industrial ANC and $\mathrm{pH}$ values than did Diatom, using calibrations in the preceding studies. To remove known calibration biases, both models were recalibrated for selected scenarios. The more realistic pre-industrial sulfur deposition level (a13\% of 1984 value) in the recalibrated MAGIC scenario reduced the hindcast ANC values significantly, reducing the discrepancy between the two models and indicating the sensitivity of process-level watershed models to assumptions concerning the quantity of atmospheric deposition. The reaggregation to subregional soils data appeared to produce little effect on hindcast ANC and $\mathrm{pH}$ values. A recalibrated MAGIC scenario using reaggregated soils data, sulfate loss-tolake sediment, and partial pressure of $\mathrm{CO}_{2}$ specific to the Adirondack subregion, was also compared to a Diatom scenario using a similar sum of base cations minus sum of strong acid anions definition of ANC. The result yielded MAGIC hindcasts closer to Diatom hindcasts, but still significantly higher pre-industrial ANC and PH values than suggested by the Diatom model. Both models suggest acidification of low ANC Adirondack region lakes since preindustrial times, but differ primarily in that MAGIC inferred greater acidification and that acidification has occurred in all lakes in the comparison, whereas 0iatom inferred that acidification has been restricted to low ANC lakes (< about 50 req $L^{-1}$ ). 
$\bullet$

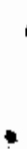

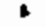




\section{EXECUTIVE SUMMARY}

Paleolimnological regression models, process-based watershed-level dynamic models, and historical lake chemistry data are the only available means of estimating the acid-base status of lakes prior to the increased acidic deposition of the last century. Paleolimnological and watershed models are currently the approaches of choice because of the uncertainty and controversy surrounding the reliability of historical measurements of $\mathrm{pH}$ and acid neutralizing capacity (ANC). Because model forecasts of future acidification are important in the development of national policy, such models must be tested and compared. In this study, 33 lakes that had been statistically selected as part of the U.S. Environmental Protection Agency's Eastern Lake Survey (ELS-I) and Direct Delayed Response Project (DDRP) were used to compare the MAGIC (watershed) and Diatom (paleolimnological) models. The study lakes represented a well-defined population of Adirondack lakes that are each larger than $4 \mathrm{ha}$ in area and have ANC less than $400 \mu \mathrm{eq} \mathrm{L}^{-1}$.

The initial step in the present study was to compare current and preindustrial (i.e., before 1850) $\mathrm{pH}$ and ANC estimates from the Diatom and MAGIC models as they were calibrated in the preceding Paleoecological Investigation of Recent Lake Acidification (PIRLA) and DDRP studies, respectively. The initial comparison of hindcasts of pre-industrial chemistry was confounded, however, by seasonal and methodological differences in lake chemistry data used in model calibration. First, the Diatom model was calibrated to summer water samples and air-equilibrated pH whereas MAGIC used fall samples and closedcontainer PH. Second, different definitions of ANC were used. The Diatom model used Gran analysis of titration data, whereas MAGIC used the sum of strong bases (including NH4, excepting Al) minus the sum of strong acid anions (except organic acids). Model comparison was also complicated by fundamental differences between the two models wherein the MAGIC model output was potentially affected by the 1) influence of watershed disturbance and land use on acid-base chemistry, 2) uncertainties in estimating atmospheric deposition of sulfur and base cations, 3) aggregation of soil properties over the northeast region (whereas the model comparison was 1 imited to the Adirondack subregion), 
4) need to estimate soil and lake $\mathrm{pCO}_{2}$ and temperatures, and 5) assumption of surface water equilibria with Al-hydroxide. A further difference between the models is that the Diatom model is separately calibrated to $\mathrm{pH}$ and to ANC, yielding estimates for both variables of similar precision. In contrast, the MAGIC model is calibrated to ANC whereas $\mathrm{pH}$ is calculated from the charge balance difference between the sum of strong base cations and strong acid anions. This yields an inherently less precise estimate of $\mathrm{pH}$ than of ANC.

Certain of these differences in model structure, features and calibration were found to be of little significance. Values for summer titration ANC and air-equilibrated $\mathrm{pH}$ were only slightly higher and lower, respectively, than fall values. However, air-equilibrated $\mathrm{pH}$ values used in the calibration of the Diatom model were higher than fall closed-container $\mathrm{pH}$ values used in the calibration of MAGIC, with the difference tending to increase with increasing

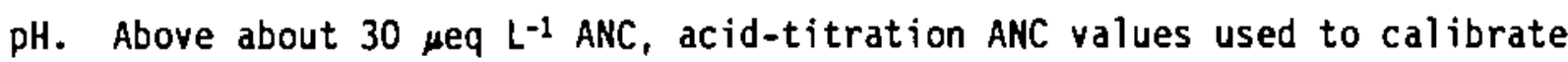
the Diatom model were on average lower than the defined charge balance ANC used to calibrate MAGIC (i.e., the total dissolved concentration of nonprotolytic cations [ $\mathrm{Ca}, \mathrm{Mg}, \mathrm{K}$, and $\mathrm{Na}$ ] minus strong mineral acid anions [ $\mathrm{SO}_{4}$, $\mathrm{NO}_{3}$, and $\left.\mathrm{Cl}\right]$ ), whereas titration ANC was higher than defined ANC at low ANC values. This difference could be attributed to the influence of $A 1$ and organic acids on acid-titration measurements of ANC. Although a number of the watersheds were classed as significantly disturbed (e.g., by liming, road construction, or road salt) and/or having altered land use (e.g., by logging or agriculture), the disturbance or altered land use did not appear to consistantly bias MAGIC to overpredict pre-industrial ANC.

The MAGIC model predicted significantly higher pre-industrial ANC and $\mathrm{pH}$ values than did the Diatom model when these models were applied as they had been calibrated in the preceding DDRP and PIRLA studies, respectively (Scenario \#1). To remove known calibration biases, both models were recalibrated as follows:

MAGIC Scenarios

\#2 Increased estimate of pre-industrial sulfur deposition from $\approx 0 \%$ of current deposition to $\mathrm{N} 13 \%$ of current (1984) deposition; otherwise the same as Scenario \#1 
\#4 Recalibrated using reaggregated soils data (including correction for coarse fragments in soils), in-lake reduction of sulfate, and partial pressure of $\mathrm{CO}_{2}$ specific to Adirondack Region, but with the same pre-industrial sulfate deposition as in Scenario $\$ 2$.

Diatom Scenario

*3 Defined ANC identical to that used in MAGIC rather than the Gran acid-titration ANC.

The more realistic pre-industrial sulfur deposition estimate of MAGIC Scenario $\$ 2$, as compared to Scenario \#1, reduced the hindcast ANC values significantly. This reduced the discrepancy between the two models and suggests that process-level watershed models are sensitive to assumptions concerning the quantity of atmospheric deposition. The reaggregation to subregional soils data appeared to produce little effect on hindcast ANC and $\mathrm{pH}$ values although recalibration of MAGIC for the Adirondack subregion improved the fit between predicted and observed current chemistry.

The most appropriate comparison available between the diatom and MAGIC hindcasts included the MAGIC scenario that was based on the subregional reaggregation and recalibration of MAGIC to the Adirondacks region (Scenario 4) and the Diatom inferences of ANC defined as the base cation sum minus the mineral acid anion sum (Scenario \#3). This comparison removed the biases associated with different ANC definitions, and the regional nature of the other MAGIC scenarios. It also minimized potential influences of organic acids and $\mathrm{CO}_{2}$ oversaturation on data interpretation, which are particularly important for $\mathrm{pH}$ comparisons. Results of this comparison showed good agreement for the estimates of current chemistry, thus demonstrating that both approaches can be successfully calibrated to current conditions. Substantial differences were observed, however, between the MAGIC and paleolimnological estimates of preindustrial chemistry. The MAGIC model estimates of pre-industrial ANC were generally higher than the diatom-inferred estimates, and MAGIC implied that lakewater acid-base chemistry had been more responsive to historical increases in acid deposition than did paleolimnology.

A decade ago, most scientists believed that $60 \%$ to $100 \%$ of the atmospheric sulfate input caused a stoichiometric decrease in ANC. Compared to 
those earlier estimates, the Diatom and MAGIC hindcast estimates are in relatively good agreement, and imply that the above percentage has been between $0 \%$ and 50\%. Both models suggest acidification of low-ANC Adirondack region lakes since pre-industrial times. The models differ primarily in that MAGIC inferred greater acidification and also that acidification has occurred in all lakes in the comparison. The Diatom paleolimnological model inferred that acidification had been restricted to low-ANC lakes (< about $50 \mu \mathrm{eq} \mathrm{L}^{-1}$ ). 


\section{CONTENTS}

PREFACE ......................

ABSTRACT ........................ v

EXECUTIVE SUMMARY $\ldots \ldots \ldots \ldots$ vii

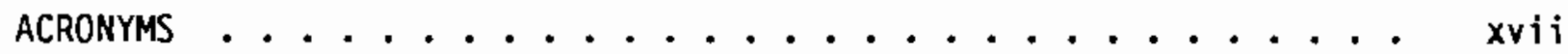

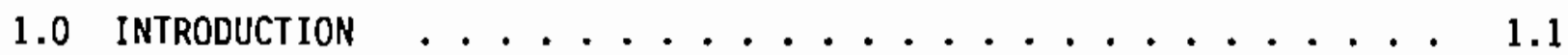

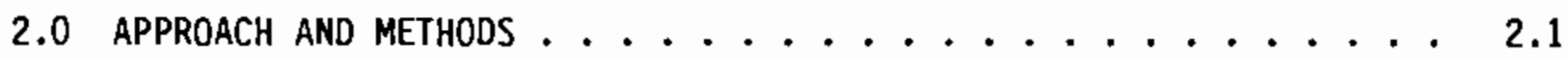

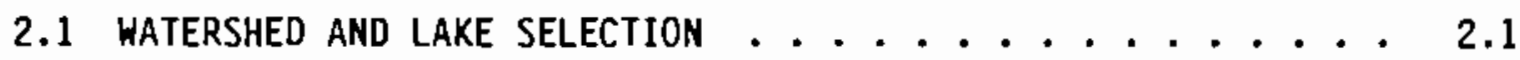

2.1.1 Direct Delayed Response Project ........ 2.1

2.1.2 Paleoecological Investigation of Recent

Lake Acidification . . . . . . . . 2.2

2.2 PALEOLIMNOLOGY $\ldots \ldots \ldots \ldots \ldots$

2.2.1 Methodology . . . . . . . . . . . 2.8

2.2.2 Error Evaluation .............. 2.14

$2.3 \mathrm{MAGIC} \ldots \ldots \ldots \ldots \ldots \ldots \ldots \ldots . \ldots \ldots$

2.3.1 Calibration ................. 2.22

2.3.2 Error Evaluation ............. 2.29

2.4 COMPARISON AND COMPLICATING FACTORS ......... 2.30

2.4.1 Watershed Disturbance/Land Use ......... 2.33

2.4.2 Lake Chemistry Seasonality . . . . . . . . 2.33

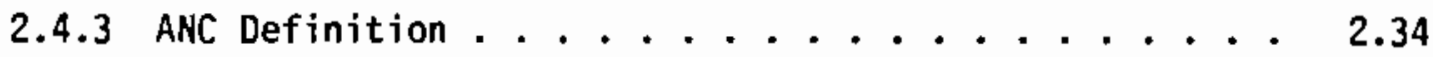

2.4 .4 Deposition ................. 2.42

2.4.5 Reaggregation of Subregional Soils Data ..... 2.46

2.5 SUMMARY OF POSSIBLE COMPARISONS BETWEEN PALEOLIMNOLOGY

AND MAGIC . . . ................. 2.50

3.0 RESULTS AND DISCUSSION . . . . . . . . . . . . 3.1 


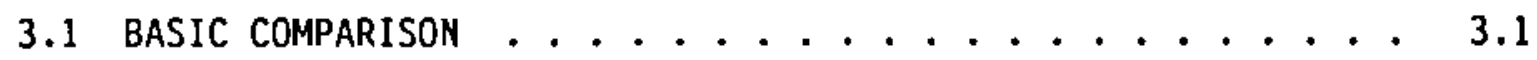

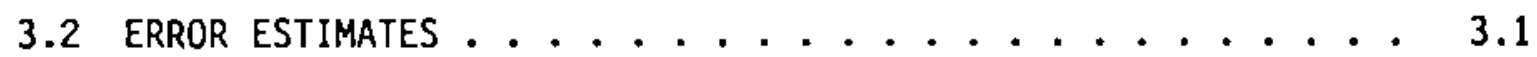

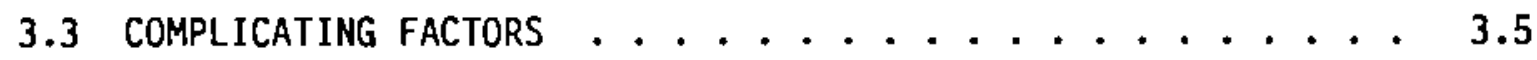

3.3.1 Watershed Disturbance/Land Use ......... 3.5

3.3.2 Lake Chemistry Seasonality . . . . . . . . 3.5

3.3.3 ANC Definition ..........................

3.3.4 Deposition Assumptions ..................... 3.13

3.3.5 Reaggregation of Subregional Soils Data ..... 3.17

3.4 SYNTHESIS . . . . . . . . . . . . . . . . 3.24

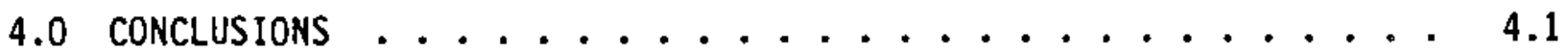

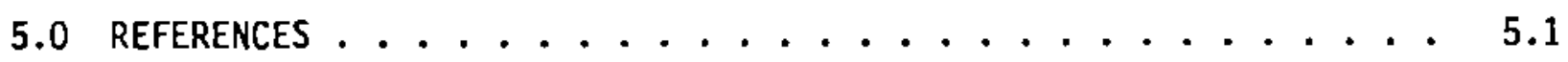

APPENDIX - ORGANIC ACID INFLUENCE ................ A.I 


\section{FIGURES}

2.1 Calibration Relationships Developed in PIRLA-II Between

Measured and Diatom-inferred Values of $\mathrm{pH}$ and ANC for

Drainage Lakes in the Adirondacks ................

2.2 Calibration Relationships Between Measured and Diatom-inferred

Values of $\mathrm{pH}$ and ANC for Seepage Lakes in the Adirondacks . . .

2.3 Calibration Relationships Between Measured and Chrysophyteinferred $\mathrm{pH}$ and ANC for Drainage Lakes in the Adirondack

Subregion ..........................

2.4 Plot of Diatom-inferred $A N C_{G}$ Versus the MAGIC Scenario \#2 Estimate of $A N C\left(C_{B}-C_{A}\right)$, with Error Estimates Placed on the Diatom-inferred Estimates .................

2.5 Difference Between Defined ANC (Equivalence of Base Cations and $\mathrm{Mn}^{2+}$ Minus Equivalence of Mineral-Acid Anions Plus Two Times $A 1_{\text {. }}$ in $\mu \mathrm{mol} \mathrm{L}^{-1}$ ) and Titration $A N C_{G}$ Versus $D O C$ for Waters in the Meander Lake Basin ..............

2.6 Acid-Neutralizing Capacity Defined as $\left[\mathrm{C}_{\mathrm{B}}\right]+2\left[\mathrm{Mn}^{2 *}\right]+2[\mathrm{Al}]-$ $\left[\mathrm{C}_{\mathrm{A}}\right]$ Versus ANC Determined by Gran Titration. . . . . . . . . 2.40

2.7 Depiction of Relative SuTfate Deposition Used in DDRP Versus that of Scenarios $\# 2$ and $\$ 4 . \ldots . . . . . .$.

3.1 Comparison Plots of (A) Current ANC Estimates Between the MAGIC Scenario \#2 Simulations of Current ANC $\left(C_{B}-C_{A}\right)$ and the Diatom Inferences of Current $A N C_{G}$ and (B) MAGIC Reference Simulations of Current $\mathrm{pH}$ and Diatom-inferred Current $\mathrm{pH}$. . 3.2

3.2 Comparison Plots of (A) Pre-industrial ANC Estimates from MAGIC Scenario *2 Simulations and Diatom-inferred Preindustrial $\mathrm{ANC}_{\mathrm{G}}$ (Based on Bottom Cores) and (B) Preindustrial $\mathrm{pH}$ Estimates from MAGIC Reference Simulations and Diatom-inferred $\mathrm{pH} . . . . . . . . . . .$.

3.3 Estimates of Change in (A) ANC and (B) $\mathrm{pH}$ Using the MAGIC Model Scenario \#2 SimuTations versus Diatom Inferences of Change..........................

3.4 Plot of Diatom-inferred Current $A N C$ Versus MAGIC Scenario \#2 Simulation Estimate of Current $A N C\left(C_{B}-C_{A}\right)$, with Error Estimates Placed on MAGIC Estimates .............

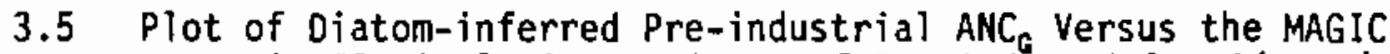
Scenario \#2 Simulation Estimate of Pre-industrial ANC $\left(C_{B}-C_{A}\right)$, with Error Estimates Placed on the MAGIC Estimates . . . . . . 3.6 
3.6 MAGIC Scenario $2 A N C\left(C_{B}-C_{A}\right)$ Versus Diatom-inferred $A N C\left(C_{B}-C_{A}\right)$. 3.7

3.7 Comparisons of (A) PIRLA measured ANC (Average of Summer Samples) and ELS-I-measured $A_{N C}$ (Falf Index Samples), (B) Air-equilibrated $\mathrm{pH}$ (Average of Sumtner Samples) and ELS-I-measured Field pH (Fall Index Samples), and (C) Field $\mathrm{pH}$ (Average of Sunmer Samples) and ELS-I-measured Field pH (Fall Index Samples) ................ 3.9

3.8 Comparison of (A) Sumer $1986 \mathrm{ANC}_{6}$ Versus Fall $1986 \mathrm{ANC}_{6}$, and

(B) Summer 1986 Station pH Versus Fall 1986 Station pH . . . . 3.10

3.9 ELS-I Chemistry Comparison of Calculated Versus Titrated ANC . . 3.11

3.10 Paleolimnological Calibration Equations for Diatom-inferred $\operatorname{ANC}\left(C_{B}-C_{A}\right)$ for $(A)$ a restricted data set of lakes having ANC $\leq 100 \mu \mathrm{eq} \mathrm{L}^{-1}$, (B) the full data set; and corresponding residual plots for (C) lakes with ANC $\leq 100 \mu \mathrm{eq} \mathrm{L}^{-1}$, and

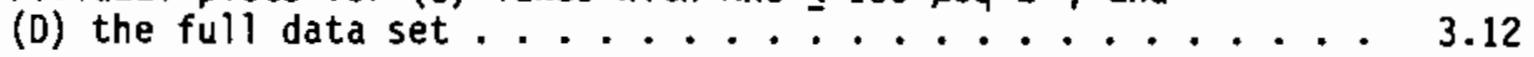

3.11 Diatom-inferred $A N C\left(C_{B}-C_{A}\right)$ Versus Measured $A N C\left(C_{B}-C_{A}\right)$ for Lakes Included in This Study .............. 3.13

3.12 Comparisons of (A) Diatom-inferred Current $A N C_{G}$ Versus Diatom-inferred Current $A N C\left(C_{B}-C_{A}\right)$ and (B) Diatom-inferred Pre-industrial ANC Versus Diatom-inferred Pre-industrial

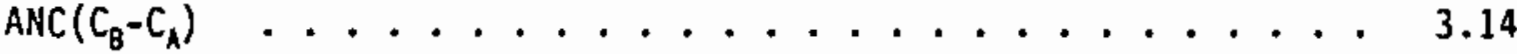

3.13 Comparison Plots of (A) MAGIC Scenarios $\# 1$ and $\# 2$ for ANC $\left(C_{B}-C_{A}\right)$ and (B) The $y$-axis is simulated current $A N C\left(C_{B}-C_{A}^{A}\right)$ for $(A)$ and current $\mathrm{pH}$ for $(B)$ using MAGIC

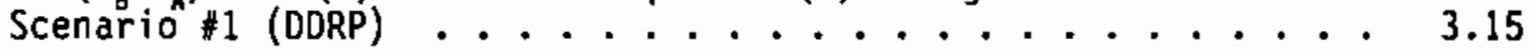

3.14 Comparison Plots of (A) MAGIC Scenarios \#1 and \#2 for ANC $\left(C_{B}-C_{A}\right)$ and (B) The $y$-axis is simulated pre-industrial ANC $\left(C_{B}-C_{A}\right)$ for $(A)$ and $\mathrm{pH}$ for $(B)$ using MAGIC Scenario \#1 ... 3.16

3.15 Comparison Between MAGIC Estimates of Current ANC $\left(C_{B}-C_{A}\right)$ for MAGIC Scenario \#2 (Calibrated to Northeastern Region) and Scenario \#4 (Recalibrated to Adirondack Subregion) . . . . 3.20

3.16 Comparison of MAGIC Scenario \#2 Simulations of Preindustrial ANC $\left(C_{B}-C_{A}\right)$ with Simulations Based on Reaggregation of Soils Data and Recalibration of MAGIC to Adirondack Subregion (Rather Than Northeastern Region) (Scenario \#4) . . . 3.20

3.17 Sulfate Calibration data for (A) MAGIC Scenario \#2 Simulations and (B) Recalibration for Adirondack Subregion (Scenario \#4) ............. 3.22 
3.18 MAGIC Pre-industrial pH Versus Diatom-inferred Pre-

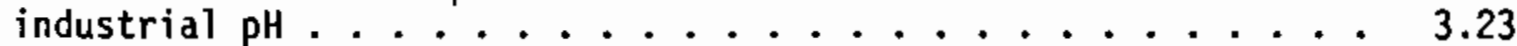

3.19 MAGIC Current pH Versus Diatom-inferred Current $\mathrm{pH} \ldots \ldots . . . .3 .23$

3.20 Comparisons of (A) Diatom Inferences and MAGIC Model Hindcasts of Pre-industrial (ca. 1850) Lakewater pH at Round Loch of Glenhead (1), Loch Chon (2), Loch Dubh (3), Loch Tinker (4), Loch Doilet (5), and Loch Uaine (6) in Scotland and (B) Simulated Present-day PH from Diatom (o) and MAGIC

(») Versus Measured pH ...............

3.21 Comparison Plot of (A) Current ANC Estimates Between the MAGIC Scenario \#4 Simulations of ANC $\left(C_{B}-C_{A}\right)$ and the Diatom Inferences of $\operatorname{ANC}\left(C_{B}-C_{A}\right)$ and (B) Current pH Estimates Between the MAGIC Scenario \#4 Simulations and Diatom

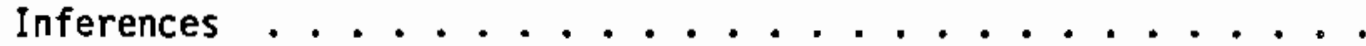

3.22 Comparison Plot of (A) Pre-industrial ANC Estimates Between the MAGIC Scenario 4 Simulations of $A N C\left(C_{B}-C_{A}\right)$ and the Diatom Inferences of ANC $\left(C_{g}-C_{A}\right)$ and (B) Comparison Plot of Pre-industrial pH Estimates Between the MAGIC Scenario \#4

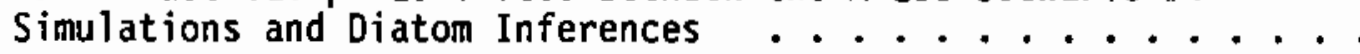

3.23 Estimates of Change From Pre-industrial Time to the Present Using the MAGIC ModeI Scenario \#4 Simulations versus Diatom Inferences of Change in (A) $A N C\left(C_{B}-C_{A}\right)$ and $(B) \mathrm{pH} \ldots \ldots$

A.1 Comparison Plot of (A) Current ANC Estimates Between the MAGIC Scenario \#4A Simulations of ANC $\left(C_{8}-C_{A}\right)$ and the Diatom Inferences of $A N C\left(C_{B}-C_{A}\right)$ and $(B)$ Current $\mathrm{pH}$ Estimates Between the MAGIC Scenario \#4A Simulations and Diatom Inferences

A.2 Comparison Plot of (A) Pre-industrial ANC Estimates Between the MAGIC Scenario \#4A Simulations of ANC $\left(C_{B}-C_{B}\right)$ and the Diatom Inferences of $A N C\left(C_{B}-C_{A}\right)$ and $(B)$ Pre-industrial PH Estimates Between the MAGIC Scenario \#4A Simulations

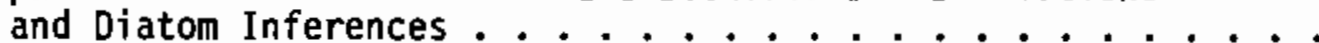




\section{$\underline{\text { TABLES }}$}

2.1 Description of Sample and Target Populations for Eastern Lake Survey I of the Northeastern United States . . . . . . . . 2.2

2.2 Structure for the Northeastern Lakes Sampled by the Direct/Delayed Response Project . . . . . . . . . . . . 2.3

2.3 Fixed Parameters Used in MAGIC . . . . . . . . . . 2.17

2.4 Adjustable Parameters Used in MAGIC . . . . . . . . . . . . 2.18

2.5 Operational Assumptions for MAGIC Modeling . . . . . . . . 2.19

2.6 Meteorological Data Required by the MAGIC/TOPMODEL Code . . . . 2.20

2.7 Chemical Constituents in Wet and Dry Deposition Considered by the MAGIC Model .................. . . 2.20

2.8 Major Processes Incorporated in the Combined

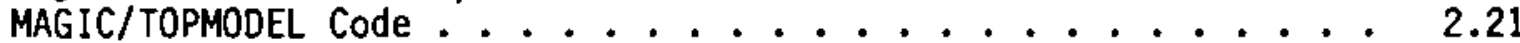

2.9 Aqueous Chemical Constituents Included in the MAGIC Code . . . 2.22

2.10 Selectivity Coefficients Used in the Calibration of MAGIC . . . 2.29

2.11 Description of Various MAGIC and Diatom Model Scenarios . . . . 2.32

2.12 Ratios of Dry Deposition to Wet Deposition for DORP Watersheds for the Typical Year Deposition Data Set . . . . . . . . .

2.13 Number of Sampled Pedons for Adirondack Sampling Classes . . . 2.48

3.1 Sampling Class Statistics and Results of Paired t-test of

Differences Between Sampling Class Means for Comparing

Soils Aggregation Results Between the Northeast and the

Adirondacks ........................

3.2 Watershed Statistics and Results of Paired t-test of Differences Between Watershed Means for Comparing Soils Aggregation Results Between the Northeast and the Adirondacks . . . . . . . . . . . . . . . . . . . .

3.3 Measured and Diatom-inferred Dissolved Organic Carbon Concentrations for Lakes Included in the Diatom/MAGIC Comparison 


\section{ACRONYMS}

ANC

Acid-neutralizing capacity

CANOCO

Canonical correspondence analys is

CEC

Cation exchange capacity

CERL

Corvallis Environmental Research Laboratory

DORP

Direct/Delayed Response Project

DCA

Detrended correspondence analysis

DOC

Dissolved organic carbon

DTBR

Depth to bed rock

ELS-I

Eastern Lake Survey, Phase I

ELS-II

Eastern Lake Survey, Phase II

EPA

U.S. Environmental Protection Agency

ETD

Enhanced Trickle Down Model

ILWAS

Integrated Lake-Watershed Acidification Study

MAGIC

Model of Acidification of Groundwater in Catchments

NAPAP

National ACid Precipitation Assessment Program

NCOC

National Climate Data Center

ORNL

Oak Ridge National Laboratory

$\mathrm{PCO}_{2}$

Partial pressure of $\mathrm{CO}_{2}$

PIRLA

Paleoecological Investigation of Recent Lake Acidification, Phase I

PIRLA-II Paleoecological Investigation of Recent Lake Acidification, Phase II

PNL Pacific Northwest Laboratory

PRL Proton reference level

RMSE Root mean square error

SSA

Sum of strong acid anions

SSB

Sum of strong base cations 
3 


\subsection{INTRODUCTION}

In 1980, the United States Congress established the interagency National Acid Precipitation Assessment Program (NAPAP) to evaluate acid-deposition causes, effects, and control strategies. This research effort will conclude in 1991 with the publication of a series of 28 State of Science and Technology (SOS/T) Reports and an Integrated Assessment (IA). The SOS/T Reports document the current scientific information on a variety of acid deposition issues. The Aquatic Effects component includes reports on current status, processes, historical change, episodes, biological effects, and future projections. The IA provides a structured synthesis of the policy-relevant technical information contained in the SOS/T Reports.

Two of the major objectives of the Aquatic Effects research of NAPAP have been to evaluate historical changes in surface-water chemistry in response to acidic deposition (e.g., Sullivan in press(a)) and to construct projections of future change under different scenarios of acidic deposition (e.g., Church et a). 1989; Thornton, Marmorek, and Ryan, in press(b)).

Largely, these efforts require different approaches, each with its own set of assumptions and limitations. A truly integrated assessment of the effects of acid deposition on aquatic systems in the United States, however, requires a comparison of estimates of past and future change. The discrepancies observed in these two approaches constitute an estimate of the uncertainty associated with our current level of understanding of the aquatic effects of acid deposition.

Evaluations of historical changes in surface-water chemistry in response to acid deposition have been based on a weight-of-evidence approach (Sullivan, in press). To document and quantify, where possible, the historical effects

(a) Sullivan, T. J. 1990. "Historical Changes in Surface Water Acid-Base Chemistry in Response to Acidic Deposition." State of the Science, SOS/T 11. National Acid Precipitation Assessment Program. (In press).

(b) Thornton, K., D. Marmorek, and P. Ryan. 1990. "Methods for Projecting Future Changes in Surface Water Acid-Base Chemistry." State of the Science, SOS/T 14, National Acid Precipitation Assessment Program. (In press). 
of acid deposition on surface-water quality in the United States, various sources of information have been used, including paleolimnological data, historical water-quality measurements, ion ratios, space-for-time substitutions, estimates of recent change, results of catchment and lake-manipulation experiments, and model hindcasts. The uncertainties in the most direct approach of using historical ANC and $\mathrm{pH}$ data have rendered its use controversial and problematic (Ashbury et al. 1990; Kramer 1990; Metcalf and Gerlach 1990). Thus, quantification of historical change is based primarily on paleolimnological data, and is possible on a regional basis only for lakes in the Adirondack subregion at this time. Sixty Adirondack lakes have been included in the paleolimnological studies, of which 35 were selected using a statistical basis, so as to allow the results to be projected to the region as a whole.

Projections of future changes in surface water chemistry in response to constant or changing deposition are based primarily on model estimates, as summarized by Thornton, Marmorek, and Ryan (in press). Among the models most commonly used for such projections are several that focus on soil-mediated processes, such as the Birkenes (Christophersen, Seip, and Wright 1982; Rustad et al. 1986), ILWAS (Chen et al. 1983; Goldstein et al. 1984; Gherini et al. 1985), MAGIC (Cosby et al. 1985a, 1985b), and Reuss and Johnson (1985) models. Reuss, Christophersen, and Seip (1986) discussed the differences in scope and structure among these models which contain similar assumptions regarding several key soil chemical processes, in particular the anion mobility concept of Seip (1980), cation exchange, the carbonic-acid system, Al-bearing weathering and Al-hydroxide dissolution and precipitation (Reuss, Christophersen, and Seip 1986). The "Trickle Down" models of Schnoor and coworkers (Stunnm, Morgan and Schnoor 1983; Schnoor and Stumm 1985; Schnoor, Nikolaidis, and Glass 1986; Lin and Schnoor, 1986) are based on mass balance for acid-neutralizing capacity (ANC). A variety of steady-state and dynamic models have been utilized within the NAPAP research efforts. Particular emphas is has been placed on the process-based models included in the Direct Delayed Response Project (DDRP): MAGIC, ILWAS, and ETD (Church et al. 1989). All three models yielded results that were generally similar for lakes in the northeastern United States (Thornton, Marmorek, and Ryan, in press). 
These dynamic watershed acidification models have proven useful for hypothesis testing and have played an integral role in the effort to understand the net effects of the complicated interacting processes that govern ecosystem response to acid deposition (Stone and Seip 1989). These models may need improvement to varying degrees (Reuss, Christophersen, and Seip 1986; Seip, Christophersen, and Sullivan 1989; Stone and Seip(a)). They are currently being applied to questions of future change under alternative acidicdeposition scenarios (Thornton, Marmorek, and Ryan, in press). Thus, it is important to test the validity, under a reasonable set of assumptions regarding pre-industrial deposition and water chemistry, of the results of watershed acidification models against independent estimates of historical change. Paleolimnological models and dynamic process modeling approaches are fundamentally different. Paleolimnology provides a direct measure of a surrogate indicator of lake acidity, whereas the process models, although rooted in hydrochemical principles, represent major temporal and spatial process aggregation, and thus constitute a simplification of the catchment system (Jenkins et al. 1990). Few direct measurement data sets are available that contain a sufficiently long period of record for validating either approach. It is therefore important to compare and contrast the results obtained from these approaches in order to assess the level of confidence that should be ascribed to estimates of change in lake acid-base status. In particular, the widespread international debate regarding future acidification of surface waters and the establishment of critical loadings of atmospheric deposition of acidic substances require validation of projections of future change. Verification of the dynamic process models can be achieved via comparison with Diatom paleolimnological model results.

The major objectives of this report are to:

- compare and contrast paleolimnological and MAGIC model hindcast estimates of historical acidification (i.e., decreased ANC and $\mathrm{pH}$ ) of the statistically (probability) sampled lakes of the Adirondack region

(a) Stone, A., and H. M. Seip. "Are Mathematical Models Useful for Understanding Water Acidification?" Sci. Total Environ. (In press). 
- evaluate the agreement between the MAGIC and paleolimnological model estimates of historical acidification of Adirondack lakes and

discuss the implications of this agreement

- explore alternative explanations for observed discrepancies between the two models

- evaluate the magnitude of the differences between the models relative to error estimates for each. 


\subsection{APPROACH AND METHODS}

\subsection{HATERSHED AND LAKE SELECTION}

The watersheds and associated lakes that were used are a subset of those used in preceding studies: Phase I of the EPA Eastern Lake Survey (ELS-I), DDRP, and PIRLA-II. Thus, the selection process of those studies is briefly described in the following subsections.

\subsubsection{Direct Delayed Response Project (DDRP)}

The 145 DDRP lakes in the northeastern United States represent a subsample of the population of lakes included in ELS-I (Linthurst et al. 1986). The ELS-I survey consisted of a probability sample of lakes in regions of the United States containing lakes (as represented on 1:250,000 scale maps) expected to have alkalinity values $\leq 400 \mu \mathrm{eq} \mathrm{L}^{-1}$, based on a regional compilation of published and unpublished data on surface-water alkalinity, and in some cases, geology (Linthurst et al. 1986). With in the Northeast, lakes were stratified based on subregions and alkalinity-map classes. Map classes were comprised of three groups of expected alkalinity $(<100 ; 100-200 ;>200 \mu$ eq $\left.\mathrm{L}^{-1}\right)$, and within each strata approximately 50 lakes were systematically selected from an ordered list following a random start. Thus, each lake was selected with a known inclusion probability (or sample weight), which varied among strata. The sample structure for ELS-I lakes in the Northeast is shown in Table 2.1.

The DDRP lakes in the Northeast were selected from this ELS-I frame, which can generally be described as lakes that are greater than $1.5 \mathrm{~m}$ deep represented on 1:250,000 scale USGS topographic maps (typically $>4$ ha in surface area). Lakes with gross anthropogenic disturbances were excluded from the DDRP subsampling frame, as were those in several other minor exclusion categories (Linthurst et al. 1986). The lakes were further restricted to exclude those with ANC $>400 \mu \mathrm{eq} \mathrm{L^{-1 }}$, surface area $>2000$ ha, or watershed area $>3000$ ha (Church et al. 1989). Lakes in the frame selected for the DDRP were grouped into three clusters based on ANC measured in ELS-I:

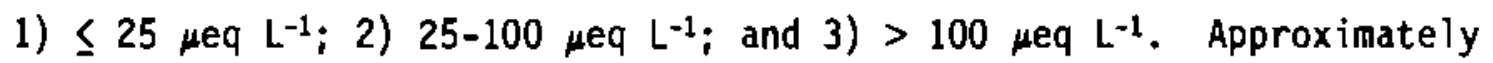
50 lakes were selected from each cluster, using a variable-probability 
TABLE 2.1. Description of Sample and Target Populations for Eastern Lake Survey I of the Northeastern United States

\begin{tabular}{|c|c|c|c|c|c|c|}
\hline Stratum & $\begin{array}{c}\begin{array}{c}\text { Frame } \\
\text { Population }\end{array} \\
\end{array}$ & $\begin{array}{l}\text { Lakes in } \\
\text { Probability } \\
\text { Sampling } \\
\end{array}$ & $\begin{array}{c}\text { Lakes } \\
\text { Sampled }\end{array}$ & $\begin{array}{l}\text { Expansion } \\
\text { Factor }\end{array}$ & $\begin{array}{l}\text { Estimated } \\
\text { Target } \\
\text { Population } \\
\text { Size (TPS) } \\
\end{array}$ & $\begin{array}{l}\text { Standard } \\
\text { Error of } \\
\text { TPS } \\
\end{array}$ \\
\hline $\begin{array}{l}1 A 1^{(0)} \\
1 A 2^{(0)} \\
1 A 3^{(2)}\end{array}$ & $\begin{array}{l}711 \\
542 \\
431\end{array}$ & $\begin{array}{l}75 \\
65 \\
68\end{array}$ & $\begin{array}{l}57 \\
51 \\
47\end{array}$ & $\begin{array}{l}9.633 \\
8.338 \\
6.719\end{array}$ & $\begin{array}{l}549.08 \\
425.24 \\
315.79\end{array}$ & $\begin{array}{l}33.08 \\
26.13 \\
22.14\end{array}$ \\
\hline $\begin{array}{l}1 \mathrm{~B} 1 \\
1 \mathrm{~B} 2 \\
1 \mathrm{~B} 3\end{array}$ & $\begin{array}{r}208 \\
96 \\
1682\end{array}$ & $\begin{array}{l}70 \\
70 \\
68\end{array}$ & $\begin{array}{l}49 \\
48 \\
47\end{array}$ & $\begin{array}{r}3.192 \\
1.477 \\
27.209\end{array}$ & $\begin{array}{r}156.41 \\
70.90 \\
1278.82\end{array}$ & $\begin{array}{r}9.29 \\
3.00 \\
90.37\end{array}$ \\
\hline $\begin{array}{l}1 \mathrm{Cl} \\
1 \mathrm{C} 2 \\
1 \mathrm{C} 3\end{array}$ & $\begin{array}{l}631 \\
752 \\
650\end{array}$ & $\begin{array}{l}88 \\
70 \\
74\end{array}$ & $\begin{array}{l}63 \\
54 \\
47\end{array}$ & $\begin{array}{r}7.822 \\
10.743 \\
8.953\end{array}$ & $\begin{array}{l}492.79 \\
580.12 \\
420.79\end{array}$ & $\begin{array}{l}27.31 \\
36.20 \\
34.59\end{array}$ \\
\hline $\begin{array}{l}101 \\
102 \\
103\end{array}$ & $\begin{array}{r}443 \\
656 \\
1568\end{array}$ & $\begin{array}{l}70 \\
95 \\
93\end{array}$ & $\begin{array}{l}47 \\
43 \\
37\end{array}$ & $\begin{array}{r}6.572 \\
6.905 \\
19.426\end{array}$ & $\begin{array}{l}308.88 \\
296.92 \\
718.76\end{array}$ & $\begin{array}{l}23.00 \\
31.14 \\
85.22\end{array}$ \\
\hline $\begin{array}{l}1 \mathrm{EI} \\
1 \mathrm{E} 2 \\
1 \mathrm{E3}\end{array}$ & $\begin{array}{r}1038 \\
606 \\
744\end{array}$ & $\begin{array}{r}130 \\
74 \\
72\end{array}$ & $\begin{array}{l}89 \\
48 \\
41\end{array}$ & $\begin{array}{r}8.070 \\
8.344 \\
10.333\end{array}$ & $\begin{array}{l}718.23 \\
400.51 \\
423.65\end{array}$ & $\begin{array}{l}39.71 \\
31.80 \\
41.55\end{array}$ \\
\hline
\end{tabular}

(a) The Adjrondacks are represented by Strata $1 \mathrm{~A} 1,1 \mathrm{~A} 2$, and $1 \mathrm{~A} 3$ with a total $\hat{N}$ of 1290.

systematic sampling design that resulted in the selected lakes having nearly equal inclusion probabilities within and among strata. This was accomplished by setting DDRP selection probabilities to be inversely proportional to ELS-I inclusion probabilities. The resulting sample structure for the DDRP is presented in Table 2.2. Additional details of the lake-selection methodology are presented in Linthurst et al. (1986) and Church et al. (1989).

\subsubsection{Paleoecological Investigation of Recent Lake Acidification (PIRLA)}

Most of the paleolimnological data for lakes in the United States were obtained by two large regional studies, PIRLA-I (Charles and whitehead 1986a 
TABLE 2.2. Structure for the Northeastern Lakes Sampled by the Direct/Delayed Response Project

\begin{tabular}{|c|c|c|}
\hline ANC Cluster(a) & $\begin{array}{l}\text { DORP Lakes } \\
\text { Sampled from } \\
\text { ANC Group } \\
\end{array}$ & $\begin{array}{l}\text { Est imated Number } \\
\text { of Lakes in DDRP } \\
\text { Target Population }\end{array}$ \\
\hline $\begin{array}{l}1 \\
2 \\
3\end{array}$ & $\begin{array}{l}55 \\
46 \\
44\end{array}$ & $\begin{array}{r}796 \\
1100 \\
1772\end{array}$ \\
\hline Total & 145 & 3668 \\
\hline
\end{tabular}
(a) $1=$ ANC $<25 \mu$ eq $\mathrm{L}^{-1}$
$2=25-100 \mu \mathrm{eq} \mathrm{L}-1$
$3=$ ANC $>100 \mu \mathrm{eq} \mathrm{L}^{-1}$
based on recalculated ANC values

and b) and the ongoing PIRLA-II (Charles and Smol in press(o)). PIRLA-I included stratigraphic analysis of approximately 35 lakes in four regions of the United States (Adirondacks, northern parts of New England, Upper Midwest, and Florida). In addition to obtaining biological data (diatoms, chrysophytes) for inferring water chemistry, sediment measurements also included analyses of metals, sulfur, nitrogen, carbon, polycyclic aromatic hydrocarbons, coal and oil carbonaceous particles, pollen, and ${ }^{216} \mathrm{~Pb}$ for dating strata. The PIRLA-I project developed standardized protocols, including quality assurance/quality control guidelines, for all aspects of diatom research (Charles and whitehead 1986a).

The PIRLA-I investigation of Adirondack subregion lakes included many of the same lakes studied in the RILWAS project (Driscoll and Newton 1985; Rudd 1987). Most of the lakes were small to moderately sized, were low in alkalinity, and had forested watersheds with little or no cultural development. Alkalinity and $\mathrm{pH}$ inference equations, based on a calibration set of 36 lakes, involved multiple linear regression of percentages of diatoms in $\mathrm{pH}$ categories. The standard errors for $\mathrm{pH}$ and alkalinity were $0.26 \mathrm{pH}$ units and

(a) Charles, C. F., and J. P. Smol. 1990. "The PIRLA II Project: Regional Assessment of Lake Acidification Trends." Verh. Internat. Verein. Limnol. (In press). 
$21 \mu$ eq $\mathrm{L}^{-1}$, respectively (Charles et al., in press(d)). Procedures for developing the inference equations were those of Charles (1985) and Charles and Smol (1988). Eight replicate analyses of a sediment interval from a core taken from Big Moose Lake showed a mean $\mathrm{pH}$ of 5.54, with standard deviation of $0.04 \mathrm{pH}$ units, well below that for the predictive equation.

The PIRLA-II research was designed to answer many of the key questions of the KAPAP State-of-Science and Assessment activities. The project was described by Charles and Smol (in press(b)). The major objectives of the PIRLA-II study are to determine the proportion of low-ANC Adirondack lakes that have become more acidic since pre-industrial times (i.e., about 1850), to quantify the ANC change that occurred, and to determine the percentage of lakes that were naturally acidic. Sediment cores from 35 of the Adirondack lakes that were included in the DDRP (Church et al. 1989) were analyzed. Because these lakes were selected statistically, estimates of historical change can be extrapolated to the population of Adirondack lakes. The "tops" (0-1 cm depth) and "bottoms" (pre-1850, usually $>30 \mathrm{~cm}$ ) of the sediment cores have been analyzed for diatoms. Major results of PIRLA-II have been presented by Smol et al. (1990)(c) and Sullivan et al. (1990). The comparison presented here is based on the statistically selected Adirondack lakes that were included in the DDRP and PIRLA-II studies.

\subsection{PALEOLIMNOLOGY}

In the absence of data from long-term chemical monitoring, inference from diatom fossil assemblages preserved in lake sediments is frequently used for evaluating historical chemical changes (Charles and Norton 1986). Diatoms

(a) Charles, D. F., M. W. Binford, E. T. Furlong, R. A. Hites, M. J. Mitchell, S. A. Norton, F. 0ldfield, M. J. Paterson, J. P. Smol. A. J. Uutala, J. R. White, D. R. Whitehead, and R. J. Wise. "Paleoecological Investigation of Recent Lake Acidification in the Adirondack Mountains, New York. J. Paleolimnology (In press).

(b) Charles, D. F., and J. P. Smol. "The PIRLA II Project: Regiona] Assessment of Lake Acidification Trends". Verh. Internot. Verein. Limnal. (In press).

(c) Smol, J. P., et al. 1990. Poster Presentation. National Acid Precipitation Assessment Program. International Review, Hilton Head, South Carolina. 
(Bacillariophyceae) are single-cell algae composed of siliceous valves. The fossil remains of these organisms are good indicators of past lakewater chemistry because 1) they are common, 2) many taxa have rather narrow ecological (water chemistry) tolerances, 3) the remains are well preserved in sediment, usually in very large numbers, and 4) they can be identified to the species level or below (Smol, Charles, and whitehead 1984; Charles 1985; Charles and Norton 1986; Smol et al. 1986; Husar, Sullivan, and Charles in press(a)).

Past lakewater chemistries are reconstructed from transfer functions derived from relationships between present chemistry and diatom remains in surficial lake-bed sediments. From these relationships, predictive equations (i.e., a model) are developed using regional lake data sets to infer water chemistry, especially pH and ANC. Calibration equations have also recently been developed for inferring concentrations of DOC, total $A 1\left(A l_{t}\right)$, and monomeric Al (A1.) (Kingston and Birks 1990; Birks et al. 1990). It is assumed that quantitative relationships observed between lakewater chemistry and the distribution and abundance of diatom taxa have remained constant over time.

Trends within sediment cores can be analyzed to determine whether they are statistically significant (Birks et al. 1990). Inferred water chemistry can be dated using ${ }^{210} \mathrm{~Pb}$ activity and compared with stratigraphies of other lake-sediment markers such as pollen, charcoal, coal and oil carbonaceous particles, polycyclic aromatic hydrocarbons, metals ( $\mathrm{Pb}, \mathrm{Zn}, \mathrm{Cu}, \mathrm{V}, \mathrm{Ca}, \mathrm{Mg}$, $\mathrm{Ti}, \mathrm{Al}, \mathrm{Si}, \mathrm{S})$, and others that provide a record either of atmospheric inputs of materials associated with the combustion of fossil fuels or watershed disturbance (Charles and Norton 1986). With these data, knowledge of watershed events, and historical information on regional atmospheric emissions of sulfur and nitrogen, scientists have evaluated whether lakes have likely been affected by acidic deposition and to what extent (e.g., Husar, Sullivan, and Charles, in press(b) and Charles et al., in press(c) $)$.

(a) Husar, R. B., T. J. Sullivan, and D. F. Charles. "Methods for Assessing Long-Term Trends in Atmospheric Deposition and Surface Water Chemistry." In Acidic Deposition and Aquatic Ecosystems: Regional Case Studies, ed. D. F. Charles. Springer-Verlag, Inc., New York. (In press).

(b) Husar, R. B., T. J. Sullivan, and D. F. Charles. "Methods for Assessing Long-Term Trends in Atmospheric Oeposition and Surface Hater Chemistry." In Acidic Deposition and Aquatic Ecosystems: Regional Case Studies, ed. D. F. Charles. Springer-Verlag, Inc., New York. (In press). 
Diatom studies have documented the rates and magnitudes of acidification for selected lakes in the Adirondack Region (Del Prete and Schofield 1981; Charles 1984; Charles et al. 1986; Charles 1987; Charles et al. 1987; Charles et al. in press; Sullivan et a1. 1990), New England (Davis et al. 1983), the Upper Midwest (Kingston et al, in press), Florida (Charles et al. 1986), Ontario (Dixit 1983; Dixit, Dixit, and Evans 1987; Dixit, Dixit, and Smol 1989a, 1989b). Sweden (Renberg and Hellberg 1982; Renberg and Hall in 1985), Finland (Tolonen and Jaakkola 1983), Norway (Davis and Anderson 1985; Davis and Berge 1980), Scotland (Flower and Battarbee 1983; Flower, Battarbee, and Appleby 1987), West Germany (Arzet, Krause-Dellin, and Steinberg 1986) and the Netherlands (van Dam et al. 1988).

In a paleolimnological study at experimentally acidified Lake 223 in the Experimental Lakes Area in Ontario, Davidson (1984) illustrated the rapid response of diatoms to changes in water chemistry. Results from the sediment core closely agreed with the plankton history measured in the water column. Similarly, paleolimnological inferences of recent changes in lakewater chemistry have been shown to correspond closely with measured $\mathrm{pH}$ values at three lakes near Sudbury, Ontario (Dixit, Dixit, and Evans 1987; Dixit, Dixit, and Smol 1989a, 1989b). Dixit, Dixit, and Evans (1987) reconstructed the pH of Hannah Lake, near Sudbury, using diatom remains. Between approximately 1880 and 1975, the inferred lakewater $\mathrm{pH}$ declined roughly from 6.0 to 4.6. After the lake was limed in 1975, its $\mathrm{pH}$ increased from 4.3 to 7.0 , and this increase was reflected in the Diatom-inferred values (Dixit, Dixit, and Evans 1987). A recent paleolimnological investigation (Dixit, Dixit, and Smol 1989a) of acidification and subsequent recovery of Swan Lake, near Sudbury, Ontario, indicated that paleolimnological reconstructions of recent chemical change corresponded well with measured values. Also significant were the large declines in trace-metal concentrations in sediments coincident with $\mathrm{pH}$ recovery. Changes in metal concentrations do not pose a problem for the diatom models because the large diatom species diversity allows accurate pH reconstruction irrespective of metal concentrations. Dixit, Dixit, and Smol

(c) Charles, D. F., R. W. Battarbee, I. Renberg, H. van Dam, and J. P. Smol. "Paleoecological Analysis of Lake Acidification Trends in North America and Europe Using Diatoms and Chrysophytes." In: Acid Precipitation, Springer-Verlag, New York (in press). 
(1989a) also used diatoms and chrysophytes to reconstruct the recovery of Baby Lake subsequent to the closure in 1972 of the nearby (1-km distance) Conistan Smelter near Sudbury. Measured lakewater pH increased from 4.2 in 1972 to 6.5 in 1987, and this recovery was closely mirrored by shifts in the diatom and chrysophyte species composition and the inferred $\mathrm{pH}$.

Paleolimnology as a quantitative science has evolved extremely rapidly over the past five years, and improved techniques are often developed before previous research has appeared in the literature. Multiple linear-regression analys is of measured lakewater $\mathrm{pH}$ with the percentage of diatoms in each $\mathrm{pH}$ category has been used to develop predictive equations (Charles 1985; Huttunen and Meriläinen 1986). Other multiple-regression approaches involve using selected taxa or principal components of taxa (Davis and Anderson 1985; Gasse and Tekaia 1983). The standard error for inferred $\mathrm{pH}$ ranges from 0.25 to $0.4 \mathrm{pH}$ units for any of these approaches and their associated data sets (Battarbee 1984; Charles and Norton 1986). Other techniques include detrended correspondence analysis (OCA) (Huttunen and Meriläinen 1986), canonical correspondence analysis (ter Braak 1986; Stevenson et al. 1989), and a multiple regression technique using both diatoms and chrysophytes (Charles and Smol 1988). ter Braak and Van Dam (1989) developed new methods using maximumlikelihood calibration based on weighted averaging and on Gaussian logit response curves of taxa against pH. Oksanen et al. (1988) used weighted averaging, least squares, and maximum likelihood to calculate pH optima and tolerance of diatom taxa, then used these estimates to predict the $\mathrm{pH}$ of other lakes, using weighted averaging. Recently, Birks et al. (1990) suggested using the straightforward but heuristic approach of weighted-averaging regression and calibration as a compromise between ecological realism and computational feasibility. For the 167 lake data set in the joint BritishScandinavian Surface Water Acidification Programe (SWAP), this method actually gave superior results in terms of a lower root mean square error (RMSE) of prediction in cross validation, than did maximum likelihood Gaussian logit regression and calibration.

Diatoms are both planktonic and benthic, but the diatom flora of low-pH (< 5.5) lakes are dominated by benthic forms (Battarbee 1984; Charles 1985; Charles and Smol 1988). Although planktonic diatoms are most abundant in 
spring, most littoral species are common throughout spring and summer (DeNicola 1986; Jones and Flower 1986; Charles and Smol 1988). In general, assemblages with the greatest diversity of algal remains will provide the largest amount of ecological information and the best predictive equations. Results must be interpreted with caution where equations are applied to assemblages containing only a few dominant taxa. In such cases, the inferred pH or ANC will be determined largely by the $\mathrm{pH}$ category or the abundanceweighted mean of the few dominant taxa. This has sometimes been a problem for highly acidic lakes. This problem can be especially important if the distribution of one or more of the dominant taxa is not well characterized in the calibration set (Charles and Smol 1988).

\subsubsection{Methodology}

Ouring the past several years, category-based, multiple-regression techniques (based on the assignment of diatom taxa to $\mathrm{pH}$ categories) have been replaced by theoretically superior 'gradient analysis' techniques. The theory has been developed and summarized primarily by ter Braak (ter Braak 1985; ter Braak and Barendregt 1986; ter Braak and Looman 1986; ter Braak 1986, 1987, 1988; ter Braak and Gremmen 1987; ter Braak and Prentice 1988). Gradientanalysis theory is based on a species-packing model along environmental gradients, assuming a simple normal distribution of each species' abundance in samples along the gradient. In the regression step, curves are fitted to each taxon's distribution, and the properties of the estimated optimum, $\mathfrak{a}_{k}$, and estimated tolerance, $t_{k}$, can be determined. The calibration step may be split further, into steps treating "active" samples (with associated environmental data) and "passive" samples (without associated environmental data). The algal assemblage in each active surface-sediment sample is used to obtain a single estimated value based on the optima, with or without tolerance downweighting. The relationship between predicted and observed environmental values emerges for the entire set of active samples. In the next calibration step, that of paleolimnological reconstruction, passive samples (sediment core samples) are used to obtain predicted environmental variable values, based on their taxa having the same characteristics obtained for the "active" taxa in the regression step. 
Notation and formulae for weighted averaging follow Birks et al. (1990) and Kingston (in press) (a):
$x$ is the environmental variable to be reconstructed,
$x_{i}$ is the value of $x$ in sample (lake) $i$,
$y_{i k}$ is the abundance of taxon $k$ in sample $i\left(y_{i k} \geq 0\right)(i=1 \ldots n$ lakes $) ;$
$k=1 \ldots m$ diatom (taxa), and
$\hat{x}_{i}$ is the estimated or inferred value of $x$ for sample $i$.

A reasonable estimate of a taxon's pH optimum is the average of all pH values for lakes in which the taxon occurs, weighted by the taxon's relative abundance. The taxon's optimum (abundance weighted mean), $\boldsymbol{o}_{k}$, is

$$
\hat{u}_{k}=\left[\sum_{i=1}^{n} y_{i k} x_{i}\right] /\left[\sum_{i=1}^{n} y_{i k}\right]
$$

and a taxon's tolerance (weighted standard deviation), $t_{k}$, is

$$
\hat{t}_{k}=\left[\sum_{i=1}^{n} y_{i k}\left(x_{i}-\hat{u}_{k}\right)^{2}\right],\left[\sum_{i=1}^{n} y_{i k}\right]^{1 / 2} .
$$

The estimated optima can be used to infer an environmental variable value from a lake's diatom assemblage by

$$
\hat{x}_{i}=\left[\sum_{k=1}^{m} y_{i k} \quad \hat{u}_{k}^{2}\right] /\left[\sum_{k=1}^{m} y_{i k}\right]
$$

(a) Sullivan, T. J. Historical Changes in Surface Hater Acid-Base Chemistry in Response to Acidic Deposition, with section by Kingston, J. C., "Recent Paleolimnological Advancements," pp. 3-26 to 3-29. State of the Science, SOS/T 11, National Acid Precipitation Assessment Program (In press). 
whereas a tolerance-weighted estimate would be

$$
\hat{x}_{i}=\left[\sum_{k=1}^{m} y_{i k}\left(\hat{u}_{k} / t_{k}\right)\right] /\left[\sum_{k=1}^{m} y_{i k} / t_{k}\right] .
$$

Averages are taken twice, once in the regression step and once in the calibration steps. The resulting shrinkage of the environmental gradient is corrected by a linear deshrinking regression. Deshrinking is discussed by ter Braak and van 0am (1989) and by Birks et a1. (1990). Weighted averaging without tolerance correction has proven superior for diatom reconstructions of several environmental variables (Birks et al. 1990; Kingston and Birks 1990), whereas tolerance correction may be superior for chrysophyte data (B. F. Cumming and H. J. B. Birks, personal communication); this may be explained by the higher diversity and greater number of "zero occurrences" in the diatom data.

For the PIRLA-II Project, weighted-averaging calibration (Birks et al. 1990) was used to develop calibration equations. Seventy-one lakes were included in the drainage-lake calibrations, 20 lakes in the seepage-1ake calibrations. The Diatom-inferred air-equilibrated versus measured (laboratory) $\mathrm{pH}$ and ANC of drainage and seepage lakes from that study are presented in Figures 2.1 and 2.2, respectively. Calibration equations were also developed for drainage lakes to infer $\mathrm{pH}$ and ANC from chrysophyte scales (Figure 2.3). The calibration relationships were not as strong for chrysophytes as for diatoms, but the chrysophyte data provide corroborative evidence of chemical change. The initial Diatom calibration equation was developed by Birks et al. (1990) on the basis of all ( $n=71)$ Adirondack drainage lakes $>1.5-m$ depth in the calibration set. A curvilinear relationship was observed, however, between inferred and measured ANC for this calibration (see figure 2.1C). Because the low-ANC lakes are of greater interest with respect to the chemical reconstructions, a separate calibration was developed for the lakes having ANC $\leq 100 \mu \mathrm{eq} \mathrm{L}^{-1}$. This revised calibration equation produced a substantially 

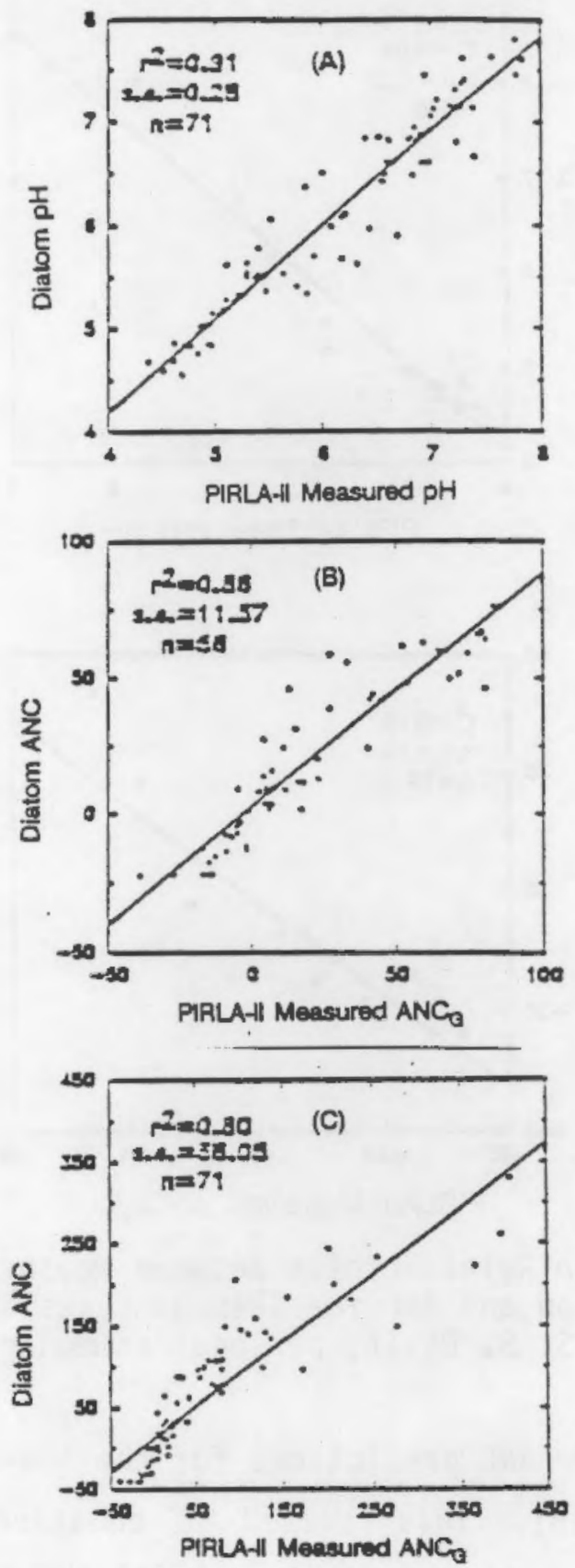

FIGURE 2.1. Calibration Relationships Developed in PIRLA-II Between Measured and Diatom-inferred Values of $\mathrm{pH}$ (Figure 2.1A) and ANC for Drainage Lakes in the Adirondacks (Source: S. S. Dixit, personal communication). Note that two calibration equations are presented for ANC. The relationship based on all calibration lakes ( $n=71$ ) was used for inferring ANC of lakes having current ANC > $100 \mu \mathrm{eq} \mathrm{L} \mathrm{L}^{-1}$ (Figure 2.1B). Because of nonlinearity and bias for acidic lakes, a restricted calibration was developed for low ANC ( $\leq 100 \mu \mathrm{eq} \mathrm{L^{-1 }}$ ) lakes (Figure 2.1C). 

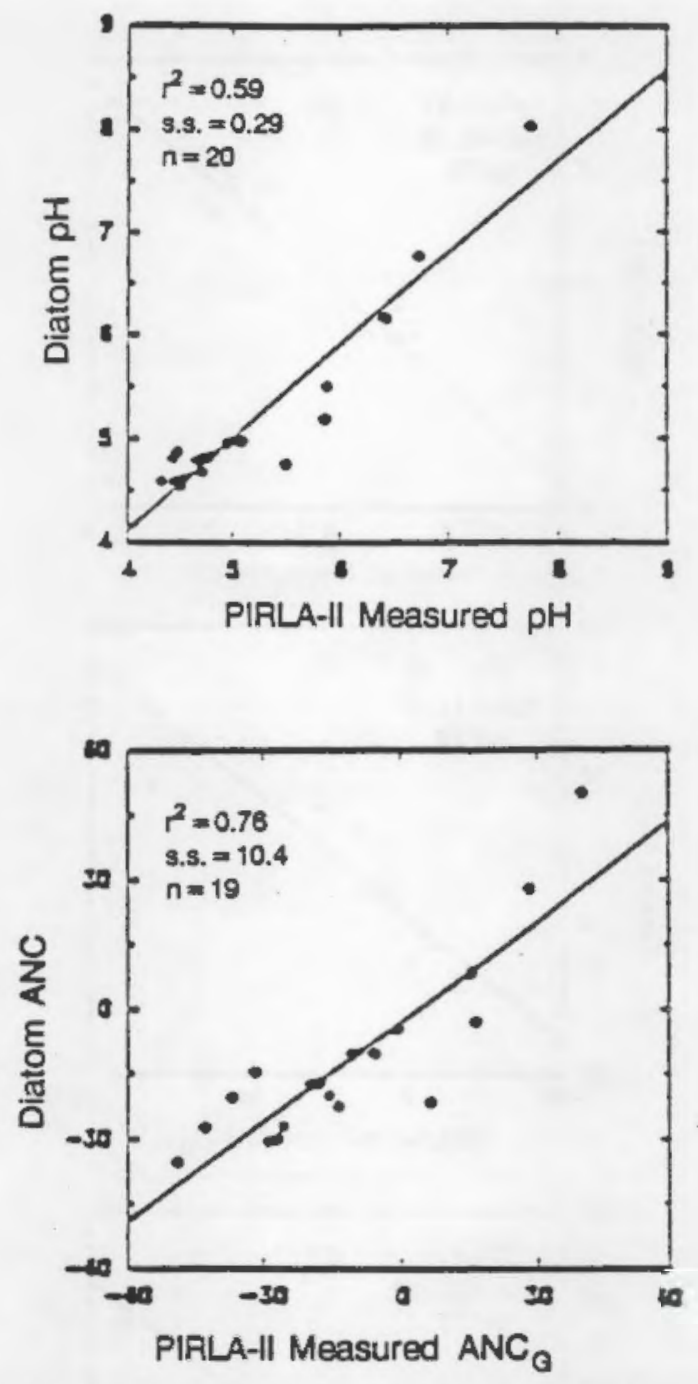

FIGURE 2.2. Calibration Relationships Between Measured and Diatom-inferred Values of $\mathrm{pH}$ and ANC for Seepage Lakes in the Adirondacks (Source: S. S. Dixit, personal communication).

reduced standard error for ANC predictions for the low-ANC lakes, from 38 to $12 \mu$ eq L-1 (see Figure 2.1B). This revised ANC equation was used in the present study to infer current and pre-industrial ANC for the low-ANC $\left(\leq 100 \mu \mathrm{eq} \mathrm{L}^{-1}\right)$ drainage lakes, whereas the full-range calibration was used for inferring ANC of the five high-ANC lakes. For the most acidic lakes in the data set (ANC < about $-20 \mu \mathrm{eq} \mathrm{L}^{-1}$ ), the ANC low-range inference equation had little discriminatory ability (Figure 2.1). 

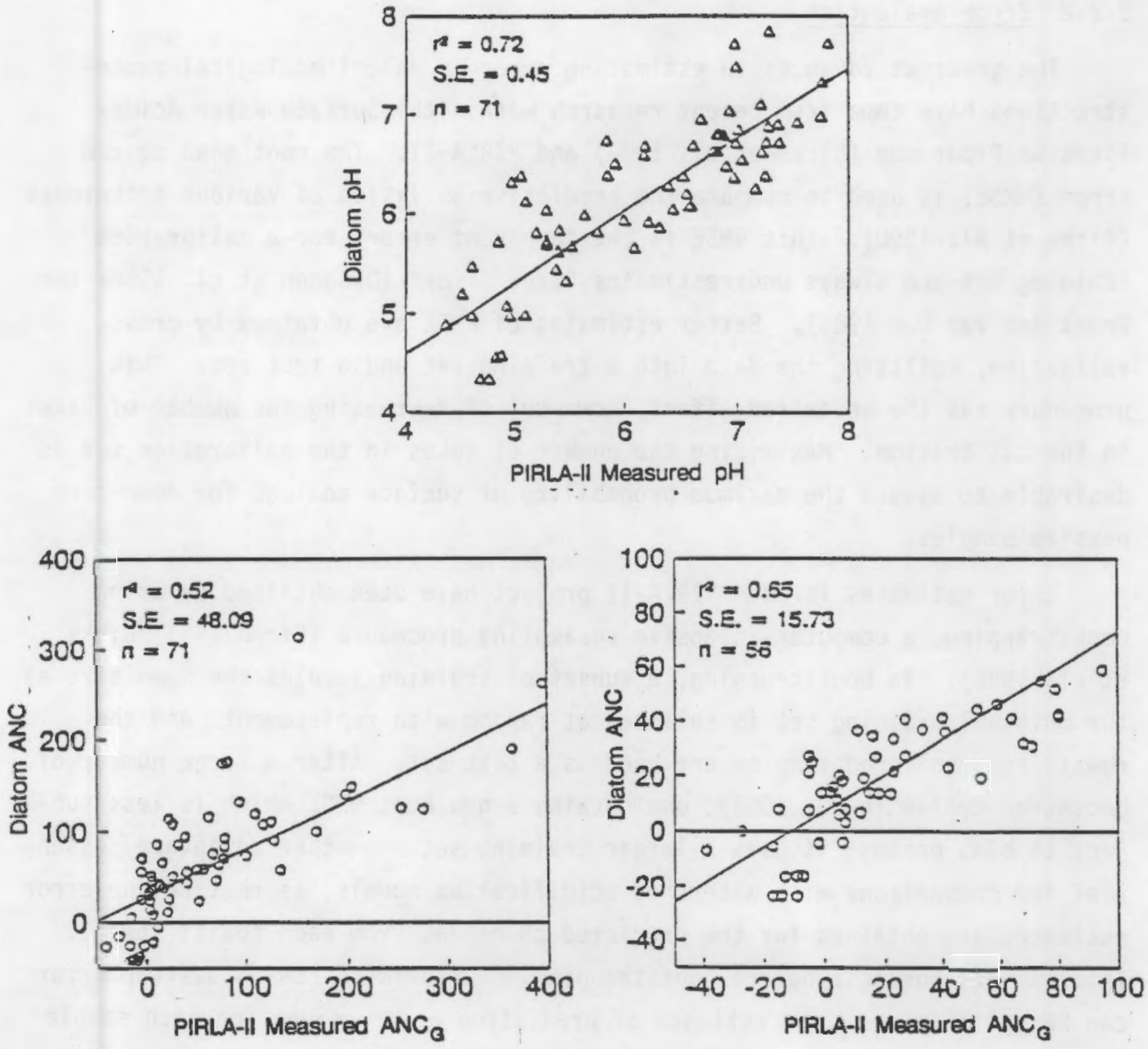

FIGURE 2.3. Calibration Relationships Between Measured and Chrysophyteinferred $\mathrm{pH}$ and ANC for Drainage Lakes in the Adirondack Subregion (Source: B. F. Cumming, manuscript in preparation) 


\subsubsection{Error Evaluation}

The greatest advances in estimating error in paleolimnological reconstructions have come from recent research within the Surface Water Acidification Programme (Birks et al. 1990) and PIRLA-II. The root mean square error (RMSE) is used to compare the predictive abilities of various techniques (Birks et al. 1990). This RMSE is the "apparent error" for a calibration training set and always underestimates "true error" (Oksanen et al. 1988; ter Braak and van Dam 1989). Better estimates of RMSE are obtained by crossvalidation, splitting the data into a training set and a test set. This procedure has the undesired effect, however, of decreasing the number of lakes in the calibration. Maximizing the number of lakes in the calibration set is desirable to assure the maximum probability of surface analogs for down-core passive samples.

Error estimates for the PIRLA-II project have been obtained by using bootstrapping, a computer-intensive resampling procedure (Efron 1983; Birks et al. 1990). In bootstrapping, a subset of training samples the same size as the original training set is selected at random with replacement, and the remaining unselected samples are used as a test set. After a large number of bootstrap cycles (e.g., 1000), one obtains a new boot RMSE which is less subject to bias because it uses a larger training set. Another advantage, essential for comparisons with watershed acidification models, is that unique error estimates are obtained for the predicted $\mathrm{pH}$ or ANC from each fossil sample. This was not possible before bootstrapping. Furthermore, the bootstrap error can be split into $s_{i 1}$, an estimate of prediction error unique for each sample (bias), and $s_{2}$, a constant error for the entire data set that represents variability (Birks et al. 1990; H. J. B. Birks, personal communication). Note that $s_{i 1}$ will become smaller as the training set gets larger; so that it will decrease in the larger PIRLA-II Adirondack data sets. For sediment core samples, the errors down-core are expected to increase above the errors for surface samples if the sampled assemblages diverge from the floristic composition of surface analogs. These errors can be greatly affected by data screening. The removal of outlier samples from the calibration can greatly improve performance of the relationships (Birks et al. 1990). Bootstrap-estimated errors for Diatom-inferred $\mathrm{ANC}_{\mathrm{G}}$ are presented in Figure 2.4. 


\subsection{MAGIC}

The Model of Acidification of Groundwater in Catchments (MAGIC) is a lumped-parameter model of intermediate complexity that was developed to predict the long-term (i.e., decades to centuries) effects of acidic deposition on surface-water chemistry. One of the model's principal assumptions is that a minimum number of critical processes in a watershed influence the long-term response to acidic deposition (Cosby et al. 1985a, 1985b). The MAGIC formulation was parsimonious in the processes selected for inclusion and was intended to be used as a heuristic tool for understanding the influences of the selected processes on surface water acidification. The spatial/temporal scales in the model reflect its intended use in assessment and multiscenario evaluations.

MAGIC represents the horizontal dimension of the watershed as a homogeneous unit with no subcatchments and the vertical dimension as two soil layers. Watershed data for MAGIC (Tables 2.3 and 2.4) were lumped or aggregated to provide average or weighted-average values for each of the soil layers. The top soil compartment represented the mass-weighted-average conditions of the $A$ and $B$ horizons. The lower soil compartment represented the mass-weighted average conditions in the $C$ horizon. Hydrologic flow of water through soil layers to the receiving system is simulated using a separate hydrologic model, TOPMODEL (Hornberger, Cosby, and Galloway 1986). TOPMODEL is a topography-based, variable contributing area, catchment model adapted from the version of Beven and Kirkby (1979). The model considers overland flow, macropore flow, drainage from the upper zone to the lower zone and to the stream, and base flow from the lower zone. Forecasting long-term effects of acidic deposition on surface water chemistry using MAGIC involves coupling MAGIC with TOPMODEL (Cosby et al. 1985a, 1985b, 1985c). Note that the DDRP analyses were constrained by a set of assumptions (Table 2.5) (Church et al. 1989). 

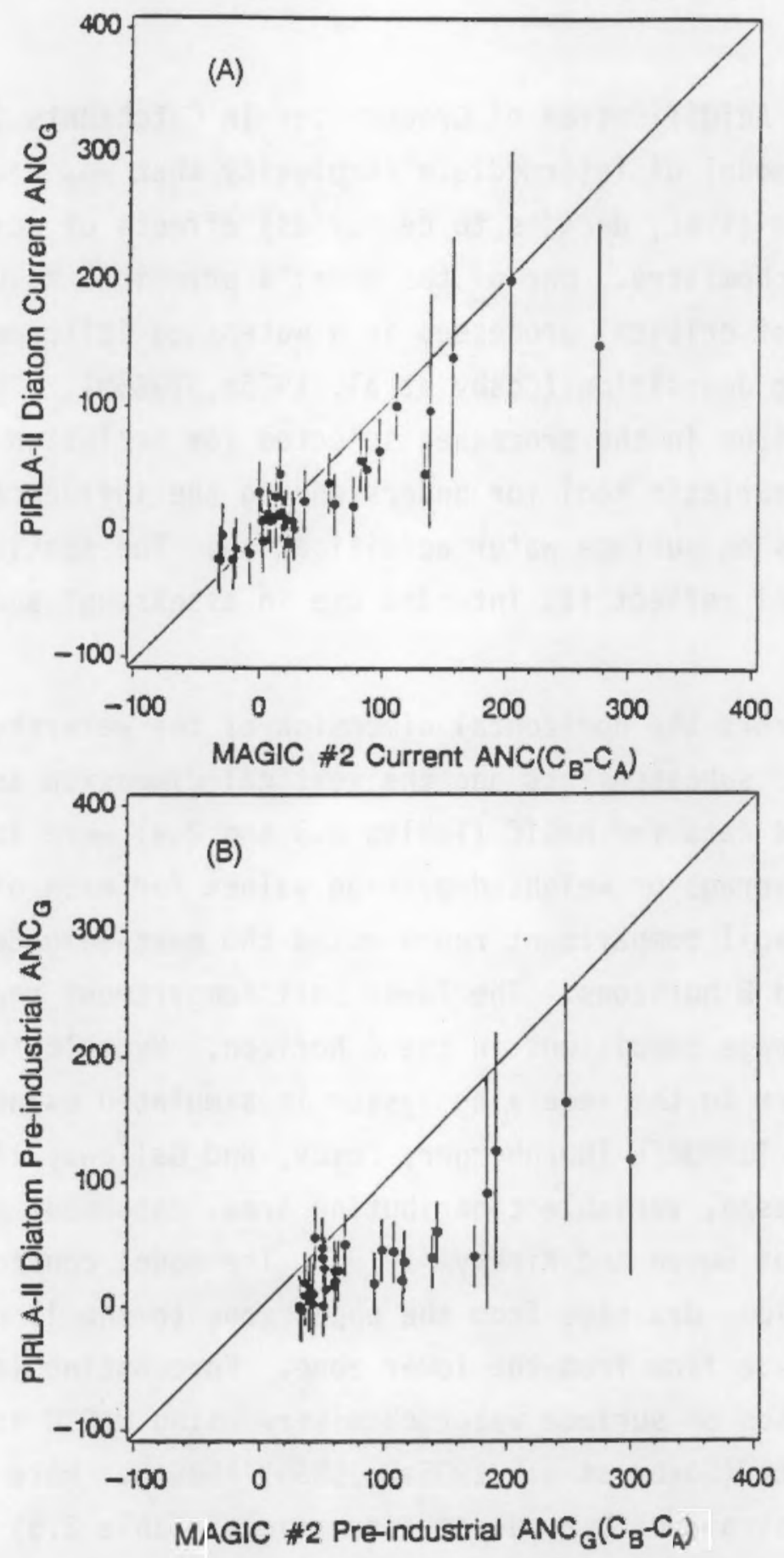

FIGURE 2.4. Plot of Diatom-inferred ANC Versus the MAGIC Scenario \#2 Estimate of $\operatorname{ANC}\left(C_{B}-C_{A}\right)$, with Error Estimates Placed on the Diatom-inferred Estimates. The error estimates reflect a $90 \%$ confidence interval from the bootstrapping procedure. Current chemistry is presented in (A) and pre-industrial chemistry in (B). 
TABLE 2.3. Fixed Parameters Used in MAGIC

\begin{tabular}{|c|c|}
\hline $\begin{array}{l}\text { Parameter } \\
\text { Name }\end{array}$ & Description \\
\hline DEP1 & Depth, soil layer 1 , meters \\
\hline POR1 & Porosity, soil layer 1 , fraction \\
\hline BD1 & Bulk density, soil layer $1, \mathrm{~kg} \mathrm{~m}^{3}$ \\
\hline CEC1 & Cation exchange capacity, soil layer 1 , meq $\mathrm{kg}^{-1}$ \\
\hline EMX1 & Maximum sulfate adsorption capacity, soil layer 1 , meq $\mathrm{kg}^{-1}$ \\
\hline $\mathrm{Cl}$ & Sulfate adsorption half saturation, soil layer 1 , $\mu$ eq $L^{-1}$ \\
\hline $\mathrm{K} 1_{\mathrm{N}}$ & Apparent aluminum solubility product, $\left(\log _{10}\right)$ soil layer 1 \\
\hline DEP2 & Depth, soil layer 2, meters \\
\hline POR2 & Porosity, soil layer 2, fraction \\
\hline BD2 & Bulk density, soil layer $2, \mathrm{~kg} / \mathrm{m}^{3}$ \\
\hline CEC2 & Cation exchange capacity, soil layer 2 , meq $\mathrm{kg}^{-1}$ \\
\hline EMX2 & Maximum sulfate adsorption capacity, soil layer 2 , meq $\mathrm{kg}^{-1}$ \\
\hline $\mathrm{C2}$ & Sulfate adsorption half saturation, soil layer 2 , req $L^{-1}$ \\
\hline $\mathrm{K} 2_{\mathcal{N}}$ & Apparent aluminum solubility product, $\left(\log _{10}\right)$ soil layer 2 \\
\hline RA & Lake-area to catchment-area ratio, fraction \\
\hline QS & Discharge per unit area of catchment, $m^{3} y^{-1}$ \\
\hline FR1 & Overland-flow fraction (routing), percent \\
\hline FR2 & Macropore-flow fraction (routing), percent \\
\hline FR3 & Interflow-fraction (routing), percent \\
\hline USOL & Sulfate uptake rate (reduction), lake, meq $\mathrm{m}^{-2} \mathrm{yr}^{-1}$ \\
\hline $\mathrm{KL}_{\mathcal{N}}$ & Apparent aluminum solubility product $\left(\log _{10}\right)$ lake \\
\hline
\end{tabular}

The meteorological and deposition input requirements for MAGIC are shown in Tables 2.6 and 2.7. The model uses equilibrium and rate-controlled expressions to represent geochemical processes to simulate both soil solution and surface water chemistry. Mass balances for the major cations and anions and the effects of aqueous $A 1$ and organic acid species on ANC are incorporated in the mode1. These processes are listed in Table 2.8. Annual output is the 
TABLE 2.4. Adjustable Parameters Used in MAGIC

\begin{tabular}{|c|c|}
\hline $\begin{array}{l}\text { Parameter } \\
\text { Name } \\
\end{array}$ & Description \\
\hline WECACa & Weathering rate, meq $\mathrm{m}^{-2} \mathrm{yr}^{-1}$ \\
\hline WEMGMg & Weathering rate, meq $\mathrm{m}^{-2} \mathrm{yr}^{-1}$ \\
\hline WENA & $\mathrm{Na}^{+}$weathering rate, meq $\mathrm{m}^{-2} \mathrm{yr}^{-1}$ \\
\hline WEK & $\mathrm{K}^{+}$weathering rate, meq $\mathrm{m}^{-2} \mathrm{yr}^{-1}$ \\
\hline $\mathrm{ECO1}$ & Initial $\mathrm{Ca}^{2+}$ base saturation, soil layer 1 , percent \\
\hline EMO1 & Initial $\mathrm{Mg}^{2+}$ base saturation, soi] layer 1 , percent \\
\hline ENO1 & Initial $\mathrm{Ma}^{*}$ base saturation, soil layer 1 , percent \\
\hline EKO1 & Initial $\mathrm{K}^{*}$ base saturation, soil layer 1 , percent \\
\hline UN01 & Initial $\mathrm{NO}_{3}$ base saturation, soil layer 1 , percent \\
\hline UNH1 & Initial $\mathrm{NH}_{4}$ base saturation, soil layer 1 , percent \\
\hline ECO2 & Initial $\mathrm{Ca}^{2+}$ base saturation, soil layer 2 , percent \\
\hline EM02 & Initial $\mathrm{Mg}^{2 *}$ base saturation, soil layer 2 , percent \\
\hline EN02 & Initial $\mathrm{Na}^{*}$ base saturation, soil layer 2 , percent \\
\hline EK02 & Initial $\mathrm{K}^{*}$ base saturation, soil layer 2 , percent \\
\hline UN02 & $\mathrm{NO}_{3}^{-}$uptake rate (biological), soil layer $2, \mathrm{yr}^{-1}$ \\
\hline UNH2 & $\mathrm{NH}_{4}^{+}$uptake rate (biological), soil layer $2, \mathrm{yr}^{-1}$ \\
\hline UNOL & $\mathrm{NO}_{3}$ uptake rate (biological), lake, $\mathrm{yr}^{-1}$ \\
\hline UNHL & $\mathrm{NH}_{4}$ uptake rate (biological), lake, $\mathrm{yr}^{-1}$ \\
\hline
\end{tabular}




\section{TABLE 2.5. Operational Assumptions for MAGIC Modeling \\ (Modified from Church et al. 1989)}

1. Index soil data froe the DOtp Soil Survey adequately characterize geochesical watershed attributas influencing surface-ntar chen istry.

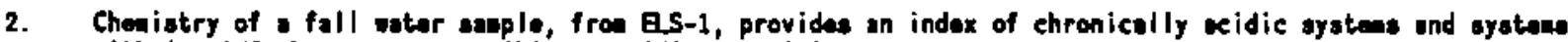
vith tos NIC that are sueceptible to ceidic doposition.

3. Dnly goocheoical and hydrologie procesean nead to be conaidered in mole endoling.

4. The eajor gocecherical proceseas are knom woll onowgh to be incorporated in maIC and uaed for hindeasting,

5. Sulfur it aseuned to be the primary acidifying aont in acidic depaition causing surface-nator acidification and alfur doposition over the last century can bo eatiated.

6. The witerahed procesese controlling the offecte of wlfur doposition on eurface-watere are sulfate adeorption and desorption, bees cation dapletion and resupply through ainoral mothering and oxchange, and inlake uptake (i.e., reduction to eulfide).

7. Hindcaste of historical ucidification considar chronic, but not epanidic, acidification.

8. Acidification ie reversible and the geochenical procesese in WGIC are adequate to deacribo both geocheaical acidification and recovery.

9. Currant ntorahed attribute and conditione (0.g., basin characteristics, clieate) have reasined rolatively constant over the last century end do not influence the reaulte of the hindeacte thereas land use is knom to have changed and the aagnitude of ite of fecte oust be oveluated.

10. The offecte of orgenic acids on scid-base cheaistry are constant through ties and independent of sulfate.

11. Base cation deposition hes not chonged significantly since pre-industrial tiaes.

12. 'Typical' yoar precipitation and deposition projectione are not intended to predict future water chen istry but rather to provide a coonon basis for comparisons anong deposition aconarios to asease potantial changes in surface-wator cheistry.

13. Uncertainty calculations provide astisates of relative orror for long-tora couparisone anong modela and deposition sconarios but do not estiuate absolute error.

14. Lake metore are in equilibriun vith alueinue hydroxide.

15. Dther than paleoliunoligical nodels, dynacic proceas-baued waterahed nodele wch as waIC, are the only foasible approach for ovaluating the long-tore effecte of alfur doposition on surface-water chesistry. 
IABLE 2.6. Meteorological Data Required by the MAGIC/TOPMODEL Code (Source: Jenne et al. 1989)

Meteorological Data

Interval for data measurement

Precipitation

Minimum air temperature

Maximum air temperature

Mean daylight hours

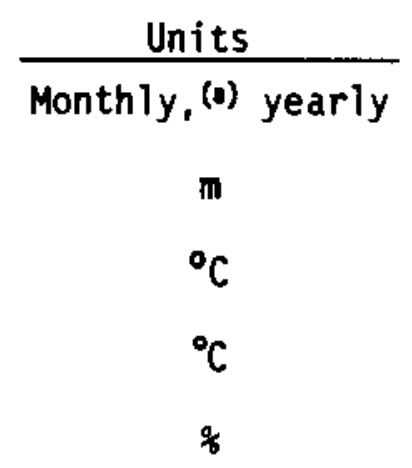

(a) TOPMODEL runs with a daily time step.

TABLE 2.7. Chemical Constituents in Het and Dry Deposition Considered by the MAGIC Model(a) (Source: Jenne et al. 1989)

\begin{tabular}{l} 
Constituent \\
\hline $\mathrm{SO}_{x}(\mathrm{~g})$ \\
$\mathrm{NO}_{x}(\mathrm{~g})$ \\
$\mathrm{Ca}^{2+}$ \\
$\mathrm{Mg}^{2+}$ \\
$\mathrm{K}^{+}$ \\
$\mathrm{Na}^{+}$ \\
$\mathrm{NH}_{4}^{+}$ \\
$\mathrm{SO}_{4}^{--}$ \\
$\mathrm{NO}_{3}^{-}$ \\
$\mathrm{Cl}^{-}$ \\
$\mathrm{F}^{-}$
\end{tabular}

MAGIC

\begin{tabular}{|c|c|}
\hline Wet & $\operatorname{Dry}^{\left.()^{\prime}\right)}$ \\
\hline- & $(x)^{(s)}$ \\
\hline -- & $(x)^{(c)}$ \\
\hline$x$ & $x$ \\
\hline$x$ & $x$ \\
\hline$x$ & $x$ \\
\hline$x$ & $x$ \\
\hline$x$ & $x$ \\
\hline$x$ & $x$ \\
\hline$x$ & $x$ \\
\hline$x$ & $x$ \\
\hline$x$ & $x$ \\
\hline
\end{tabular}

(a) Units are for monthly or yearly average.

(b) The MAGIC code requires that dry deposition be expressed by means of a dry deposition factor.

(c) $\mathrm{SO}_{x}(\mathrm{~g})$ and $\mathrm{NO}_{\mathrm{x}}(\mathrm{g})$ are implicitly included by means of the dry deposition factor. 
TABLE 2.8. Major Processes Incorporated in the Combined MAGIC/TOPMODEL Code (Jenne et al. 1989)

Processes

Atmospheric Processes

- Dry deposition

- Wet deposition

Hydrological Processes

- Evapotranspiration

- Interception storage

- Snownelt

- Overland flow

- Macropore flow

- Unsaturated subsurface flow

- Saturated subsurface flow

- Stream flow

Geochemical Processes

- Carbonic acid chemistry

- Aluminum chemistry

- Organic acid chemistry

- Weathering

- Anion Retention

- Cation exchange
MAGIC/TOPHODEL(a)

$x$

$x$

\section{Biogeochemical Processes}

- $\mathrm{SO}_{4}^{2-}$ reduction in lake

- Nitrification in soil

- Nutrient uptake

- Canopy interactions

- Litter decay

- Root respiration

$x$
$(x)$ (b)
$x$
$x$
$x$
$x$
$x$
$x$

(a) Parentheses indicate limited treatment of process.

(b) Canopy interactions and root decay and respiration are implicitly included in the MAGIC code by use of dry deposition factor and by designation of $\mathrm{CO}_{2}$ partial pressure in soils and surface-waters.

(c) Sulfate reduction, nitrification, and uptake of ions can be simulated with the MAGIC code by specifying uptake rates of $\mathrm{SO}_{4}$ and $\mathrm{NH}_{4}$ for various hydrologic compartments. 
typical temporal resolution of the model, but monthly output also can be obtained for the constituents listed in Table 2.9. MAGIC does not use a Gran ANC in simulating watershed response. Rather, it uses two definitions of ANC as follows:

$$
\begin{aligned}
\mathrm{ANC}_{\mathrm{NL}}= & {\left[\mathrm{HCO}_{3}^{-}\right]+2\left[\mathrm{CO}_{3}^{2-}\right]+\left[\mathrm{OH}^{-}\right]+\left[\mathrm{HR}^{\prime \prime}\right]+2\left[\mathrm{R}^{\prime 2-}\right]+\left[\mathrm{Al}(\mathrm{OH})_{4}^{-}\right] } \\
& \left.-\left[\mathrm{H}^{*}\right]-3[\mathrm{~A}]^{3 \cdot}\right]-2\left[\mathrm{AL}(\mathrm{OH})^{2+}\right]-[\mathrm{A}](\mathrm{OH})^{+} \\
\mathrm{ANC}_{\mathrm{CNX}}= & \mathrm{SBC}+\mathrm{NH}_{4}-\mathrm{SSA}=\mathrm{C}_{\mathrm{g}}-\mathrm{C}_{\mathrm{A}}
\end{aligned}
$$

where $\mathrm{SBC}=\left[\mathrm{Ca}^{2+}\right]+\left[\mathrm{Mg}^{2+}\right]+\left[\mathrm{Na}^{*}\right]+\left[\mathrm{K}^{*}\right], \mathrm{SSA}=\left[\mathrm{Cl}^{-}\right]+\left[\mathrm{NO}_{3}\right]+\left[\mathrm{SO}_{4}^{2-}\right], \mathrm{R}^{\mathrm{1*} 2-}$ is a doubly charged organic ligand, and all units are microequivalents per liter ( $\mu$ eq $L^{-1}$ ). Equation (2.6), referred to as charge balance ANC, is identical to calculated $\operatorname{ANC}\left(C_{B}-C_{A}\right)$ as used in this report, unless stated otherwise.

\subsubsection{Calibration}

Calibration of MAGIC involves selecting a set of initial parameter values that, in conjunction with estimated precipitation and deposition, yield a trajectory from 1844 through a "window" about the 1984 measured lake chemistry values. The hindcast pre-industrial lakewater chemistry used here is the mean of those runs with initial conditions that resulted in a trajectory that passed through a specified window for 1984 chemistry. The calibration exercise was a three-step process. The first step was to specify the model inputs such as precipitation, deposition (both wet and dry), an estimate of historical inputs for the long-term model, and fixed parameters whose values correspond directly to (or can be computed directly from) field measurements, e.g., topographic variables such as slope, aspect, and area. This approach, in effect, assigns all of the uncertainty associated with sampling, aggregation, and intrinsic spatial variability to the "adjustable" parameters. The adjustable parameters are those that are calibrated or scaled to match observed field measurements. 
TABLE 2.9. Aqueous Chemical Constituents Included in the MAGIC Code (Source: Jenne et al. 1989)

\begin{tabular}{|c|c|c|}
\hline ANC & $\mathrm{Ca}^{2+}$ & $\mathrm{Mg}^{2+}$ \\
\hline $\mathbf{K}^{*}$ & $\mathrm{Ma}+$ & $\mathrm{NH}_{4}^{+}$ \\
\hline$H^{*}$ & $\mathrm{Al}^{\mathrm{3}}$ & $A 1(O H)_{n}^{3-n}(n=1$ to 4$)$ \\
\hline A] $(F)_{n}^{3-n}(n=1$ to 6$)$ & Al $\left(\mathrm{SO}_{4}\right)_{n}^{3-n}(n=1$ to 2$)$ & $\mathrm{SO}_{4}^{2-}$ \\
\hline $\mathrm{NO}_{3}^{-}$ & $\mathrm{Cl}^{-}$ & $F^{*}$ \\
\hline $\mathrm{CO}_{2}(\mathrm{~g})$ & $\mathrm{CO}_{2}(\mathrm{aq})$ & $\mathrm{H}_{2} \mathrm{CO}_{3}(\mathrm{aq})$ \\
\hline $\mathrm{HCO}_{3}^{-}$ & $\mathrm{CO}_{3}^{2-}$ & $R^{112-}$ \\
\hline
\end{tabular}

The second step was to select optimal values for the adjustable parameters, optimizing both MAGIC and TOPMODEL using the method of Rosenbrock (1960). Optimal values were determined by minimizing a loss function defined by the sum of squared errors between simulated and observed values of system state variables. Different loss functions were used for the hydrologic and chemical models. The loss function for the hydrological model was based on measured monthly catchment discharge values. The loss function for the MAGIC model was based on surface water concentrations of $\mathrm{Ca}^{2+}, \mathrm{Mg}^{2+}, \mathrm{Na}^{+}, \mathrm{K}+, \mathrm{SO}_{4}^{2-}$, $\mathrm{Cl}^{-}, \mathrm{NO}_{3}^{-}, \mathrm{NH}_{4}^{*}$, and $\mathrm{F}^{-}$(taken from the ELS-I fall lake chemistry), and soil exchange fractions of $\mathrm{Ca}^{2+}, \mathrm{Mg}^{2+}, \mathrm{Na}^{+}$, and $\mathrm{K}^{+}$for the upper and lower soil layers (aggregated by ORNL from DDRP soil survey data).

The final step was to assess 1) the structural adequacy of the model to reproduce the observed behavior of the measured variables and 2) parameter identifiability or the uniqueness of the set of optimized parameters. Structural adequacy was assessed by examining the mean error in simulated values of observed state variables for those variables used in the calibration procedure as well as for an additional state variable not used during calibration. Parameter identifiability was assessed using approximate estimation-error variances for the optimized parameters (Bard 1974). Additional information on the MAGIC calibration process was presented by Cosby, Hornberger, and Wright (1989).

Atmospheric deposition data, supplied by Pacific Northwest Laboratory (PNL), was assumed to be uniform over the individual catchments. Atmospheric 
fluxes in the code are calculated from concentrations of the ions in precipitation and from estimated rainfall volume interpolated to each catchment (Church et al. 1989). The wet-deposition data and annual-precipitation volume provided for each DDRP catchment were used to calculate annual average concentrations for each ion in precipitation. Dry deposition of particulates and aerosols was represented as a fraction of wet deposition by a dry-deposition factor, calculated for each mass-balance ion for each catchment (Church et al. 1989).

Discharge data, provided by the Environmental Research Laboratory of EPA (EPA/CERL) for each catchment, was obtained by interpolation from U.S. Geological Survey discharge maps. Relative lake area was determined from data on terrestrial and lake areas provided by EPA/CERL.

Depth, bulk density, cation-exchange capacity, maximum sulfate-adsorption capacity, and the sulfate-adsorption half-saturation constant were from the DDRP data set (EPA/CERL). Oak Ridge National Laboratory (ORNL) aggregated parameters of the $A$ and $B$ soil horizons for MAGIC Layer 1 and those of the $C$ soit horizon for MAGIC Layer 2. The depth used for the soil Layer 2 was derived as one of two possible values in the data base. If the depth to bedrock (DTBR) was less than the sum of the layer depths (DEP1 + DEP2, provided in the soils data base), then the aggregated depth (DEP2) was used for the lower soil layer in MAGIC. If, however, DTBR was greater than DEP1+DEP2, the depth of the lower soil layer was redefined as DEP2 = DTBR - DEP1. This procedure assured that a conservative (large) total soil depth was used when ambiguity in the data existed. Soil-layer depths were not corrected for coarse-fragment content in the initial DDRP aggregations, but this correction was made for the MAGIC Scenario \#4 (see Section 2.4.5). Porosity was calculated from the bulk-density measurement for each layer, assuming a specific gravity for the soil particles of $2.65 \mathrm{~g} \mathrm{~cm}^{-3}$.

Soil temperatures were not provided in the DDRP data sets, but daily air temperatures for each catchment were provided. Mean annual soil temperatures were derived from the daily air-temperature data by 1) setting all daily values that were less than $-1.5^{\circ} \mathrm{C}$ to be equal to $-1.5^{\circ} \mathrm{C} ; 2$ ) calculating the mean annual air temperature from the modified daily values; and 3 ) setting the 
mean annual soil temperature equal to the modified mean annual air temperature. This procedure was tested by applying it to data from Soil Conservation Service sites for which mean annual air and soil temperatures were both available (Smith et al. 1964). The procedure was found to produce unbiased estimates of soil temperatures. The same soil temperature was used for both soil layers. Mean annual surface-water temperature was assumed to be equal to the mean annual soil temperature.

Cosby et al. (1986) have demonstrated that the calibration of MAGIC is sensitive to the value of soil $\mathrm{PCO}_{2}$ but soil $\mathrm{pCO}_{2}$ measurements were not provided in the DORP data sets. Soil $\mathrm{pCO}_{2}$ was estimated from a regression on soil temperature constructed from mean growing-season soil $\mathrm{pCO}_{2}$ data from 19 regions of the world (Brook, Polkoff, and Box 1983):

$$
\log _{10}\left(\mathrm{pCO}_{2}\right)=0.03 \mathrm{~T}-2.48
$$

where $\mathrm{pCO}_{2}$ is in atmospheres and $\mathrm{T}$ is the soil temperature in ${ }^{\circ} \mathrm{C}$. Using this expression, a mean annual soil temperature of $10^{\circ} \mathrm{C}$ would produce a soil $\mathrm{pCO}_{2}$ of 0.0066 atm. (approximately 20 times atmospheric $\mathrm{pCO}_{2}$ ). However, sone of the catchments could not be calibrated using a $\mathrm{PCO}_{2}$ value derived from the relationship in Equation (2.7). For those catchments, which tend to be in the lower $\mathrm{pH}$ range, the $\mathrm{pCO}_{2}$ was increased by a factor of 10 from the value derived from Equation (2.7). Insufficient primary data on soil partialpressure of $\mathrm{CO}_{2}$ exist to evaluate the error in either approach. However, Schecher and Driscoll (1988) noted that the carbonate alkalinity of RILWAS lakes in the Adirondack Region was frequently greater than the value calculated for equilibria with the $\mathrm{pCO}_{2}$ in the atmosphere.

Because surface-water $\mathrm{PCO}_{2}$ values were also unavailable, the surfacewater chemistry data were used to estimate values of surface-water $\mathrm{pCO}_{2}$. Assuming that all titrated ANC results from carbonate buffering, an expression for $\mathrm{pCO}_{2}$ as a function of surface-water ANC and $\mathrm{pH}$ can be derived from the equilibrium equations for the dissociation of inorganic carbon and the dissociation of water, i.e.,

$$
A N C=\left[\mathrm{HCO}_{3}^{-}\right]+2\left[\mathrm{CO}_{3}^{2-}\right]+\left[\mathrm{OH}^{-}\right]-\left[\mathrm{H}^{+}\right] .
$$


Substituting into the equilibrium equations, and solving for $\mathrm{pCO}_{2}$ yields

$$
\mathrm{pCO}_{2}=\frac{10^{(-3 \mathrm{pH})}+(\mathrm{ANC}) 10^{(-2 \mathrm{pH})}-\mathrm{a}_{1} 10^{(-\mathrm{pH})}}{\mathrm{a}_{2} 10^{(-\mathrm{pH})}+2 \mathrm{q}_{3}}
$$

where ANC is in equivalents per liter, and the constants $a_{1}, a_{2}, a_{3}$ are functions of thermodynamic equilibrium constants for the dissociation of water, the reaction of $\mathrm{CO}_{2}$ with water and subsequent deprotonation:

$$
a_{1}=K_{1}, \quad a_{2}=K_{\mathrm{CO}_{2}} \quad K 2_{\mathrm{CO}_{2}}, \quad \mathrm{a}_{3}=\mathrm{K}_{\mathrm{CO}_{2}} \quad \mathrm{~K} 2_{\mathrm{CO}_{2}} \quad \mathrm{~K} 3_{\mathrm{CO}_{2}} \cdot
$$

Equation (2.9) was solved using the measured values of ANC and closedhead-space $\mathrm{pH}$. The mean over all catchments was 0.00066 atmospheres (twice atmospheric $\left.\mathrm{pCO}_{2}\right)$. This value was lower than the soil $\mathrm{pCO}_{2}$ values calculated from soil temperature. The use of the mean surface water of $\mathrm{pCO}_{2}$ values for all catchments removes any bias due to a lack of precision of measurement for individual lakes. However, the results are biased for those lakes wherein $A l$ and DOC contribute significantly to ANC. The results may also be biased by the assumption of equilibrium between lake water and $\mathrm{Al}(\mathrm{OH})_{3}(\mathrm{~s})$.

Apparent Al-hydroxide solubility products for both soil layers $\left(K 1_{A 1}\right.$. $\mathrm{K}_{\mathrm{Al}}$ ), given as negative logarithms (base 10 ), were assumed to be equal to 9.05 at $25 \mathrm{C}$ for both soil layers for all catchments. The assumed value represents a solid phase of $\mathrm{AI}(\mathrm{OH})_{3}$ intermediate in solubility between natural and synthetic gibbsite (see Cosby et al. 1985b). The apparent Al-hydroxide solubility product for surface-waters $\left(\mathrm{KO}_{\mathrm{Al}}\right)$ was estimated from an analys is of surface-water $\mathrm{pH}$ and $\mathrm{Al}$ concentrations provided in the DDRP lake index data base for the northeast. If the complexation reactions of $\mathrm{Al}$ with $\mathrm{F}^{-}, \mathrm{SO}_{4}^{2-}$ and dissolved organic carbon are disregarded, total monomeric $A 1$ (Al.) can be defined as:

$$
\left.A l_{1}=[A]^{3 *}\right]+\left[\mathrm{Al}(\mathrm{OH})^{2 *}\right]+\left[\mathrm{Al}(\mathrm{OH})_{2}^{+}\right]+\left[\mathrm{Al}(\mathrm{OH})_{3}^{\circ}\right]+\left[\mathrm{Al}(\mathrm{OH})_{4}^{-}\right] \text {. }
$$


An equilibrium expression for $\mathrm{Al}$. as a function of $\mathrm{pH}, \mathrm{Al}$-hydroxide solubility product and the thermodynamic constants for Al-hydrolysis species is given by

$$
A 1_{0}=\mathrm{KO}_{\mathrm{Al}}[10(-3 \mathrm{pH})+10(\mathrm{a} 1-2 \mathrm{pH})+10(\mathrm{a} 2-\mathrm{pH})+10(\mathrm{a} 3)+10(\mathrm{a} 4+\mathrm{pH})]
$$

where $a_{1}, a_{2}, a_{3}$, and $a_{4}$ are the thermodynamic constants for $K 1_{A 1}, K 2_{A 1}, K 3_{A 1}$, and $K 4_{A l}$, respectively [see Equation (2.9)], and equilibrium between the lake water and Al-hydroxide is assumed.

Given the measurements of closed-head-space $\mathrm{pH}$ and total inorganic Al $\left(A I_{i}\right)$, assumed to be equal to $A l_{1}$, Equation (2.12) was solved for an Alhydroxide apparent solubility value $\left(\mathrm{KO}_{\mathrm{Al}}\right)$ for each lake. The values of $\mathrm{KO}_{\mathrm{Al}}$ thus derived for each catchment were arithmetically averaged over all catchments to obtain a regional mean value of 8.06 which was used for all of the northeastern catchments. The use of the mean value for all catchments results in an unbiased estimate of surface-water Al-hydroxide solubility value over the group of catchments as a whole, assuming equilibrium between the lake waters and an Al-hydroxide.

Significant amounts of sulfur can be retained in lakes through dissimulatory reduction of $\mathrm{SO}_{4}^{2-}$, with $\mathrm{H}_{2} \mathrm{~S}$, ester sulfates, or metal sulfides being produced as end products (Rudd, Kelly, and Furutani 1986; Brezonik, Baker, and Perry 1987). Sulfate uptake in the lake sediments was calculated from the Baker and Brezonik (1988) model of lake sulfate retention using hydraulic resident time calculated from lake-area to catchment-area ratio and unit area discharge (see Table 2.3). Reduction rates for [ $\left.\mathrm{SO}_{4}^{2-}\right]$ are approximately first order at concentrations typically encountered in these soft-water lakes. In-lake reduction rates are apparently 1 imited by diffusion into the sediments (Baker, Brezonik, and Pollman 1986; Kelly et al. 1987). Baker, Brezonik, and Pollman (1986) and Kelly et al. (1987) showed that this process can be represented effectively by the following:

$$
\because \mathrm{SO}_{4} \text { retained }=\frac{100 \mathrm{k}_{\mathrm{SO}_{4}}}{\left(z / t_{\mathrm{w}}\right)+\mathrm{k}_{\mathrm{SO}_{4}}}
$$


where $\quad \begin{aligned} k_{\mathrm{sa}_{4}} & =\text { sulfate mass-transfer coefficient }\left(\mathrm{m} \mathrm{yr} \mathrm{y}^{-1}\right) \\ Z & =\text { mean lake depth }(\mathrm{m})\end{aligned}$

$t_{w}=$ hydraulic residence time (yr) (outflow based).

The DDRP modeling of watersheds in the Northeast (Cosby et al. 1989) employed the in-lake sulfate reduction model and used an average $k_{\mathrm{SO}_{4}}$ value of 0.52 which compares with average sulfate mass-transfer coefficients computed by Baker, Brezonik, and Pollman (1986) and Kelly et al. (1987) of 0.54 and $0.46 \mathrm{~m} \mathrm{yr}^{-1}$, respectively. Although sulfur retention can be very high in seepage systems and other lakes with long residence times (Lin and Schnoor 1986; Schindler et al. 1986; Baker, Pollman, and Eilers 1988), computations of in-lake alkalinity generation indicated that the drainage lakes in ELS-I subregion $1 \mathrm{~A}$ (the Adirondack region) have a median $\mathrm{SO}_{4}^{2-}$ retention of $2.8 \%$. Only approximately $8 \%$ of these lakes exhibit sulfur retention $>10 \%$ (Shaffer and Church 1989). This low sulfur retention for drainage lakes in the Adirondack region is attributed to their short hydraulic-retention times, which, based on data from Linthurst et al. (1986) and Kanciruk et al. (1986), average $0.23 \mathrm{yr}$ for the estimated population of 1091 drainage lakes.

Biological uptake of $\mathrm{NO}_{3}$ and $\mathrm{NH}_{4}$ were simulated as first-order rate processes. That is, the uptake parameters were considered to be rate constants that represent the fraction of nitrogen input to a layer taken up per unit time (units $=\mathrm{yr}^{-1}$ ). These parameters were calibrated by selecting values for the rate constants that produced the correct surface-water concentrations. Calibration of the weathering fluxes and specification of the initial saturation of the exchange sites with individual base cations (a fixed parameter) specifies the selectivity coefficients for the base cations. These selectivity coefficients (Table 2.10) are calibrated parameters of the model. Weathering was calibrated per unit-area of catchment, i.e., as a flux. Weathering products were distributed between the two soil layers using a weighting scheme based on the total mass of soil per unit area in each layer (the product of depth and bulk density for each layer). Weathering fluxes and selectivity coefficients were chosen in the calibration procedure such that the individual base saturations and the surface-water base-cation concentrations simulated for 1984 matched those provided in the DDRP data base. 
TABLE 2.10. Selectivity Coefficients Used in the Calibration of MAGIC (All Log Base 10)

Selectivity Coefficient

SALCA1

SALMG1

SALNA1

SALK1

SALCA2

SALMG2

SALNA2

SALK2
Description

Ca/Al selectivity coefficient, soil-Jayer 1 $\mathrm{Mg} / \mathrm{Al}$ selectivity coefficient, soil-layer 1 $\mathrm{Na} / \mathrm{Al}$ selectivity coefficient, soil-layer I $\mathrm{K} / \mathrm{Al}$ selectivity coefficient, soil-layer 1 Ca/Al selectivity coefficient, soil-layer 2 Mg/Al selectivity coefficient, soil-layer 2 $\mathrm{Na} / \mathrm{Al}$ selectivity coefficient, soil-layer 2 K/Al selectivity coefficient, soil-layer 2

Results from MAGIC for three lakes in the Northeast have previously been compared with resuits from ILHAS, another process-based model used in the DDRP (Eary et a1. 1989; Jenne et al. 1989). The outputs (discharge and concentrations of cations, anions, $\mathrm{Al}$ and $\mathrm{H}^{+}$) compared favorably with the observed standard error for the study sites. The similarities in calibration/ confirmation RMSEs for MAGIC indicate that parameter values for all processes can be constrained by watershed and lake attributes to achieve calibration within the range of observed values. However, for a few watersheds, no acceptable calibration of MAGIC was obtained, while in others fewer than 10 acceptable calibrations were obtained by the automatic optimization procedure. MAGIC modeling conducted within both DDRP and the present study did not consider potential organic acid influence on acid-base chemistry. Limited sensitivity analyses were subsequently performed to evaluate the potential extent to which this onission may explain discrepancies between Diatom and MAGIC model results, and the results are presented in the Appendix.

\subsubsection{Error Evaluation}

Because the measurements of the fixed parameters and the target variables used in the calibration procedure are subject to errors, a "fuzzy" optimization procedure was implemented for calibrating MAGIC. The "fuzzy" calibration procedure provided estimates for uncertainty widths for simulated variables; that is, the values represented the width of the interval containing equally viable simulated variable values. The fuzzy optimization procedure consisted 
of multiple calibrations of each catchment using perturbations of the values of the fixed parameters. All successful calibrations for a site fall within the ranges specified by the output uncertainty width. The size of the perturbations was based on known measurement errors for the fixed parameters (error estimates provided for the DDRP aggregated-soils data base). Each of the multiple calibrations began with 1) a random selection of perturbed values of fixed parameters and 2) a random selection of the starting values of the adjustable parameters. The adjustable parameters were then optimized using the Rosenbrock algorithm to achieve a minimum error-fit to the target variables. This procedure was undertaken 10 times at each site. The final calibrated model is represented by the median parameter values and median variable values of the successful calibrations, and the (maximum-minimum) values of the multiple simulations were taken as the uncertainty estimates. An average of more than eight successful calibrations was achieved for the DDRP sites. All catchments had at least three successful calibrations.

Using the fuzzy optimization based on multiple calibrations, uncertainty bands for the model simulations can be presented as maximum and minimum values for output variables in any year derived from the group of successful calibrations. These uncertainty bands encompass the range of variable values that were simulated, given the specified uncertainty in the parameter values and measured target variables. The difference between maximum and minimum simulated values derived from the multiple optimizations defines an uncertainty width around the simulated value arising from parametric uncertainty. Using this procedure, a measure of parametric uncertainty for each variable of interest for each of the catchments was derived. These uncertainty widths are available for all years simulated for each catchment. The uncertainty widths are smallest for the calibration year (when the measured data are available). The uncertainty widths for each variable for each catchment increase as the simulations move away from the calibration year; that is, the uncertainty estimates are nonstationary. The uncertainty widths for a given variable in a given year are different for different catchments. 


\subsection{COMPARISON AMD COMPLICATING FACTORS}

The three separate intercomparisons used to evaluate the estimates of historical acidification obtained from the Diatom and MAGIC models are estimates of current chemistry, pre-industrial chemistry, and change from pre-industrial to present chemistry. Prior to presenting these comparisons, however, we first establish the comparability of the data used, the ANC definitions, the deposition assumptions, and the region definition. Differences in the manner in which observational data are treated that potentially can introduce bias into the comparison include:

1. Watershed Disturbance and/or Land Use - A number of factors, other than acid deposition, particularly those related to disturbance and land use, can influence surface water acid/base status. The dynamic models are not constructed to estimate changes associated with these complicating factors. In contrast, the Diatom model provides estimates of the actual water chemistry and net changes, irrespective of the causes of change. For example, if a given watershed had experienced a loss of $10 \mu \mathrm{eq} \mathrm{L}^{-1}$ of ANC in response to acid deposition, and in addition had either gained or lost $15 \mu \mathrm{eq} \mathrm{L}^{-1}$ of ANC because of watershed disturbance, the results for paieolimnological versus MAGIC evaluation would be quite different. The former would provide an estimate of the net change in ANC, whereas the latter would provide an estimate of the change associated with acid deposition only, because the model is driven by estimated deposition.

2. Lake Chemistry Seasonality - The Diatom model was originally calibrated to average summer lakewater chemistry (air-equilibrated pH; PIRLA-I and -II), whereas the MAGIC model was calibrated to ELS-I fall index chemistry (closed-system $\mathrm{pH}$ ). Seasonal differences between summer and fall may bias the results.

3. ANC Definition - The ANC calculated by MAGIC is a defined $\operatorname{ANC}\left(C_{B}-C_{A}\right)$ (see Equation [6]), whereas the Diatom estimates of ANC were calibrated to titrated ANC ( $A N C_{0}$ ) in the PIRLA study. Unfortunately, $A N C_{0}$ and defined $A N C\left(C_{B}-C_{A}\right)$ of ten differ for low-ANC waters, largely due to the influence of aqueous $A 1$ and organic acids (Sullivan et al. 1989).

4. Deposition Assumptions - Hindcasting pre-industrial surface water chemistry, using a process-based model such as MAGIC, has different requirements than projecting into the future because a single accurate estimate of pre-industrial chemistry is needed. A primary limitation on the reliability of hindcasts is the limited quality of the data available to estimate pre-industrial $\mathrm{SO}_{4}^{2-}$ and base cationdeposition. This uncertainty could have an appreciable effect on the accuracy of the modeled chemistry. 
5. Reaggregation of Subregional Soil Data - Scenario 1 of the MAGIC model simulations (Table 2.11) was conducted as part of the DDRP, which was designed to make regional, rather than subregional, projections. Est imates of soil-chemistry data input to MAGIC for Adirondack 1ake/watershed systems were based on an aggregation of sampled soil classes across the 145 DDRP watersheds in the northeastern United States. Differences between soil chemistry in the Adirondack subregion and the general soil-chemistry patterns observed throughout the region could bias the simulations for the Adirondack subregion.

Potential bias introduced from any or all of the five issues discussed above complicates a direct comparison between Diatom and MAGIC results. He evaluate the influence of each of these factors in turn in the following sections, in an effort to present an unbiased overview of the differences in results obtained by the two approaches. The various MAGIC scenarios and Diatom calibrations used in the comparisons are outlined in Table 2.11. Finally, methods are described for estimating the errors associated with both the Diatom and MAGIC model estimates of lake chemistry. Evaluation of the potential pre-industrial organic acid influence is presented in the Appendix.

\subsubsection{Watershed Disturbance/Land Use}

The disturbance classification( $(v)$ was based on a number of currently observable characteristics of the lakes and watersheds. A lake was designated "disturbed" if there was any indication of recent liming or road-salt application, if the number of shoreline structures exceeded 10 (criterion reduced to three structures for lakes smaller than $8 \mathrm{ha}$ ), or if paved roads were present in the watershed. These evaluations were made on the basis of input data from 7.5 minute topographic maps, DDRP aerial photos, field sampling reports, Adirondack Lake Survey Corporation and New York Department of Environmental Conservation records, and ELS records. Potential road-salt input was evaluated by identifying lakes having high $\left[\mathrm{Cl}^{-}\right]$(> $\left.20 \mu \mathrm{eq} \mathrm{L}^{-1}\right)$, and examining topographic maps for likely road-salt influence. On the basis of the above criteria, a total of three lakes were designated as disturbed and seven lakes as relatively disturbed. This is largely a subjective designation and must be interpreted as a general indication of the lakes in the data set

(a) A. Selle, unpublished data 
TABLE 2.11. Description of Various MAGIC and Diatom Model Scenarios

Scenario

MAGIC Model

$\$ 1$

DDRP

$\# 2$

$\$ 4$
Type of Reconstruction

Reference simulations

Subregional
Description

Assumed pre-industrial deposition of $\mathrm{SO}_{4}^{2-}$ equal to sea-salt component (near zero) and base cations equal to current base-cation deposition. Used soils data aggregation and calibration to northeast region, Baker-Brezonik lake sulfate "uptake" coefficients, and $\mathrm{pCO}_{2}$ averaged over 145 watersheds.

Modified from Scenario 1 using the historical deposition scenario of Husar, Sullivan, and Charles (in press) and its assumption of a pre-industrial $\mathrm{SO}_{4}^{2-}$ value equal to $13 \%$ of current value.

Modified from Scenario 11 by reaggregating the soils data (with correction for coarse fragments) for the Adirondack subregion only (rather than the northeast region) and recalibrating the model, use of original Baker-Brezonik lake sulfate "uptake" coefficients, and $\mathrm{pCO}_{2}$ values specific to Adirondack subregion, assuming preindustrial [ $\mathrm{SO}_{4}^{2-}$ ] equal to $13 \%$ of current (Husar, Sullivan, and Charles in press).

Diatom Model

$\# 1 \quad \mathrm{pH}$

$\# 2$

ANC $_{0}$

$\$ 3$
Calibrated to air-equilibrated $\mathrm{pH}$

Calibrated to titrated $\mathrm{ANC}_{\mathrm{G}}$

Calibrated to defined $\operatorname{ANC}\left(C_{B}-C_{A}\right)$ 
most likely to have experienced anthropogenic disturbances that may have altered their chemistry.

\subsubsection{Lake Chemistry Seasonality}

Differences between summer and fall lakewater chemistry can potentially bias the results of the comparison because the Diatom model was calibrated to sumer chemistry whereas the MAGIC model was calibrated to fall chemistry. This issue was assessed by comparing fall measurements from ELS-1 with the average summer chemistry obtained in the PIRLA-II study for the same lakes. An additional set of comparisons was conducted between summer 1986 and fall 1986 measurements for ELS-II Adirondack lakes. The latter comparison involved 36 lakes, 30 of which were also included in the DDRP statistical sampling.

\subsubsection{ANC Definition}

The $\mathrm{pH}$ of water is extremely useful as an $\mathrm{H}$-ion-intensity parameter. However, $\mathrm{H}^{*}$ is not conserved as precipitation moves through a watershed because it reacts with a multitude of solutes and soil minerals. Thus, the capacity of the system to neutralize added $\mathrm{H}^{*}$ must be calculated in any process-based modeling. In the geochemical literature, the term alkalinity has been extensively used and is generally defined in terms of carbonate alkalinity:

$$
\text { Alkalinity }=\left[\mathrm{CO}_{3}^{2-}\right]+\left[\mathrm{HCO}_{3}^{-}\right]+\left[\mathrm{OH}^{-}\right]-\mathrm{H}^{+} \text {. }
$$

Acid-base titration results have generally been corrected for the acid consumption by other proton acceptors by use of geochemical models, e.g., WATEQ (Truesdel and Jones 1974) and MINTEQ (Felmy, Girvin, and Jenne 1984), However, in the acid-to-circumneutral waters of most interest in acid rain research, carbonate alkalinity is low to nonexistent and the other acidtitratable species and $\mathrm{H}^{*}$ become of primary importance. Acid-neutralizing capacity is the principal variable used to classify the acid-base status of surface waters (Omernik and Powers 1982), those waters with an ANC of $\leq 0$ being commonly defined as acidic. The ANC is used qualitatively to evaluate the susceptibility of surface waters to acidic deposition, whereas the change in ANC, by direct measurement (Smith, Alexander, and Wolman 1987) or inference from lake sediment diatom assemblages (Charles and Smol 1988; Sullivan et al. 
1990), is used to quantify the extent of prior acidification (Altshuller and Linthurst 1984; Schindler 1988). Acid-neutralizing capacity is a major variable used in dynamic, process-based models that simulate the response of ecosystems to changing atmospheric deposition (Christophersen, Seip, and Wright 1982; Goldstein et al. 1984; Reuss and Johnson 1985; Cosby et al. 1985b; Lin and Schnoor 1986).

The ANC, a measure of the titratable bases in solution to a specified $\mathrm{pH}$ endpoint, is measured by quantifying the amount of strong acid that must be added to a solution to neutralize these bases. The endpoint of this strongacid titration is easily identified, except in low-ANC waters where weak acids and relatively small amounts of strong bases obscure the endpoint. Because of the endpoint problem, the Gran procedure (Gran 1952) for determining the endpoint is commonly used to yield more accurate ANC estimates. Granestimated ANC is termed titrated $A_{N C}$ (for Gran analysis of the titration curve).

Alternatively, the ANC can be defined by two distinct methods of calculation without the use of titration data. Using the principles of conservation of charge and conservation of mass, these two techniques have been shown to be mathematically equivalent (Gherini et al. 1985). In one method (Stumn and Morgan 1981). ANC is calculated as the difference between the sum of proton $\left(\mathrm{H}^{+}\right)$acceptors and the sum of the proton donors, taking into consideration the proton reference level (discussed below):

$$
\text { ANC }=\left[\mathrm{HCO}_{3}^{-}\right]+2\left[\mathrm{CO}_{3}^{2-}\right]+\left[\mathrm{OH}^{-}\right]+[\text {other proton acceptors }]-\left[\mathrm{H}^{+}\right]
$$

where brackets denote molar concentrations. The other method relates ANC to the sum of cation concentrations (excluding $H^{+}$), $M_{t i}$, minus the sum of the strong acid anions, $A_{t j}$. Defined ANC is calculated using the relation

$$
A N C=\left[\sum_{i}^{n}\left|z_{i}\right| M_{t i}\right]-\left[\sum_{j}^{m}\left|z_{j}\right| A_{t j}\right]
$$

where $z_{i}$ and $z_{j}$ are the charges on the individual uncomplexed cations and anions at the equivalence point (i.e., the point during titration where the 
concentration of proton donors equals the concentration of proton acceptors) (Church et al. 1984; Gherini et al. 1985; Schofield, Galloway, and Hendry 1985). For aerobic surface-waters the first term on the right-hand side of Equation (2.15) is typically approximated as:

$\left.\sum_{i}^{n}\left|z_{j}\right| M_{t i} \approx 2\left[\mathrm{Ca}_{t}\right]+2\left[M g_{t}\right]+2\left[\mathrm{Mn}_{t}\right]+\left[\mathrm{K}_{t}\right]+\left[\mathrm{Na}_{\mathrm{t}}\right]+\left[\mathrm{NH}_{4}\right]+x[\mathrm{~A}]_{t}\right]$

and the second term is approximated as

$$
\sum_{j}^{m}\left|z_{j}\right| A_{t j} \approx 2\left[\mathrm{SO}_{4}\right]+\left[\mathrm{NO}_{3}\right]+\left[\mathrm{Cl}_{t}\right]+\left[\mathrm{F}_{t}\right]
$$

where $x$, the $\left.[A]_{t}\right]$ coefficient, is the mean charge of all dissolved $A 1$ species. The charges $z_{i}$ and $z_{j}$ (and thus the concentration multipliers in Equations [2.16] and [2.17]) are determined by the predominant charges of the uncomplexed constituents at the equivalence point. However, since very little effort is required to actually calculate the quantities of the various cationanion complexes with a geochemical speciation model (Felmy et at. 1984; Parkhurst et a1. 1980; Mattigod and Sposito 1979), it is generally preferable to do so rather than using an estimated average charge for components such as Al.

Because much of the early research was carried out in a survey mode and by groups with limited analytical support facilities, the minimum number of constituents usually were analyzed. Thus, ANC in many studies is defined:

$$
\begin{aligned}
\text { ANC }= & 2\left[\mathrm{Ca}^{2+}\right]+2\left[\mathrm{Mg}^{2 *}\right]+\left[\mathrm{Na}^{*}\right]+\left[\mathrm{K}^{*}\right]+\left[\mathrm{NH}_{4}^{+}\right] \\
& -2\left[\mathrm{SO}_{4}^{2-}\right]-\left[\mathrm{Cl}^{-}\right]-\left[\mathrm{NO}_{3}^{-}\right] .
\end{aligned}
$$

This definition, the one used in DDRP, omits $\mathrm{Al}, \mathrm{Fe}, \mathrm{Mn}$, and organic acids and yields variable errors in the resulting calculations. Indeed, numerous studies omit $\mathrm{NO}_{3}^{-}$and sometimes $\mathrm{K}^{*}$. Below $\mathrm{pH} 6$, where $\mathrm{CO}_{3}^{2-}$ and $\mathrm{OH}^{-}$make a 
negligible contribution to ANC, the charge-balance equation is sometimes written (Reuss, Christophersen, and Seip 1986)

$$
A N C=\left[\mathrm{HCO}_{3}^{-}\right]-\left[\mathrm{H}^{+}\right]-\left[\mathrm{A} 1_{\mathbf{l}}\right] .
$$

Equations (2.16-2.17) implicitly assume that all dissolved Fe is complexed with dissolved organic carbon (DOC) (e.g., Perdue, Beck, and Reuter 1976), that the contribution of organic acids and organic-Fe complexes to the titrated $A N C_{0}$ is minimal, and that dissolved Mn does contribute significantly to ionic charge.

For strong base cations and acid anions, there is little uncertainty as to the absolute value of the predominant uncomplexed charge at the equivalence point (e.g., $\mathrm{Ca}=2, \mathrm{Na}=1, \mathrm{SO}_{4}=2, \mathrm{Cl}=1$ ). However, because of complexation with $\mathrm{OH}^{-}, \mathrm{F}^{-}$, and organic ligands, the mean charge of $\mathrm{Al}$ [ $\mathrm{X}$ in Equation (2.16)] is not aiways obvious. Designation of the mean Al charge, however, establishes the proton reference level (PRL). Both +3 and 0 have been used as the PRL for Al in calculating the defined ANC (Cosby et al. 1985a; Church et al. 1984; Schofield, Galloway, and Hendry 1985).

Data collected during the Regionalized Integrated Lake-Watershed Acidification Study (RILWAS) (Driscoll and Newton 1985; Goldstein et a1. 1987) from 25 lake-watershed systems in the Adirondack subregion were used by Sullivan et al. (1989) to estimate the mean Al PRL. The speciation of Al was calculated using the chemical equilibrium model ALCHEMI (Schecher and Driscoll 1987). The ALCHEMI output was used to sum the product of the concentration of an individual inorganic ion (e.g., $\mathrm{Al}^{3+}, \mathrm{AlF}_{2}, \mathrm{Al}(\mathrm{OH})^{2 \cdot}, \mathrm{Al}(\mathrm{OH})_{2}^{*}, \mathrm{Al}\left(\mathrm{SO}_{4}\right)^{+}$) times its respective charge (neglecting potential contributions of organic-Al to the titrated $A N C)$. Division of this sum by the $A l_{t}$ concentration gives the mean PRL. This approach yields results that are quantitatively very similar to simply designating a charge of +2 for all Al, for ELS-II lakechemistry data ( $T$. Sullivan, unpublished data). Although the mean charge on Al, decreases with $\mathrm{pH}$, a mean charge of +2 approximates the charge at the equivalence point of acid-sensitive waters (pH 4.8 to 5.2) (Driscoll and Bisogni 1984; Sullivan et al. 1989). 
The acid-neutralizing capacities calculated using Equation (2.18) may overestimate the titratable ANC because of the dissociation of organic acids. Titrating to low $\mathrm{pH}$ (e.g., $\mathrm{pH} 3$ ) reduces the concentration of organic anions that remain unprotonated during the titration and minimizes curvature in the Gran function, thus reducing the DOC effects on $A_{0 N}$ (Sullivan et al. 1989). This is evident in surface-water data for the Meander Lake basin in northern Minnesota. Values of DOC at the out let of Meander Lake average only approximately $400 \mu \mathrm{mol} \mathrm{L}-1$ (1000 mol L-1 of $\left.C=12 \mathrm{mg} \mathrm{L}^{-1} \mathrm{DOC}\right)$, but one of the inlets drains a spruce bog and contains DOC values as high as $2400 \mu \mathrm{mol} \mathrm{L}^{-1}$ (Chen et al. 1988). The discrepancy between the calculated and titratable ANC for this lake can be as large as $50 \mu \mathrm{eq} \mathrm{\textrm {L } ^ { - 1 }}$ at DOC concentrations of $800 \mu$ miol $\mathrm{L}^{-1}$. A single maximum discrepancy of $180 \mu \mathrm{eq} \mathrm{L}^{-1}$ was observed for a sample from the bog inlet with $2400 \mu \mathrm{mol} \mathrm{\textrm {L } ^ { - 1 }}$ of DOC (Figure 2.5). Concentrations of Al in Meander waters are very low (mean $\mathrm{Al}_{\mathrm{a}}=1.3 \mu \mathrm{mol} \mathrm{\textrm {L } ^ { - 1 }}$ ) and do not account for the difference between calculated and titrated $\mathrm{ANC}_{0}$.

The process-based watershed models include mono- and di-protic organic acids in calculated ANC. The MAGIC model (Cosby et al. 1985a) includes the HR" $\mathrm{COO}^{-}$and $\mathrm{R}^{\prime} \mathrm{COO}^{2-}$ species (where $\mathrm{R}^{\prime}, \mathrm{R}^{\prime \prime}$, and $\mathrm{R}^{\prime \prime}$ ' are mono-, di- and triprotic acids). The ILWAS model (Goldstein et al. 1984) includes the two additional organic ligands and four organic-Al complexes. Husar, Sullivan, and Charles (in press) have proposed the inclusion of a single organic term $\left(\mathrm{RCOO}_{\sigma}^{-}\right)$as an acid anion in Equation (2.15) to reflect the influence of organic anions on Gran titration results. The value for organic acids ( $\mathrm{RCO}_{6}^{-}$) required in Equation (2.15) to make the calculated ANC comparable to titration ANC depends, in part, on the extent of DOC-induced curvature in the Gran function and extent to which the DOC is protonated. These two factors are dependent on the strength of the organic-acid functional groups relative to the end point $\mathrm{pH}$ used in the Gran titration. Using data from ELS-II, collected in autumn 1986, Husar, Sullivan, and Charles (in press) estimated that for lakes

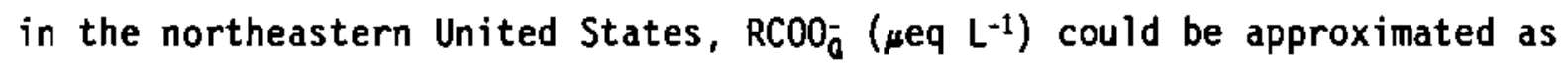
$7.5 \times$ DOC ( $\left.\mathrm{mg} \mathrm{L}^{-1}\right)$ (Figure 2.6). This estimate agrees with that of Eshleman and Hemond (1985), based on one lake in Massachusetts. Data presented by 


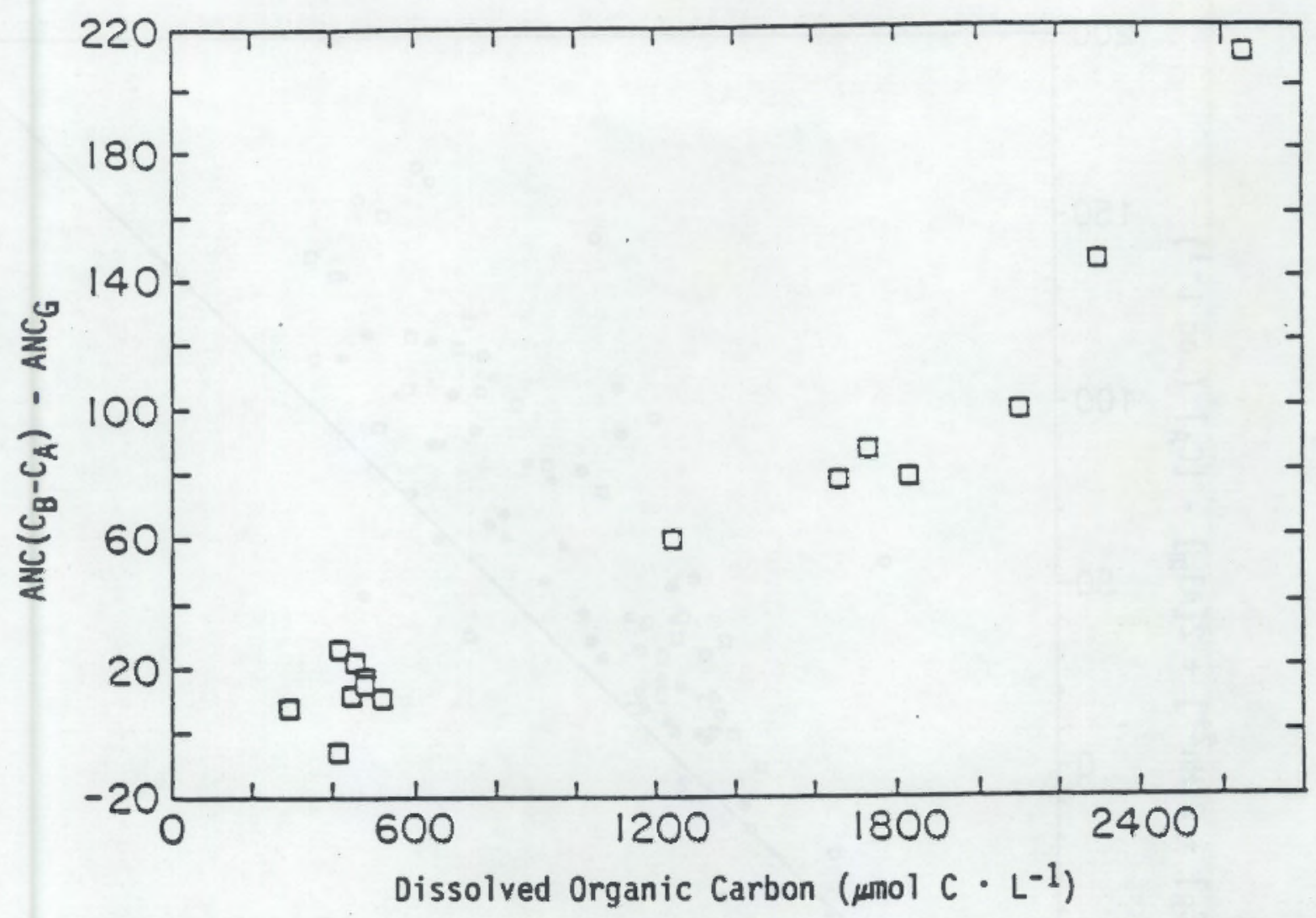

FIGURE 2.5. Difference Between Defined ANC (Equivalence of Base Cations and Mn' ${ }^{2+}$ Minus Equivalence of Mineral-Acid Anions Plus Two Times Al, in $\mu \mathrm{mol} \mathrm{L}^{-1}$ ) and Titration $A N C$ Versus DOC for Waters in the Meander Lake Basin (Source: Sullivan et al. 1989)

Sullivan et al. (1989) for Meander Lake, however, suggest a charge of only $4.0 \mu \mathrm{eq} \mathrm{mg}{ }^{-1}$. Estimation of $\mathrm{RCOO}_{a}^{-}$defined in such a way is ambiguous. Husar, Sullivan, and Charles (in press) noted, however, that interpretation of the exact cause of the discrepancy between titrated ANC and that calculated according to Equation (2.15) (Figure 2.6) is not important if one is interested in quantifying the influence of organic acids on titration $\mathrm{ANC}_{\hat{\theta}}$. Regardless of the relative importance of curvature in the Gran function (Sullivan et al. 1989), whether due to protonation of adjacent functional groups of polyprotic organic acids (01iver, Thurman, and Malcolm 1983; Stevenson 1982) or strength of carboxylic acidity (Eshleman and Hemond 1985), the titrated ANC is somewhat lower than the calculated ANC [Equation (2.15)] because of the presence of organic acids. Whether the data points in Figure 2.6 are shifted to the left (e.g., curvature) or upward (e.g., low pk $)$, 


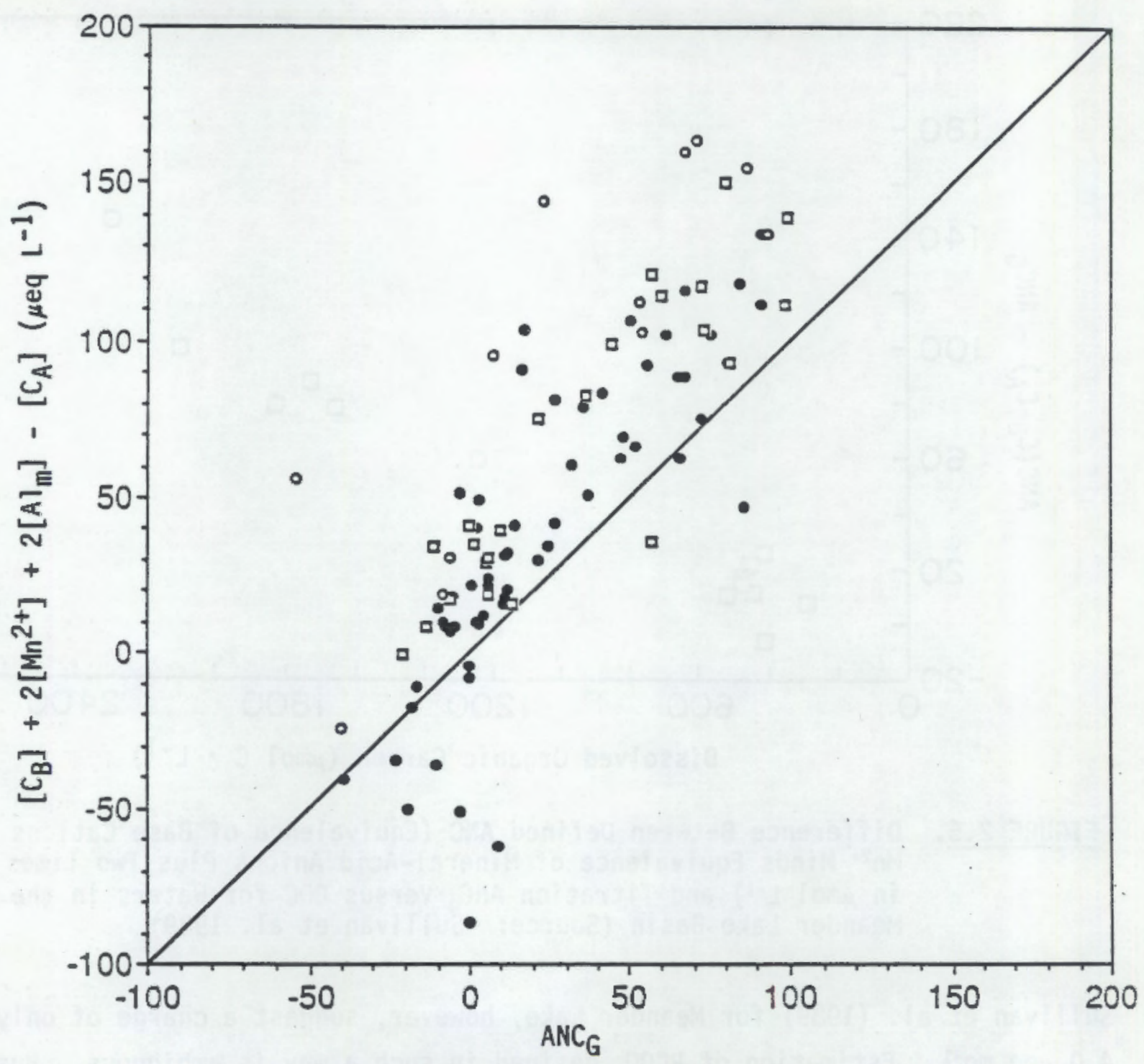

FIGURE 2.6. Acid-Neutralizing Capacity Defined as $\left.\left[\mathrm{C}_{\mathrm{B}}\right]+2\left[\mathrm{Mn}^{2+}\right]+2[\mathrm{~A}]_{\mathrm{B}}\right]-$ $\left[C_{A}\right]$ Versus ANC Determined by Gran Titration. $C_{B}$ is the equivalent sum of base cations $\left(\mathrm{Ca}^{2+}+\mathrm{Mg}^{2+}+\mathrm{Na}^{+}+\mathrm{K}^{+}+\mathrm{NH}^{+}\right), \mathrm{C}_{\mathrm{A}}$ is the equivalent sum of acid anions $\left(\mathrm{SO}_{4}^{2-}+\mathrm{NO}_{3}^{-}+\mathrm{Cl}^{-}+\mathrm{F}^{-}\right)$, ,

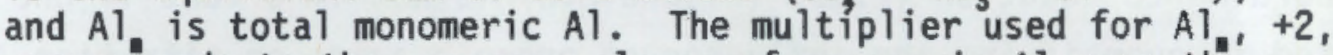
corresponds to the average valence of monomeric Al near the equivalence of Gran titrations for dilute waters ( $\mathrm{pH} 4.8$ to 5.2) (Sullivan et al. 1989). Data are from the Eastern Lake Survey. Phase II, collected in autumn 1986 in the northeastern United States. Data points are coded by dissolved organic carbon: 0 is $>6 \mathrm{mg} \mathrm{L}^{-1}, \square$ is $4-6 \mathrm{mg} \mathrm{L}^{-1},-$ is $\leq 4 \mathrm{mg} / \mathrm{L}$. The vertical distance from each data point to the $1: 1$ line is an estimate of organic acid influence on the Gran titration estimation of ANC as compared with defined ANC (Source: Husar, Sullivan, and Charles, in press). 
the bias is largely attributable to the presence of organic acids and can be approximated as a function of $\mathrm{DOC}$. Charge for $\mathrm{RCOO}_{G}^{-}$in the range of 4 to $7.5 \mu \mathrm{eq} \mathrm{mg}^{-1}$ appears reasonable for estimating the influence of organic-acid anions on titration $\mathrm{ANC}_{0}$. The total concentration of organic acid anions $\left(\mathrm{RCOO}_{\bar{t}}^{-}\right)$as a function of $\mathrm{DOC}$ is generally higher and has been estimated to be approximately $10 \mu \mathrm{eq} \mathrm{mg}^{-1}$ (0liver, Thurman and Malcolm 1983).

The discrepancy between calculated and titrated ANC caused by organicacid influence and/or differences in defining the proton reference level for AT has significant implications for the NAPAP assessment activities. Titration $\mathrm{ANC}_{0}$ is used primarily for classifying, evaluating current status, monitoring temporal trends, and calibrating paleolimnological transfer functions. Defined ANC (defined in different ways) is used for dynamic-model predictions (see, e.g., Reuss, Christophersen, and Seip 1986) and for interpreting trends in some instances (e.g., Wright, Lotse, and Semb 1988). Unfortunately, the differences between the various definitions of ANC are seldom considered. These differences can drastically affect interpretations of chemical change. For example, Wright, Lotse, and Semb (1988) presented results for 1983-1987 at the Risdalsheia site of the RAIN Project in southernmost Norway, where acidic deposition has been excluded by placing a roof over the minicatchment and applying neutralized rainwater below. Wright, Lotse, and Semb (1988) concluded that $40 \%$ of the observed reduction in $\left[\mathrm{SO}_{4}^{2-}+\mathrm{NO}_{3}\right]$ in runoff had resulted in an increase in defined ANC as calculated from the difference of summed base cations and summed acid anions $\left(C_{B}-C_{A}\right)$. This ANC definition treats $A 1^{n+}$ as an acidic cation, similar to $\mathrm{H}^{*}$, whereas the Gran titration treats $\mathrm{A}]^{\mathrm{n} *}$ as a base cation, similar to $\mathrm{Ca}^{2+}$. However, if an alternative definition of ANC, such as carbonate alkalinity minus $\mathrm{H}^{+}\left(\mathrm{HCO}_{3}^{-}-\mathrm{H}^{*}\right)$, were used, it would be concluded that only $9 \%$ of the change in $\left[\mathrm{SO}_{4}^{2-}+\mathrm{NO}_{3}^{-}\right]$ resulted in an increase in ANC. An additional $5 \%$ of the change in $\left[\mathrm{SO}_{4}^{2-}+\right.$ $\mathrm{NO}_{3}^{-}$] was attributable to a decrease in Al. An appreciable proportion of the surface-water response was attributable to deprotonation of organic acids, which are present in very high concentrations at this site. It is apparent that interpretation of acidification and recovery depends on the specific ANC definition used. Any comparison of current and pre-industrial defined $\operatorname{ANC}\left(C_{B}-C_{A}\right)$ will incorporate any change in $\mathrm{RCOO}^{\prime}$ as a change in alkalinity, in 
addition to strong base cations and anions, because RCOO- is not explicitly included in the $\left(C_{B}-C_{A}\right)$ term.

It should be noted that $\mathrm{Al}_{\mathrm{g}}$ is low (e.g., $<2 \mu \mathrm{mol} \mathrm{L^{-1 } )}$ in most of the ELS-I lakes. But both $\mathrm{Al}$ and DOC become increasingly important at lower-pH and ANC values. For the lakes and streams of greatest interest, the acidic and near-acidic systems, the influence of $A 1$ and/or DOC on Gran titration results is often as much as 20 peq $\mathrm{L}^{-1}$ or more.

Estimation of surface-water ANC from charge balance (e.g., $C_{g}-C_{A}$ ) and the influence of organic acids on $A N C_{0}$ is potentially compromised by inclusion of the measurement errors associated with determination of a large number of chemical concentrations. D. J. Blick (EPA/CERL unpublished data) evaluated the uncertainty associated with charge-balance estimation of organic-anion concentration, using measurements of 19 variables. Precision was evaiuated using data from 41 replicate analyses of the ELS-I natural audit sample from Big Moose Lake in the Adirondack subregion. The mean and standard deviation of 41 estimates of the anion deficit (sum of cations minus sum of anions) were 22 and $15 \mu \mathrm{eq} \mathrm{L-1}$, respectively. The standard deviation for replicate $\left(C_{B}-C_{A}\right)$ calculations was identical to that for the anion deficit and was not excessively large in comparison with standard deviations of several of the individual ions, e.g., 11, 9, and $9 \mu \mathrm{eq} \mathrm{L}^{-1}$ for $\mathrm{SO}_{4}^{2-}, \mathrm{Cl}^{-}$, and $\mathrm{Ca}^{2+}$, respectively.

\subsubsection{Deposition}

Total atmospheric deposition in the DDRP (Scenario 1) was estimated as a "typical year" representation for process-based model analyses. The watershed models required a time resolution that corresponded to realistic precipitation/hydrologic events for the calibration of the hydrologic subroutines. The typical year employed daily precipitation and monthly chemicalconcentration data. Daily precipitation during a month was adjusted to match the 30-year normal precipitation for the given month. Each daily value was multiplied by the ratio of the 30-year normal for the month and the monthly total for the typical year. Precipitation volume for each lake was estimated by using daily precipitation from adjacent National Climate Data Center (NCOC) stations (tape TD9641: monthly normais of temperature, precipitation, and heating-and-cooling degree days 1951:1980). Precipitation zones were defined 
for a specific subregion, and all sample lakes within a given precipitation zone were assigned a synthesized annual record of daily precipitation. Within the Adirondack region, nine precipitation zones were delineated.

Precipitation chemistry data were obtained from the Acid Deposition System database at Pacific Northwest Laboratory. This data base comprises data from all of the major wet-deposition monitoring networks in the United States, including the National Trends Network (NADP/NTN). The typical year was defined as the year between 1951 and 1980 that compared best with [SO2-], $\left[\mathrm{NO}_{3}^{-}\right]$, and precipitation volume, as determined from a comparison of cumulative distribution functions for each individual year versus the summary cumulative distribution functions for each of the above three parameters. The wetdeposition chemistry was also associated with an individual lake/watershed through delineation of "concentration zones," but the sparse density of wetdeposition chemistry sites in the Adirondack region only permitted characterization of two such zones. Wet deposition is simply the product of the precipitation volume and the precipitation chemistry within the respective zones.

Estimates of dry deposition to individual watersheds were made on an ionby-ion basis. Preliminary dry-sulfur deposition estimates for the DORP were provided by output from the RADM model. These estimates were based on simulations of six 3-day episodes averaged across a region. Spatial adjustments to the output were made from a sparse dry-deposition network (Hicks, Hosker, and Womack 1986; Hosker and Womack 1986). This "spatially adjusted" output was then used to estimate, using kriging, sulfur deposition to individual DDRP sites. Upon examination, the adjusted RADM output was judged to underestimate annual dry deposition of sulfur at DDRP sites in the Northeast by about $20 \%$. This judgment was based on an analysis of sulfur input/output budgets for sites in the Mortheast and the belief that watersheds in this region are generally at steady-state with respect to sulfur (Galloway, Norton, and Church 1983; Rochelle, Church, and David 1987; Rochelle and Church 1987). Consequently, RADM estimates of annual dry-sulfur deposition to the DORP sites in the Northeast were increased by $20 \%$. This annual dry deposition sulfur estimate was then apportioned on a monthly basis. Information on vegetation types in each watershed was used to compute a seasonally variable leaf-area index, 
based in part on data reported by Goldstein and Gherini (1984). An iterative correction was applied to the monthly deposition to ensure that this sum agreed with the annual total.

The pre-industrial background sulfate deposition in DDRP (Scenario 1 ) was assumed to be sea-salt-derived and was estimated from 1984 [ $\left.\mathrm{Cl}^{-}\right]$using the $\left[\mathrm{SO}_{4}^{2-}\right]$ to $\left[\mathrm{Cl}^{-}\right]$ratio in seawater. This assumes that sea salt was the only important source of $\mathrm{SO}_{4}^{2-}$ for Adirondack lakes. This resulted in near-zero pre-industrial [ $\left.\mathrm{SO}_{4}^{2-}\right]$ values, with only three exceptions.

Dry deposition of base cations $\left(\mathrm{Ca}^{2+}, \mathrm{Mg}^{2+}, \mathrm{Na}^{+}, \mathrm{K}^{+}\right)$and $\mathrm{Cl}^{-}$at inland sites (e.g., Adirondack region) was estimated by assuming deposition velocities of $0.8 \mathrm{~cm} \mathrm{sec}^{-1}$ for fine-particulate deposition $(<2 \mu \mathrm{m})$. Annual values were partitioned into monthly fluxes. Coarse-particle dry deposition (>2 mm) for these ions was estimated by coarse-to-fine ratios of 1.5 for $\mathrm{Ca} ; 1.0$ for $\mathrm{Mg}, \mathrm{Na}$, and $\mathrm{K}_{i}$ and 0.2 for $\mathrm{Cl}$.

Dry depositions of $\mathrm{NO}_{3}^{-}$and $\mathrm{NH}_{4}^{+}$were estimated to be equal to 0.5 of wet deposition. (Note that there is an inconsistency in $\left[\mathrm{NO}_{3}^{-}\right]$between the text and tables in the DDRP report of Church et al. 1989). Dry deposition of $\mathrm{H}^{+}$ was computed as the charge difference between the sum of dry anions and dry cations, and $\mathrm{H}^{*}$ was set to zero in cases where cations exceeded anions. The resulting ratios of dry deposition to wet deposition used for the typicalyear-deposition data set (Church et al. 1989) are summarized in Table 2.12.

\section{Alternative Pre-industrial Sulfate Deposition}

Considerable uncertainties surround the estimates of pre-industrial deposition of $\mathrm{SO}_{4}^{2-}$ and base cations required as input for MAGIC. The potential importance of uncertainties in pre-industrial $\mathrm{SO}_{4}^{2-}$ deposition levels were assessed by comparison of Scenarios $\$ 1$ and $\$ 2$ (Table 2.11). Sullivan et al. (1988) concluded that, at distances greater than about 50 to $60 \mathrm{~km}$ from the coast, marine contributions of chloride were negligible. Therefore, marine contributions of $\mathrm{SO}_{4}^{2-}$ to lakes in the Adirondacks approach zero. For Scenario 2 in the present study, we assumed that some sulfur is derived from background contributions of entrained soil particles. Sulfate deposition in 
TABLE 2.12. Ratios of Dry Deposition to Wet Deposition for DDRP Watersheds for the Typical Year Deposition Data Set

\begin{tabular}{|c|c|c|c|}
\hline NE & Median & Mean & $\begin{array}{l}\text { Standard } \\
\text { Deviation }\end{array}$ \\
\hline $\mathrm{SO}_{4}^{2-}$ & 0.44 & 0.48 & 0.12 \\
\hline $\mathrm{Ca}^{2+}$ & 1.13 & 1.12 & 0.42 \\
\hline $\mathrm{Mg}^{2+}$ & 1.92 & 1.82 & 0.72 \\
\hline $\mathrm{Na}^{+}$ & 1.29 & 1.29 & 0.61 \\
\hline$K^{\bullet}$ & 1.56 & 1.66 & 0.71 \\
\hline $\mathrm{Cl}^{-}$ & 0.38 & 0.33 & 0.12 \\
\hline $\mathrm{NO}_{3}^{-}$ & $1.0^{(2)}$ & $1.0^{(0)}$ & -- \\
\hline $\mathrm{NH}_{4}^{*}$ & $0.5^{(b)}$ & $0.5^{(b)}$ & -- \\
\hline $\mathrm{H}^{*}$ & 0.47 & 0.46 & 0.23 \\
\hline
\end{tabular}

(a) Nitrate set to 1.0 .

(b) Ammonium set to 0.5 .

1844, using the deposition scenario of Husar, Sullivan, and Charles (in press), was about $13 \%$ of 1984 levels. The deposition scenarios used are shown in Figure 2.7.

\section{Alternative Base-Cation Deposition}

The simulations conducted in Scenario $\$ 2$ assumed that base-cation deposition had not changed from pre-industrial times to the present. Data for the Hubbard Brook Experimental Forest suggested, however, that base-cation deposition there has fallen, coincident with decreased $\mathrm{SO}_{4}^{2-}$ deposition during the past 25 years (Driscoll et al. 1989). The degree to which the changes in $\mathrm{SO}_{4}^{2-}$ and base cation deposition at Hubbard Brook may have been coupled is unclear. To assess the sensitivity of MAGIC output to potential historical changes in base-cation deposition, a sensitivity analysis is needed that involves readjusting pre-industrial base-cation deposition to lower levels and increasing simulated base-cation deposition along the estimated historical $\mathrm{SO}_{4}^{2-}$ trajectory provided by Husar, Sullivan, and Charles (in press). 


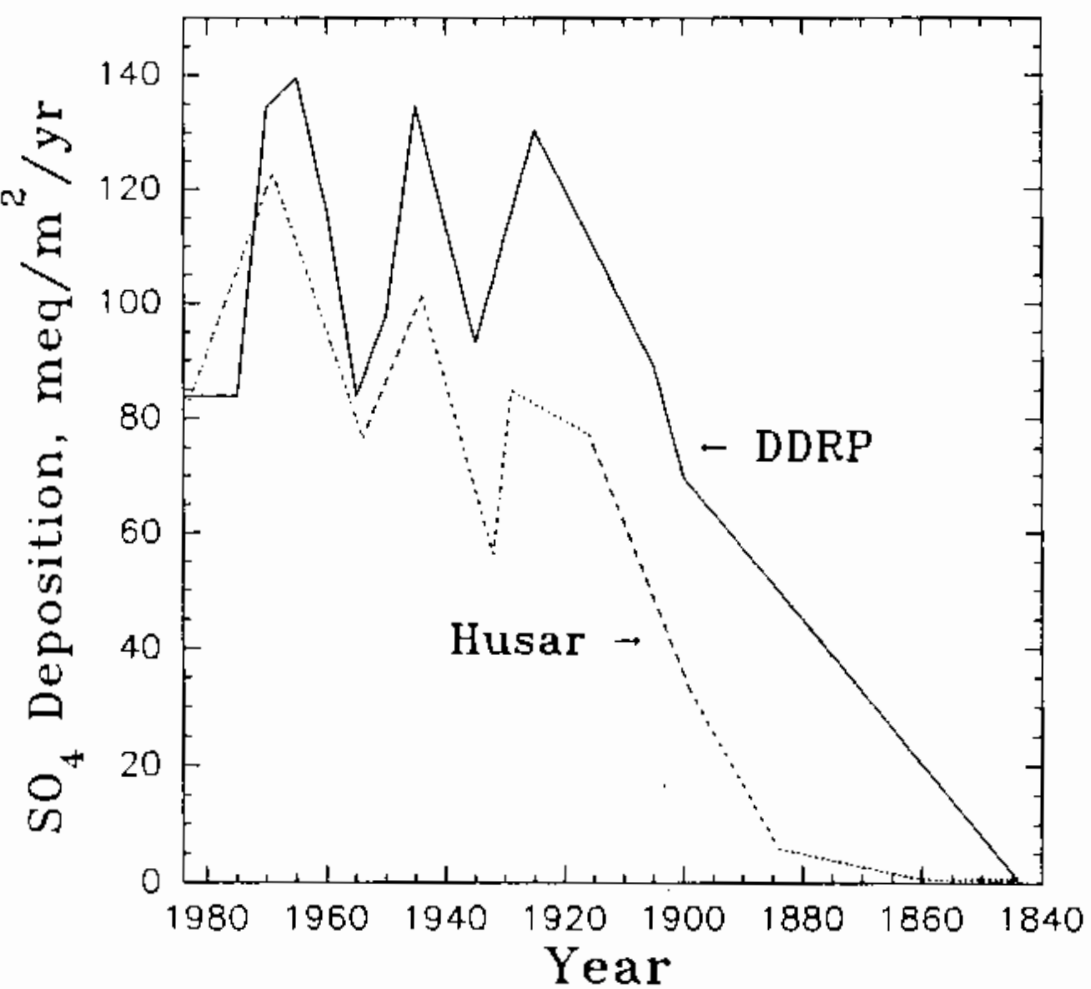

FIGURE 2.7. Depiction of Relative Sulfate Deposition Used in DDRP (MAGIC Scenario 11) Versus that of Husar, Sullivan and Charles (in press) Scenarios 12 and 4

\subsubsection{Reaggregation of Subregional Soils Data}

The DORP soil aggregation characterized watershed soils based on attributes of sampling classes estimated from pedons collected across the entire Northeast. In January, 1990, however, ORNL reaggregated the DDRP soils data, based only on data collected from the Adirondack region. The purpose of this reaggregation was to characterize Adirondack watershed soil attributes using only soil data actually collected from pedons in the Adirondacks. The concern was that the Adirondack soils might differ in their chemical properties from similar soils in other areas of the Northeast, and that MAGIC projections for Adirondack watersheds might be in error (i.e., biased) because they were based on soil attributes that actually reflected conditions elsewhere than the Adirondacks. This reaggregation also included a correction for the coarsefragment content (e.g., rocks) of the various horizons in which the range and mean fragment content of Layer 1 (A+B horizon) were 10.1-24.2\% and 18.3\%, 
respectiveiy, and of Layer 2 ( $C$ horizon) were 19.9-40.5\% and 24.05\%, respectively (C. C. Brandt, written communication, January 18, 1990).

Table 2.13 lists the soil sampling classes mapped in the Adirondacks together with the number of pedons sampled in this subregion and in the entire Northeast. The regional (DDRP) estimates of watershed soil chemistry are based on all Northeast pedons belonging to the sampling classes listed in Table 2.13. The subregional (reaggregated) watershed soil chemistry estimates are based on only the pedons sampled in the Adirondacks.

In the following discussion of the lateral and vertical aggregation method let $k$ denote the subhorizon, $j$ the pedon, $i$ the sampling class, and $h$ the watershed. The method used to create the two sampling class data sets was:

1. Subset the subhorizon chemistry by retaining only those observations with acceptable confidence levels from the mineral horizons of the routine pedons (i.e., discard extreme data).

2. Weight each subhorizon chemistry observation $\left(x_{i j k}\right)$ by its mass per unit area $\left(m_{i j k}\right)$ to obtain a mass-weighted average for each pedon $\left(x_{i j}\right)$ in a sampling class:

$$
x_{i j}=\left|\Sigma_{k} m_{i j k} x_{i j k}\right| /\left|\Sigma_{k} m_{i j k}\right| .
$$

The mass of subhorizon $k$ is given by

$$
m_{i j k}=\text { SOILDEN } \times(\text { THKM } \times[1-\text { FRAG/100]) }
$$

where SOILDEN is the bulk density of the soil, THKM is the measured thickness of the subhorizon, and FRAG is the percent of coarse fragments in the soil. The term (THKM $\times[1-F R A G / 100]$ ) is the soil thickness adjusted for rock fragments. 
IABLE 2.13. Number of Sampled Pedons for Adirondack Sampling Classes

\section{Sampling Class}

E02

E05

E06(1)

H01

H02

H03

101

102

105

106

109

I10(b)

I25

137

I38

I46(b)

SO1

S02

SO5(b)

S09

S10

S11

S12

$\$ 13^{(b)}$

S14

S15
Number of Sampled Pedons

Adirondack Northeast

4

4

1

6

1

4

6

0

0

1

0

0

0

0

0

1

6

4

3

4

1

3

4

1

4

0
8

7

6

8

8

6

10

5

8

8

8

8

9

8

6

7

11

8

3

8

7

8

8

6

8

6

(a) Sampling class was sampled but not mapped in the Adirondack region.

(b) Contaminated pedons not included. 
3. Weight the pedon values $\left(x_{i j}\right)$ by their mass per unit area $\left(m_{i j}\right)$ to obtain a sampling class weighted average $\left(x_{i}.\right)$ :

$$
x_{i . .}=\left|\Sigma_{j} m_{i j .} x_{i j .}\right| /\left|\Sigma_{j} m_{i j .}\right|
$$

where the mass of pedon $j$ is given by

$$
m_{i j .}=\Sigma_{k} m_{i j k} \text {. }
$$

For bulk density, the adjusted horizon thickness (THKM $x[1-F R A G / 100]$ ) was used instead of the subhorizon mass as the weight in calculating the pedon values. Estimates of measured and adjusted thickness were calculated in the same way as the mass estimate.

The watershed estimates $\left(w_{h}\right)$ based on the Northeast pedons are a weighted average of the sampling classes occurring on a watershed:

$$
w_{h}=\left|\Sigma_{i} a_{h i} x_{i} . .\right| /\left|\Sigma_{i} a_{h i}\right| .
$$

where $x_{i . .}$ denotes the sampling class estimate and $a_{h i}$ is the areal fraction of the sampling class on the watershed. A slightly different weight was used in aggregating the Adirondack sampling class estimates to watersheds. The watershed estimates $\left(w_{h}\right)$ are calculated by:

$$
w_{h}=\left|\Sigma_{i} a_{h i} m_{i . .} x_{i . .}\right| /\left|\Sigma_{i} a_{h i} m_{i . .}\right|
$$

where $x_{i . .}$ denotes the sampling class estimate, $m_{i .}$ is the unit mass of the sampling class, and $a_{h i}$ is the areal fraction of the sampling class on the watershed. In this aggregation, the volume of the soil $\left(a_{h i} m_{i . .}\right)$ is used as the weight. The average pedon mass of sampling class $i$ is given by: 


$$
m_{i \ldots}=\left[\sum_{j} m_{i j .}\right] / n_{i} .
$$

where $n_{i}$, is the number of pedons in the $i$ th sampling class. Estimates of measured and adjusted thickness were calculated in the same way as the mass estimate.

The MAGIC model was recalibrated for the Adirondack lakes using these re-aggregated soils data. The calibration procedure was identical to that described in Section 2.3.2, except that the new subregional values of Adirondack soils were used. In addition to the modified soils data, the recalibration included new calculations of $\mathrm{PCO}_{2}$ in lake water and apparent Al-hydroxide solubility products for lakes. These new calculations were performed as described in Section 2.3.2, except that the lakes were restricted to the Adirondack region.

\subsection{SUMMARY OF POSSIBLE COMPARISONS BETWEEN PALEOLIMNOLOGY ANO MAGIC}

As discussed in the previous sections of this report, a number of factors could potentially bias the comparison between paleolimnological and MAGICmodel hindcast results for the Adirondack lakes. To evaluate and correct potential bias, three separate sets of MAGIC simulations were conducted, as outlined in Table 2.11, and in addition, the diatom assemblages were calibrated to two different $A N C$ definitions (titrated $A N C_{G}$ and $A N C\left(C_{B}-C_{A}\right)$ ). The Scenario 2 MAGIC simulations were unchanged from the DORP program, with the exception that pre-industrial $\mathrm{SO}_{4}^{2-}$ deposition was estimated as suggested by Husar, Sullivan, and Charles (in press) ( $13 \%$ of 1984 deposition), rather than assuming sea-salt deposition as the principal source of $\mathrm{SO}_{4}^{2-}$ (nearly zero), as was done in DDRP (Church et al. 1989). Output from Scenario 1 (Table 2.11), in comparison with Scenario $\$ 2$, evaluates the sensitivity of MAGIC output to assumptions regarding pre-industrial $\mathrm{SO}_{4}^{2-}$. Scenario $\$ 4$ represents the most appropriate currently available scenario comparison with the Diatom model. In this scenario, both models use a comparable ANC definition (i.e., $C_{B}-C_{A}$ ) and both are calibrated to the Adirondack subregion only; the MAGIC model used the Husar et al. (in press) estimate of preindustrial $\mathrm{SO}_{4}^{2-}$ deposition and a revised estimate of $\mathrm{pCO}_{2}$. Scenario 44 , 
presented in the Appendix, provides an approximation of the potential influence of organic acids on the MAGIC estimates of pre-industrial acid-base chemistry. 


\subsection{RESULTS AND DISCUSSION}

\subsection{BASIC COMPARISON}

Comparisons between the Diatom model and MAGIC model (Scenario \#2) results are presented in Figures 3.1 to 3.3. Figure 3.1a shows the MAGIC current-day estimated defined $A N C\left(C_{B}-C_{A}\right)$ plotted against the Diatom estimates of $\mathrm{ANC}_{\mathrm{G}}$. There is general agreement between the models for the low-ANC lakes, but for lakes having ANC greater than about $25 \mu \mathrm{eq} \mathrm{L^{-1 }}$, either MAGIC is biased to higher estimates of ANC or the Diatom model is biased to lower ANC values. MAGIC also yielded slightly higher estimates of current pH (Figure 3.1b).

Agreement between the models was considerably poorer for estimates of pre-industrial (pre-1850) chemistry (Figure 3.2). The MAGIC model gave higher estimates for both ANC and $\mathrm{pH}$ during the pre-industrial period. The minimum estimated ANC and $\mathrm{pH}$, using MAGIC, were approximately $30 \mu \mathrm{eq} \mathrm{\textrm {L } ^ { - 1 }}$ of ANC and pH 6.4. In contrast, the Diatom model estimated that some lakes had been slightly acidic (ANC $\leq 0$ ) and that the minimum $\mathrm{pH}$ was about 5.2.

Estimates of change in ANC and $\mathrm{pH}$ from pre-industrial time to the present are contrasted in Figure 3.3. The MAGIC model estimated that all lakes had acidified (decreased in both ANC and $\mathrm{pH}$ ) since pre-1850, whereas the Diatom model estimated that some lakes increased in ANC and $\mathrm{pH}$, while others decreased. The magnitude of estimated acidification was generally greater for the MAGIC than the Diatom model.

\subsection{ERROR ESTIMATES}

The uncertainty estimates calculated for the Diatom and the MAGIC simulations are not directly comparable, and only approximate the errors associated with the comparison between the Diatom and MAGIC models. It is not possible to quantify the errors associated with the underlying assumptions of the MAGIC and Diatom models, or the assumptions regarding pre-industrial deposition (which must be estimated in order to hindcast with MAGIC). Note that prediction errors cannot be calculated for the pre-industrial chemistry because we do not know what the "true" measured values were. Therefore, the average 

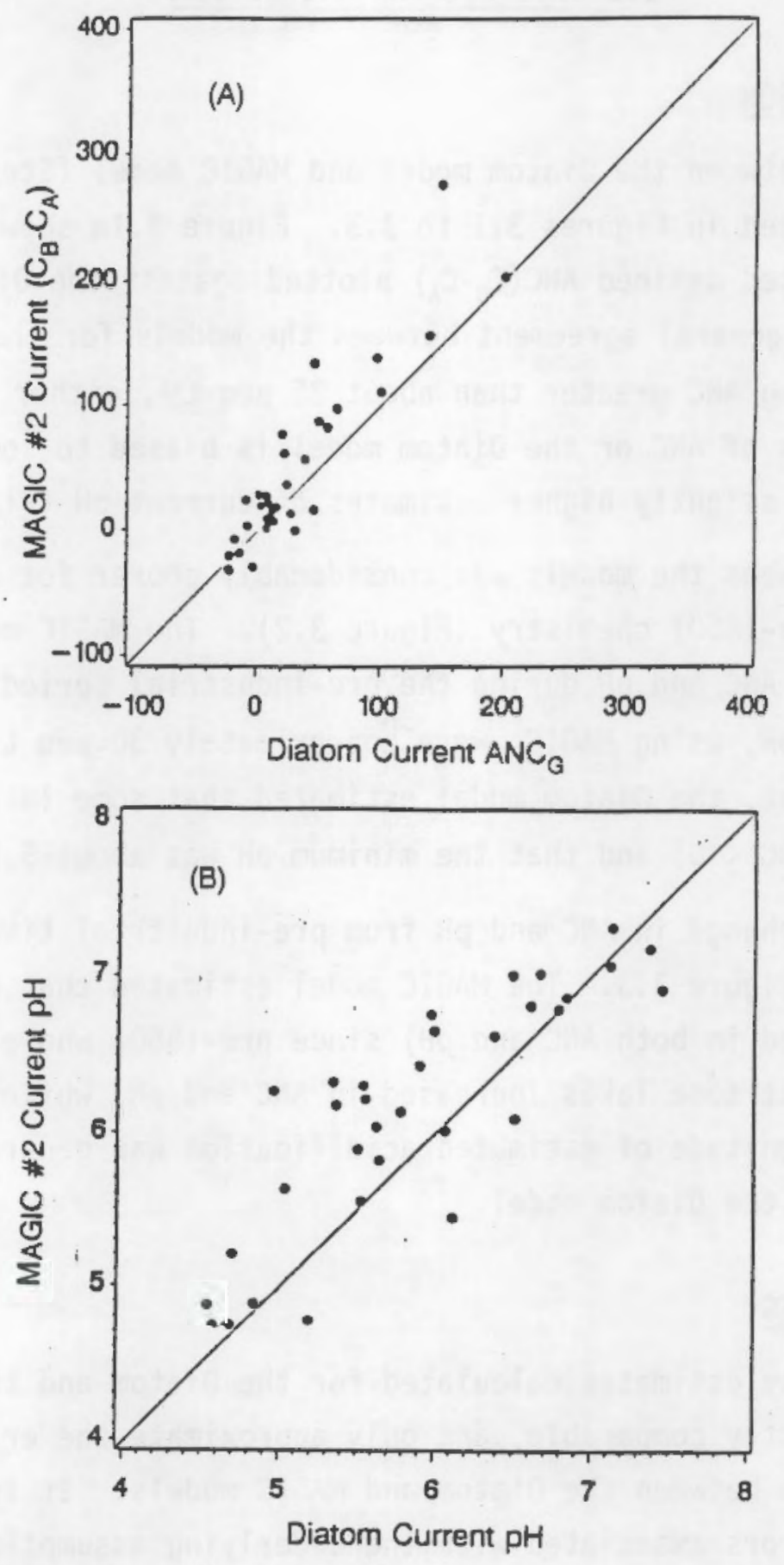

FIGURE 3.1. Comparison Plots of (A) Current ANC Estimates Between the MAGIC Scenario \#2 Simulations of Current $A N C\left(C_{B}-C_{A}\right)$ and the Diatom Inferences of Current $A N C_{G}$ and (B) MAGIC Reference Simulations of Current pH and Diatom-inferred Current pH (Based on Tops of Cores) 

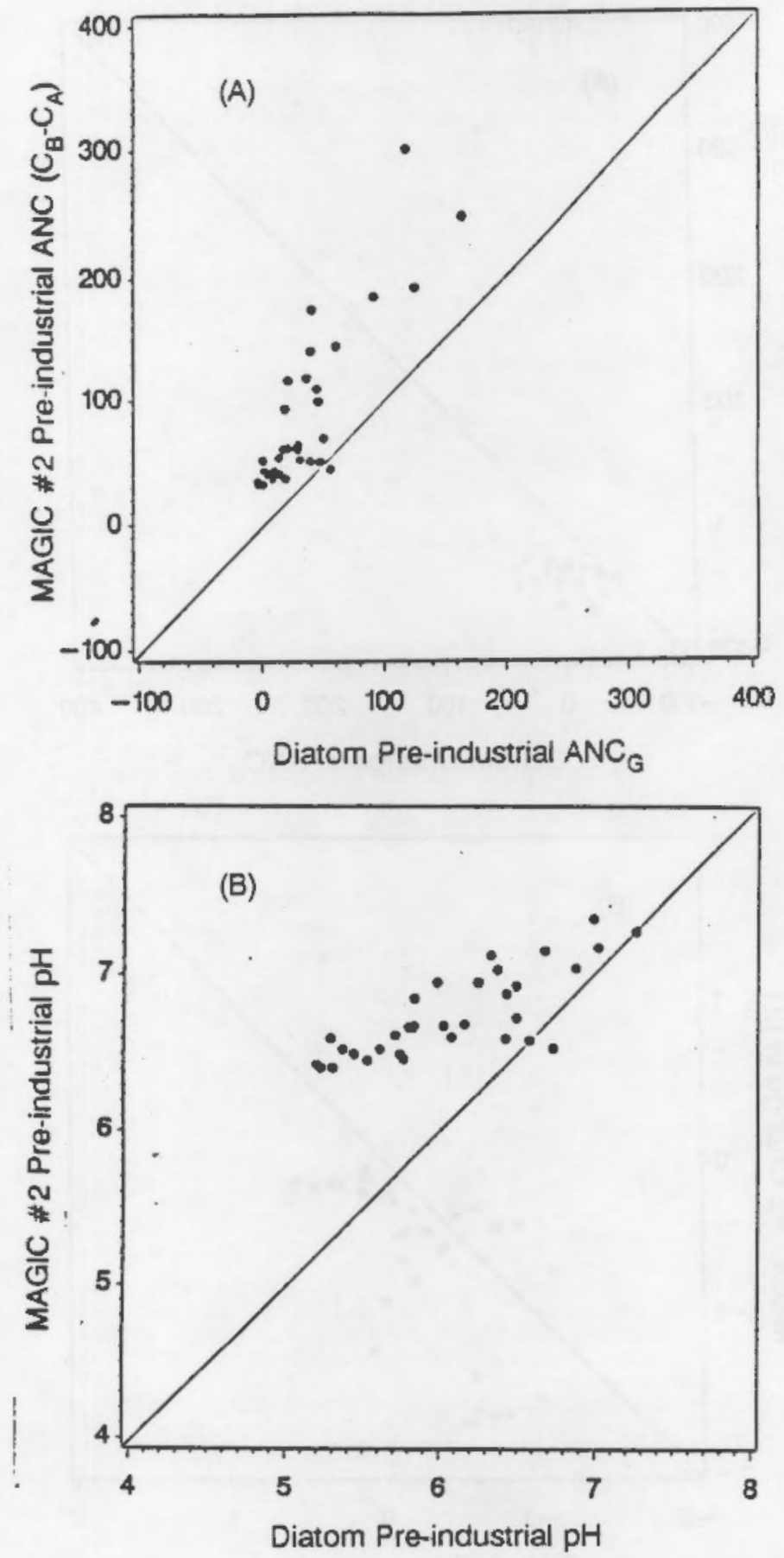

FIGURE 3.2. Comparison Plots of (A) Pre-industrial ANC Estimates from MAGIC Scenario \#2 Simulations and Diatom-inferred Pre-industrial ANC (Based on Bottom Cores) and (B) Pre-industrial pH Estimates from MAGIC Reference Simulations and Diatom-inferred pH (Based on Bottom Cores) 

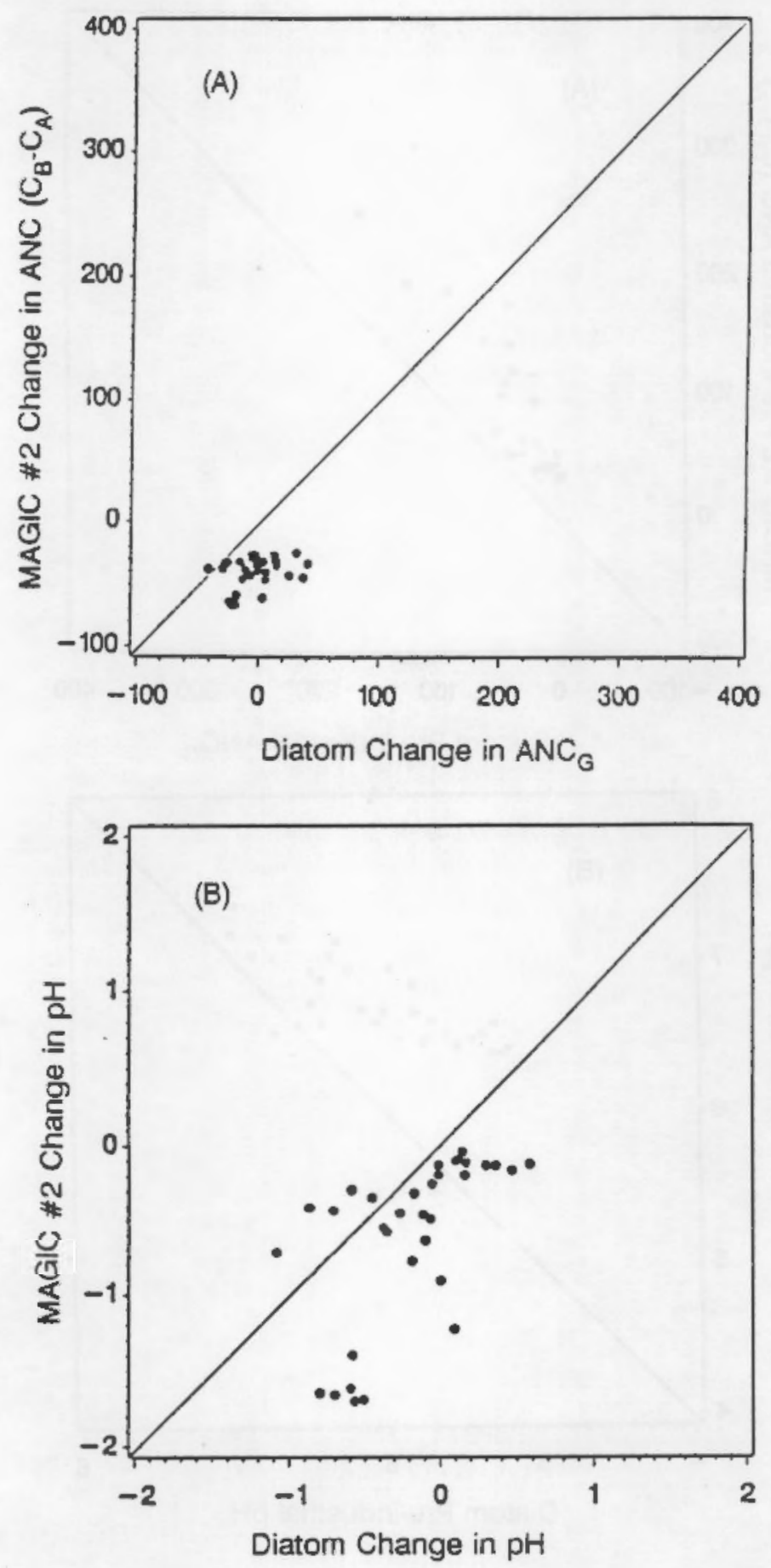

FIGURE 3.3. Estimates of Change in (A) ANC and (B) pH Using the MAGIC Model Scenario \#2 Simulations versus Diatom Inferences of Change 
Diatom prediction errors for the current chemistry estimates were also applied to the historical-chemistry estimates. The Diatom model error estimates are presented as $90 \%$ confidence intervals, which include the variability component of multiple bootstrap calibrations $\left(s_{2}\right)$ and the average prediction error (bias) for the inferences of current chemistry $\left(s_{i 1}\right)$ (Figure 2.4).

MAGIC error estimates were derived from the "fuzzy" calibration procedure, as described in Section 2.3.3. They represent the width of the interval containing equally viable simulated variable values from up to $10 \mathrm{calibra-}$ tions. The error bars thus reflect an uncertainty associated with the calibration procedure (Figure 3.5 ).

\subsection{COMPLICATING FACTORS}

\subsubsection{Watershed Disturbance/Land Use}

A rigorous evaluation of the impact of watershed disturbance and landuse activities on estimates of acidification of Adirondack lakes was not part of our analyses. It is clear that disturbance and land use changes can have significant effects on surface water acid-base chemistry (see, e.g., review of Sullivan, in press), and may have played a role in recent changes in the chemistry of Adirondack lakes. However, the lakes investigated here were assigned by $A$. Selle (unpublished data) to one of three current "disturbance" categories based on road networks, shoreline structures, lakewater [ $\left.\mathrm{Cl}^{-}\right]$, and liming records. As shown in Figure 3.6a, lakes with alkalinity values $>100 \mu \mathrm{eq} \mathrm{L^{-1 }}$ were generally rated as being disturbed. There is no evidence, however, that disturbance exerted a significant influence on the results of the comparison because undisturbed lakes did not generally exhibit better agreement between methods than did disturbed lakes (Figure $3.6 \mathrm{~b}$ ).

\subsubsection{Lake Chemistry Seasonality}

The MAGIC model was calibrated to fall index lakewater chemistry using closed-system pH values, whereas the Diatom model was calibrated to an average of lakewater chemistry derived primarily from multiple summer samples using air-equilibrated $\mathrm{pH}$ values. It was therefore important to evaluate any potential bias introduced into the comparison from seasonal differences in 


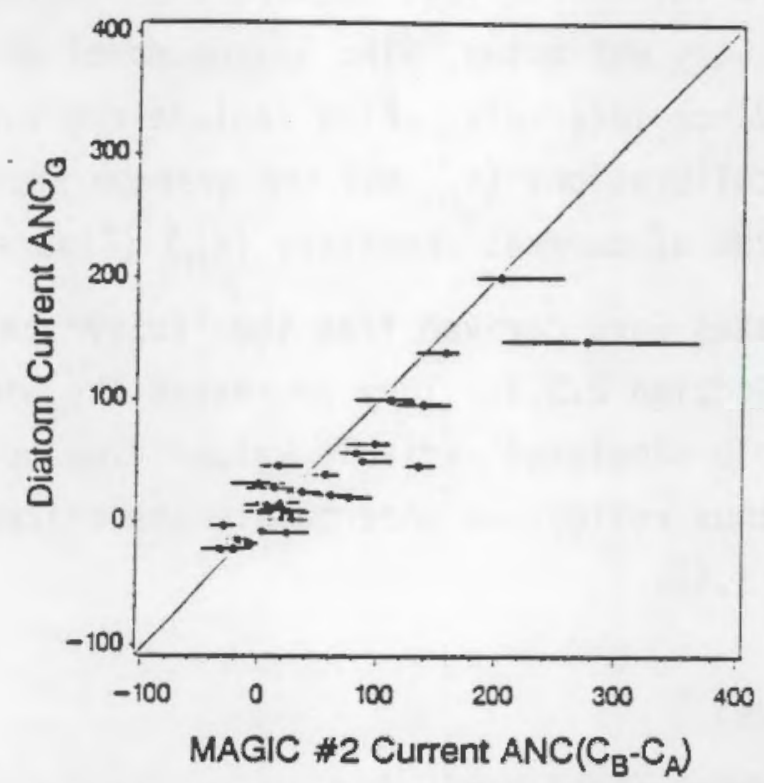

FIGURE 3.4. Plot of Diatom-inferred Current ANC Versus MAGIC Scenario \#2 Simulation Estimate of Current $\operatorname{ANC}\left(C_{B}-C_{A}\right)$, with Error Estimates P1 aced on MAGIC Estimates. The error estimates represent a confidence width, derived as the maximum and minimum of up to 10 separate calibrations for each lake.

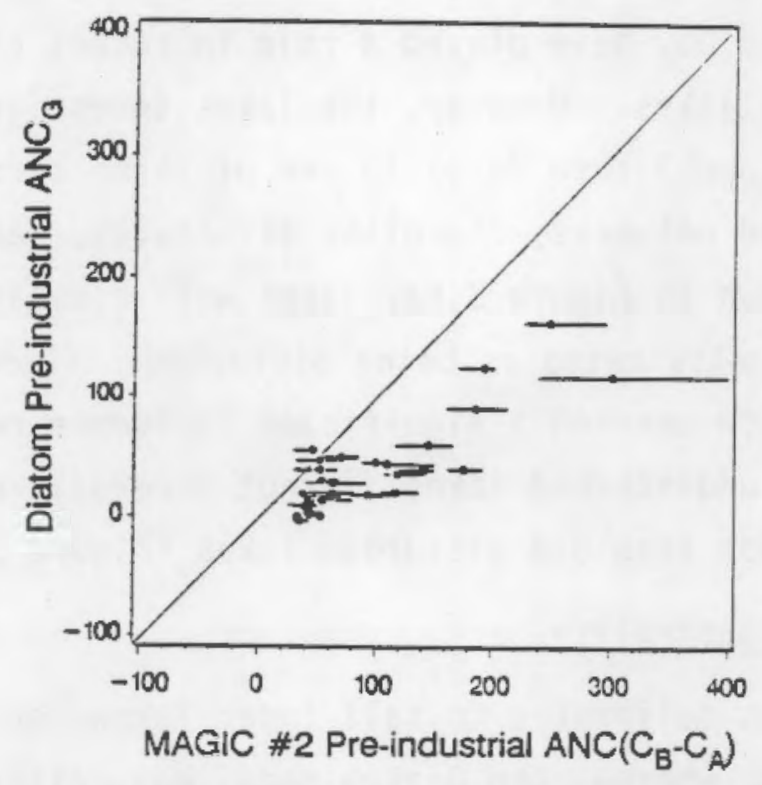

FIGURE 3.5. Plot of Diatom-inferred Pre-industrial ANC Versus the MAGIC Scenario \#2 Simulation Estimate of Pre-industrial $\operatorname{ANC}\left(C_{B}-C_{A}\right)$, with Error Estimates Placed on the MAGIC Estimates. The error estimates represent a confidence width, derived as the maximum and minimum of up to 10 separate calibrations for each lake. 

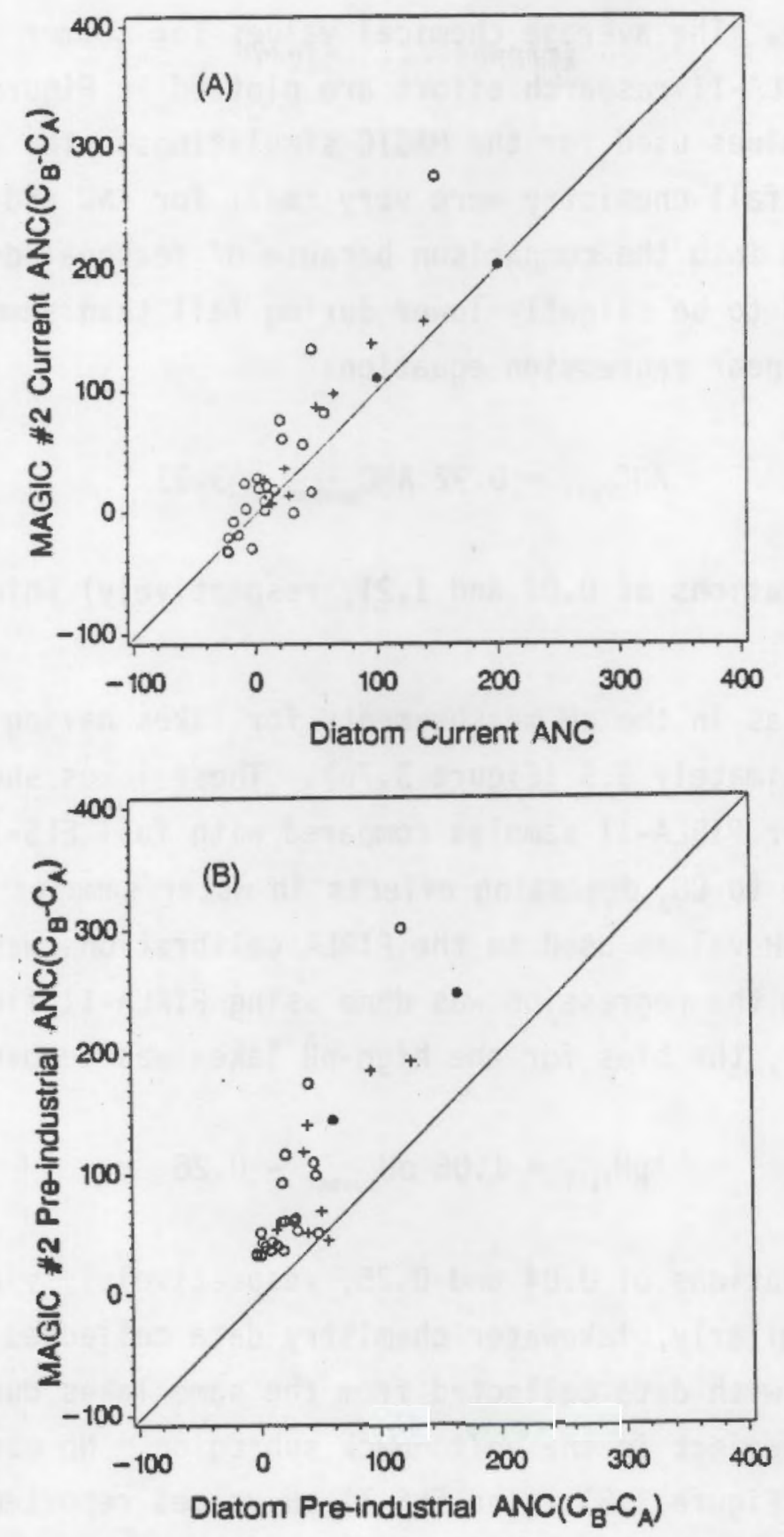

FIGURE 3.6. MAGIC Scenario $\# 2$ ANC $\left(C_{B}-C_{A}\right)$ Versus Diatom-inferred ANC $\left(C_{B}-C_{A}\right)$ ( $\mu$ eq $\left.L^{-1}\right)$. Lakes are coded by disturbance classes determined by $A$. Selle: - is disturbed, + is relatively disturbed, and $O$ is undisturbed. Current chemistry is presented in (A) and pre-industrial chemistry in (B). 
lakewater chemistry. The average chemical values for summer samples collected as part of the PIRLA-II research effort are plotted in Figure 3.7 versus ELS- 1 fall index values used for the MAGIC simulations. The differences between summer and fall chemistry were very small for ANC and pH, and no major bias was introduced into the comparison because of seasonal differences. In general, ANC tended to be slightly lower during fall than summer as indicated by the following linear regression equation:

$$
\mathrm{ANC}_{\text {fall }}=0.92 \mathrm{ANC}_{\text {suener }}-3.93
$$

(with standard deviations of 0.02 and 1.21 , respectively) which yields an $r^{2}$ of $0.99(n=33)$.

There was a bias in the $\mathrm{pH}$ measurements for lakes having $\mathrm{pH}$ values greater than approximately 5.5 (Figure $3.7 \mathrm{~b}$ ). These lakes showed slightly higher $\mathrm{pH}$ for summer PIRLA-II samples compared with fall ELS-1 samples. This may be attributable to $\mathrm{CO}_{2}$ degassing effects in water samples from the higher pH lakes, because pH values used in the PIRLA calibrations were airequilibrated. When the regression was done using PIRLA-II field pH measurements (Figure 3.7c), the bias for the high-pH lakes was removed, i.e.,

$$
\mathrm{pH}_{\text {fall }}=1.05 \mathrm{pH}_{\text {sunser }}-0.26
$$

(with standard deviations of 0.04 and 0.25 , respectively), yielding an $r^{2}$ of $0.95(n=33)$. Similarly, lakewater chemistry data collected during summer 1986 were compared with data collected from the same lakes during fall 1986 within the ELS-II project in the Adirondack subregion. No obvious seasonal bias was observed (Figure 3.8). The ELS-II pH values reported for both seasons were field laboratory (non-equilibrated) measurements.

On the basis of the above comparisons, we conclude that seasonal differences do not introduce any substantial bias into the comparison of MAGIC (fall) with Diatom (summer) results. The use of air-equilibrated $\mathrm{pH}$ values in the Diatom reconstructions versus the non-equilibrated (i.e., closed system) $\mathrm{pH}$ estimates used for MAGIC may, however, bias results for high-pH lakes. The 

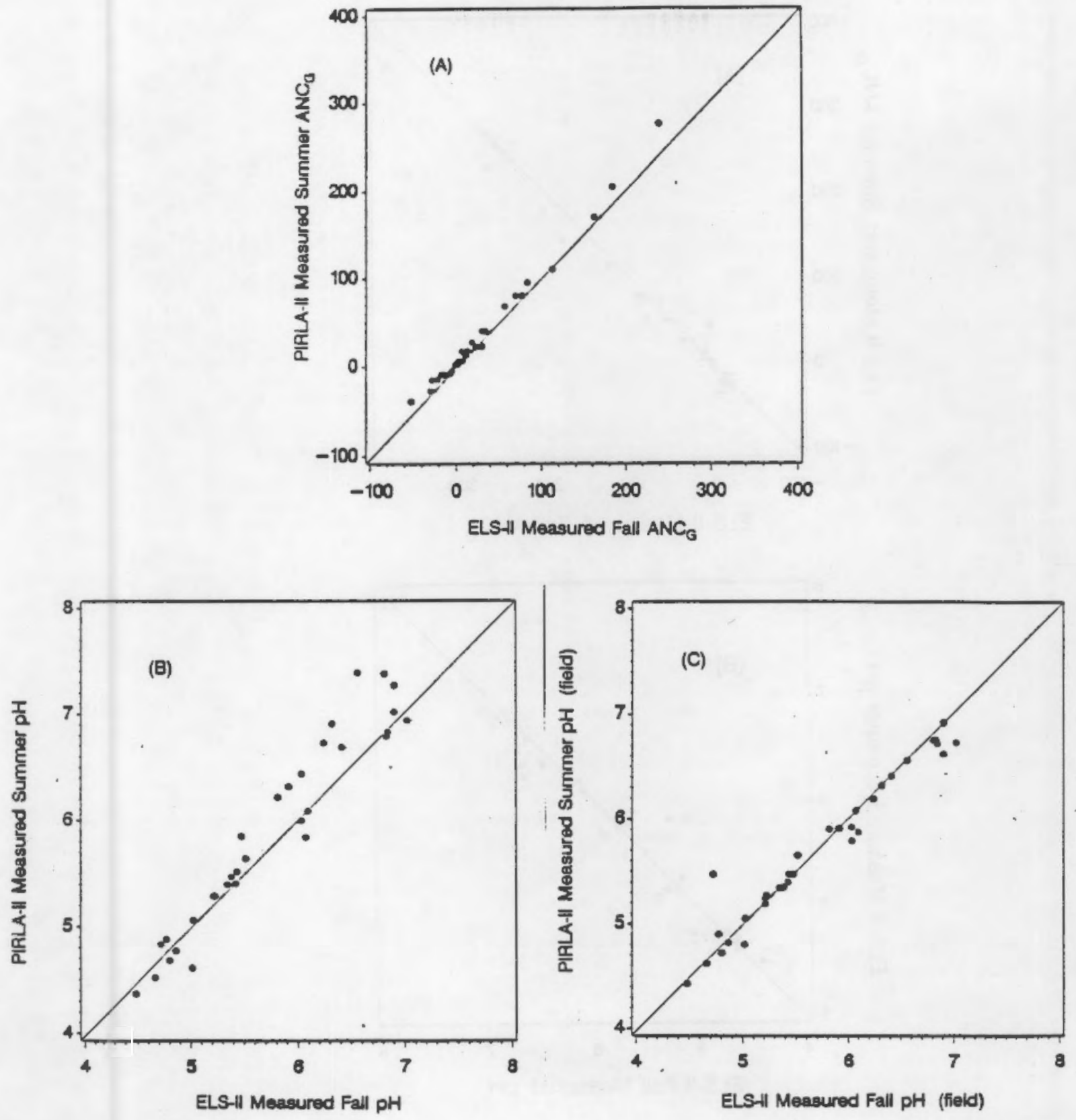

FIGURE 3.7. Comparisons of (A) PIRLA-II measured ANC (Average of Summer Samples) and ELS-I-measured ANC (Fall Index Samples), (B) Air-equilibrated $\mathrm{pH}$ (Average of Summer Samples) and ELS-I-measured Field $\mathrm{pH}$ (Fall Index Samples), and (C) Field $\mathrm{pH}$ (Average of Summer Samples) and ELS-I-measured Field pH (Fall Index Samples) 

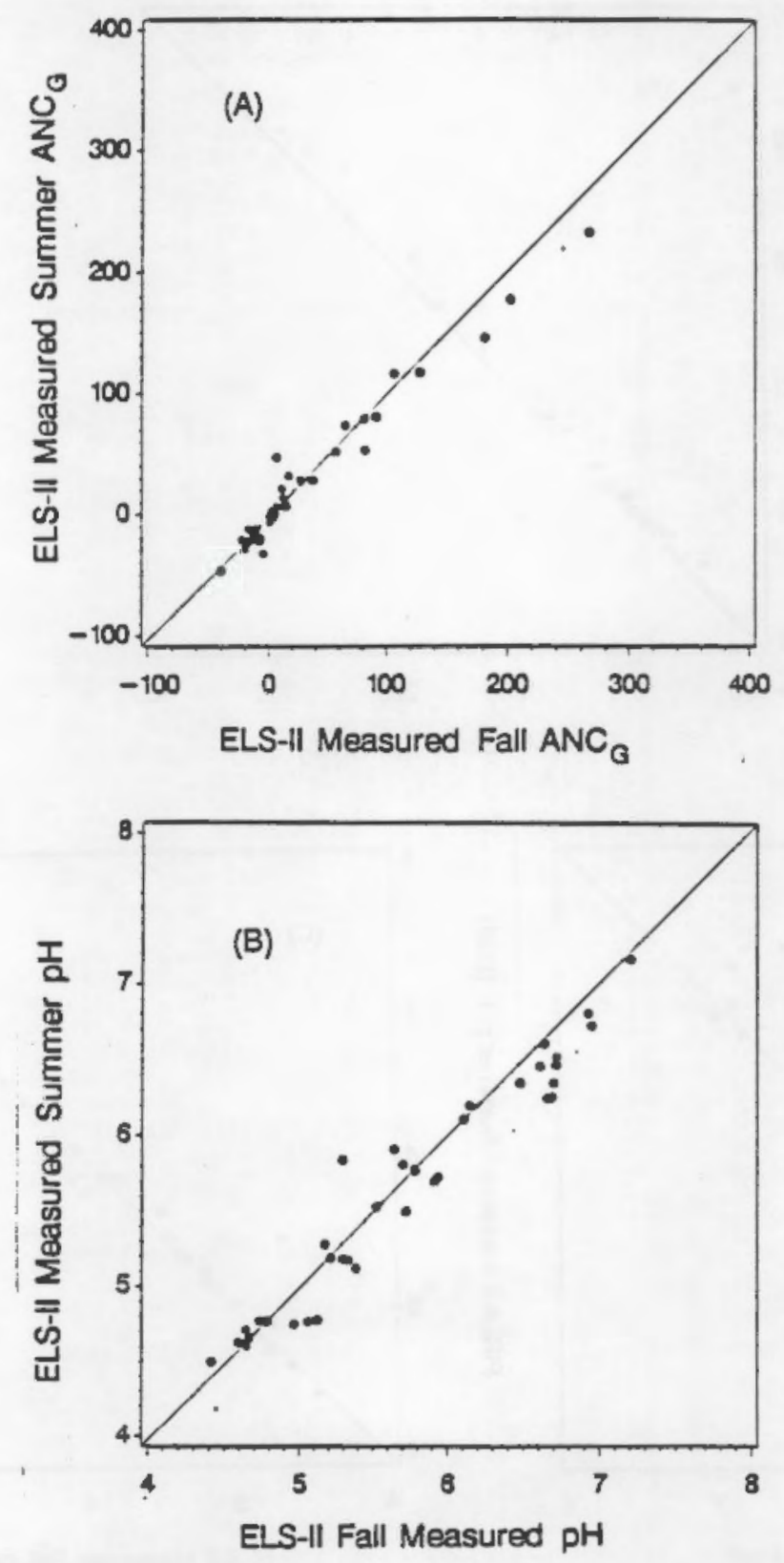

FIGURE 3.8. Comparison of (A) Summer 1986 ANC $_{G}$ Versus Fall 1986 ANC $_{G}$, and (B) Summer 1986 Station pH Versus Fall 1986 Station pH. Interseasonal comparison for 36 lakes in the Adirondack subregion sampled by ELS-II; unofficial and unverified version of the ELS-II 1986. 
Diatom model should yield slightly higher estimates of $\mathrm{pH}$ for high $\mathrm{pH}$ lakes because they were based on air-equilibrated values.

\subsubsection{ANC Definition}

Because the Diatom model was calibrated to titration ANC ( $A N C_{G}$ ) (Diatom Scenario \#2) and the MAGIC model used a defined $A N C\left(C_{B}-C_{A}\right.$ ) (all MAGIC Scenarios), it was necessary to reconcile the differences between these two estimates of ANC. The differences are caused primarily by the partially counteracting influences of $A 1$ and organic acids on titration ANC results. Aluminum tends to increase $A_{N} C_{G}$ relative to defined $A N C\left(C_{B}-C_{A}\right)$ because it acts essentially as a base cation in the titration procedure. Some relatively strong organic acids depress $A N C_{G}$ relative to $\left(C_{B}-C_{A}\right)$. The difference between titrated and defined ANC for the set of study lakes is depicted in Figure 3.9 using measured values from ELS-I. The Al influence causes a shift to higher ANC $_{G}$ for acidic lakes, and the organic acids influence causes a shift to lower ANC $_{G}$ for higher ANC lakes that do not contain appreciable concentrations of Al (Figure 3.9).

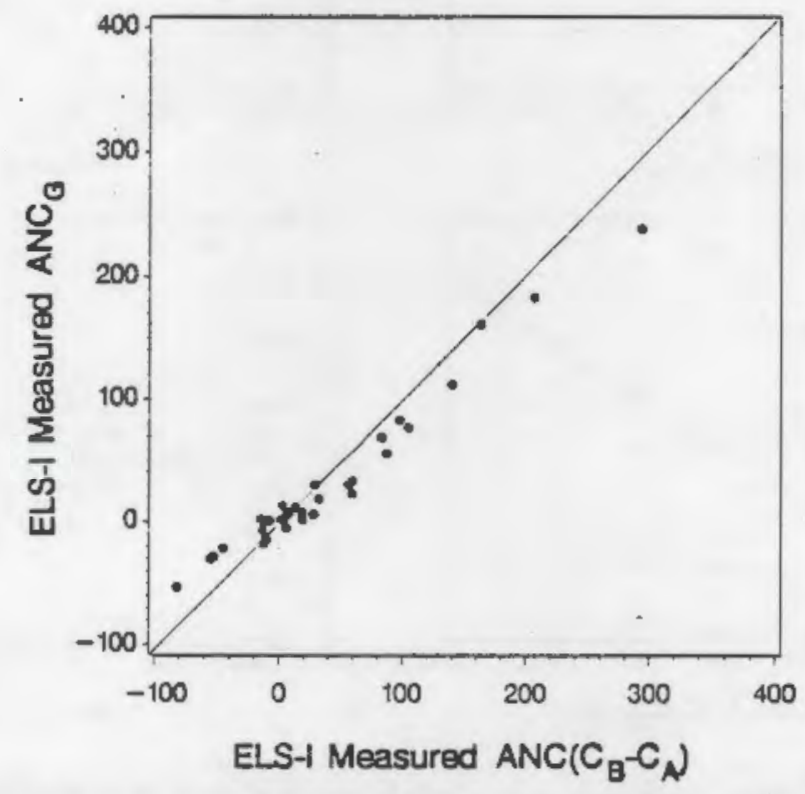

FIGURE 3.9. ELS-I Chemistry Comparison of Calculated Versus Titrated ANC. The $x$-axis is ELS defined $\operatorname{ANC}\left(C_{B}-C_{A}\right)$, where $C_{B}$ is $\mathrm{Ca}^{2+}+\mathrm{Mg}^{2+}+\mathrm{Na}^{+}+\mathrm{K}^{+}+\mathrm{NH}_{4}^{+}$and $\mathrm{C}_{4}$ is $\mathrm{SO}_{4}^{2-}+\mathrm{NO}_{3}^{-}+\mathrm{Cl}^{-}$The $y$-axis is ELS 1984 measured ANC $_{a}$. 
The difference in ANC definition between models was removed in Diatom Scenario \#3 by recalibrating the diatom assemblages in the PIRLA-II lakes to a defined $\operatorname{ANC}\left(C_{B}-C_{A}\right)$. The calibration data for Diatom-inferred $A N C\left(C_{B}-C_{A}\right)$ are presented in Figure 3.10 for $10 \mathrm{w}-\mathrm{ANC}\left(\leq 100 \mu \mathrm{eq} \mathrm{L}^{-1}\right)$ lakes and for the full data set. The equation derived for low-ANC lakes had a standard error of $18 \mu$ eq $L^{-1}$. A plot of current Diatom-inferred $A N C\left(C_{B}-C_{A}\right)$ versus measured ANC $\left(C_{B}-C_{A}\right)$ for the comparison lakes is presented in Figure 3.11. The Diatominferred estimates of $A N C\left(C_{B}-C_{A}\right)$ exhibited similar shifts relative to Diatom-inferred estimates of $\mathrm{ANC}_{G}$ (Figure 3.12), as were found for the measured values (Figure 3.9). For pre-industrial chemistry, the differences between Diatom-inferred $A N C\left(C_{B}-C_{A}\right)$ and Diatom-inferred $A N C_{G}$ were less
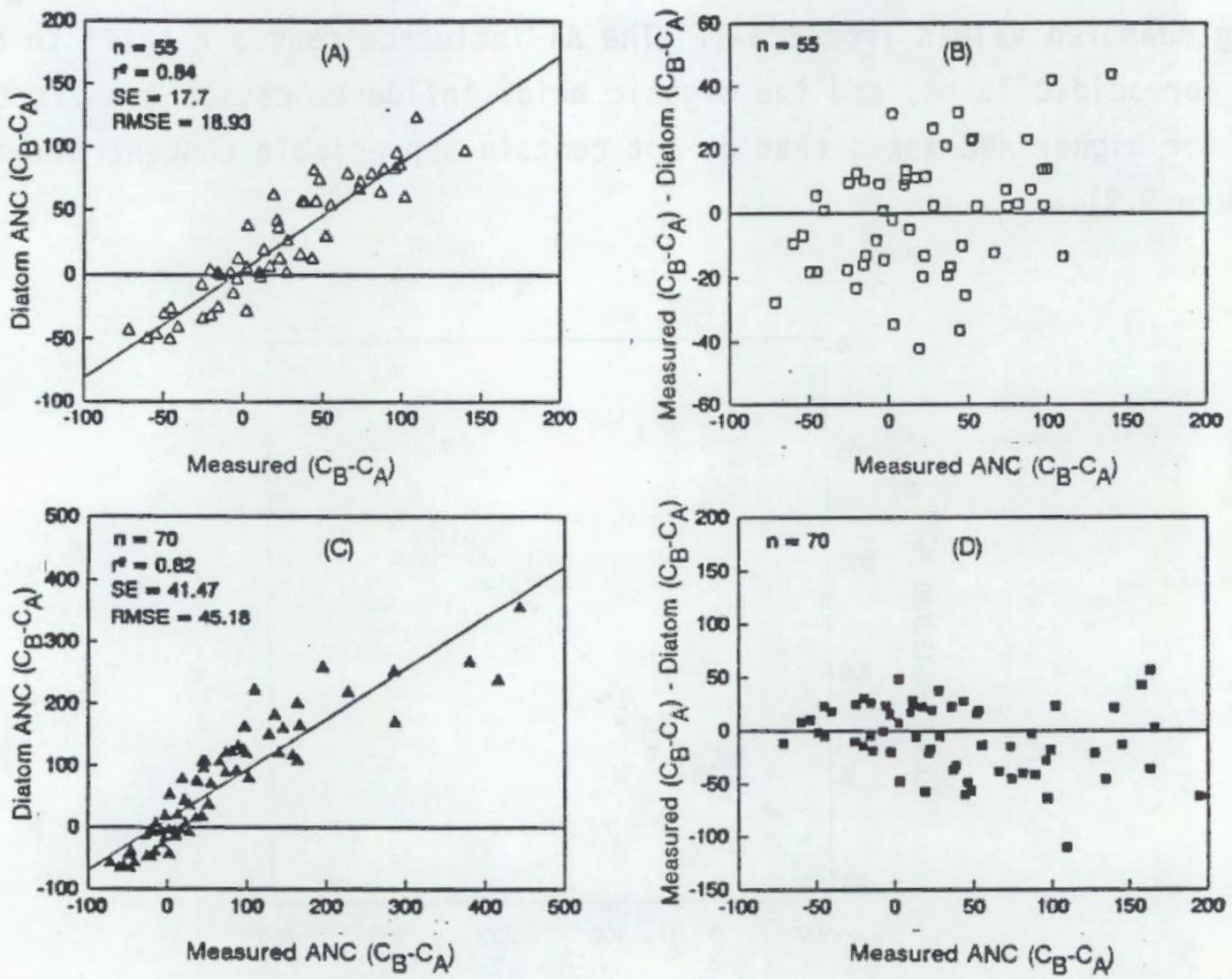

FIGURE 3.10. Paleolimnological Calibration Equations for Diatom-inferred $\operatorname{ANC}\left(C_{B}-C_{A}\right)$ for $(A)$ a restricted data set of lakes having ANC $\leq 100 \mu \mathrm{eq} \mathrm{L^{-1 }}$, (B) the full data set; and corresponding residual plots. for (C) lakes with ANC $\leq 100 \mu \mathrm{eq} \mathrm{L}^{-1}$, and (D) the full data set 


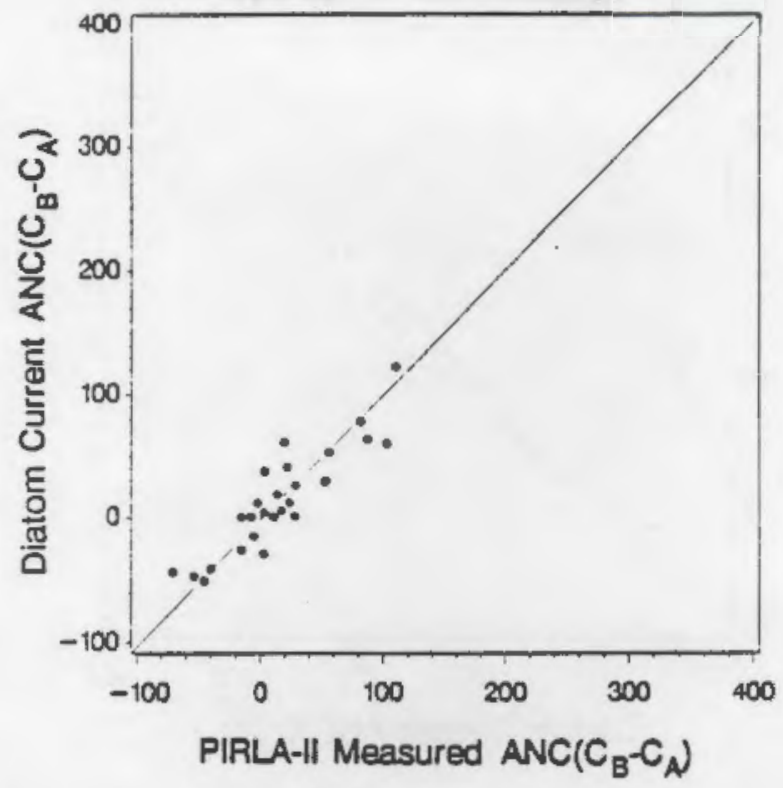

FIGURE 3.11. Diatom-inferred $A N C\left(C_{B}-C_{A}\right)$ Versus Measured $A N C\left(C_{B}-C_{A}\right)$ for Lakes Included in This Study

pronounced for the lower-ANC lakes (Figure 3.12b). This is attributed to the lower concentrations of $\mathrm{Al}_{\mathrm{a}}$ in pre-industrial times in those lakes with higher $\mathrm{pH}$ values in pre-industrial times.

\subsubsection{Deposition Assumptions}

Two scenarios were devised to evaluate the general sensitivity of MAGIC to the assumptions regarding pre-industrial deposition of sulfur and base cations. First, the MAGIC Scenario $\# 2$ differed from $\# 1$ in that pre-industrial sulfur deposition was estimated to be approximately $13 \%$ of current deposition (Husar et al. in press) instead of the near-zero value for pre-industrial Adirondack lakewater [ $\mathrm{SO}_{4}^{2-}$ ] that results from assuming all $\mathrm{Cl}^{-}$is of seasalt origin.

As expected, the slight difference in the sulfur deposition scenario did not affect the MAGIC simulations for current chemistry (Figure 3.13), because the model is calibrated to current measured chemistry. The pre-industrial estimates of defined $A N C\left(C_{B}-C_{A}\right)$ and $\mathrm{pH}$ were higher, however, for Scenario \#1 

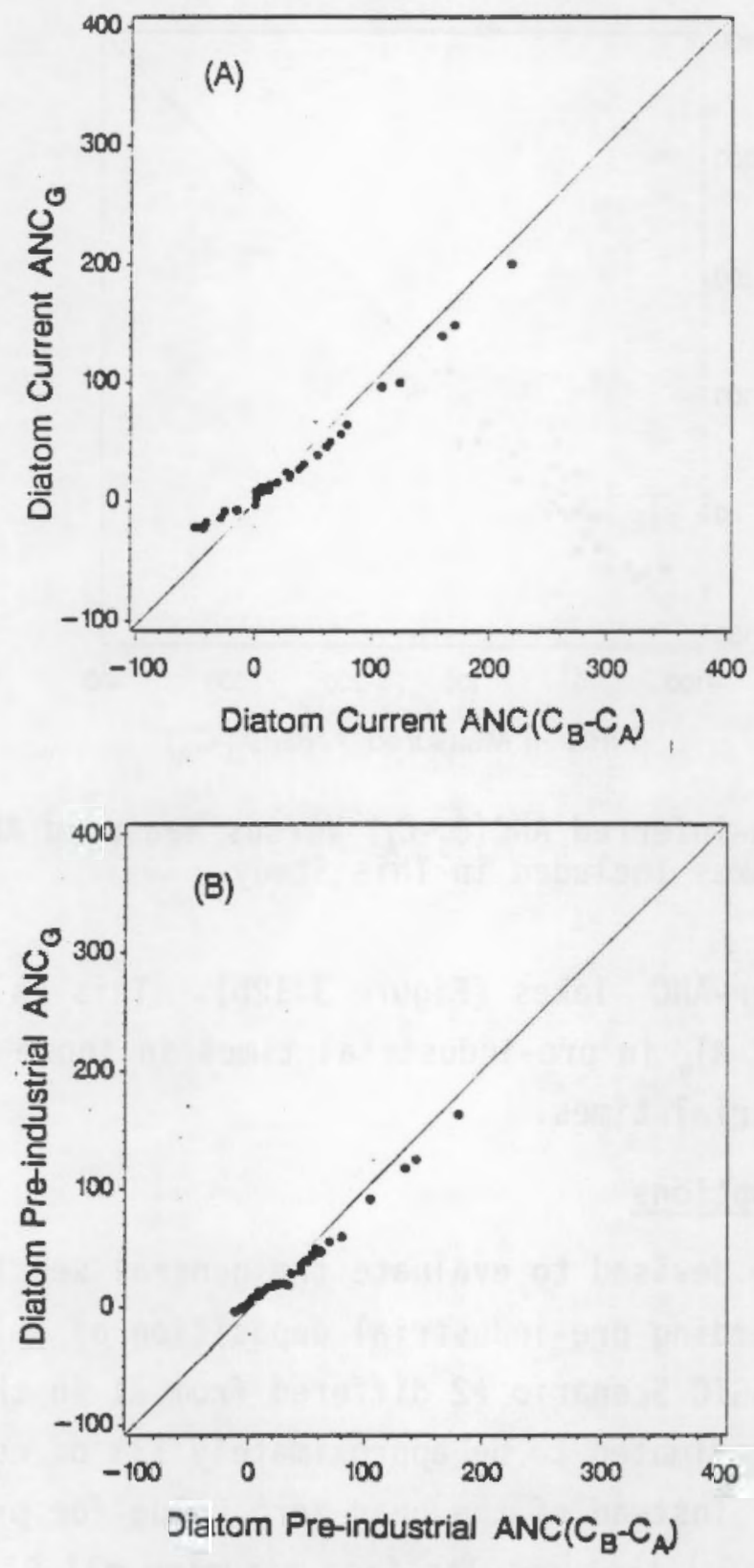

FIGURE 3.12. Comparisons of (A) Diatom-inferred Current ANC Versus Diatom-inferred Current $A N C\left(C_{B}-C_{A}\right)$ and (B) Diatominferred Pre-industrial ANC Versus Diatom-inferred Pre-industrial $A N C\left(C_{B}-C_{A}\right)$ 

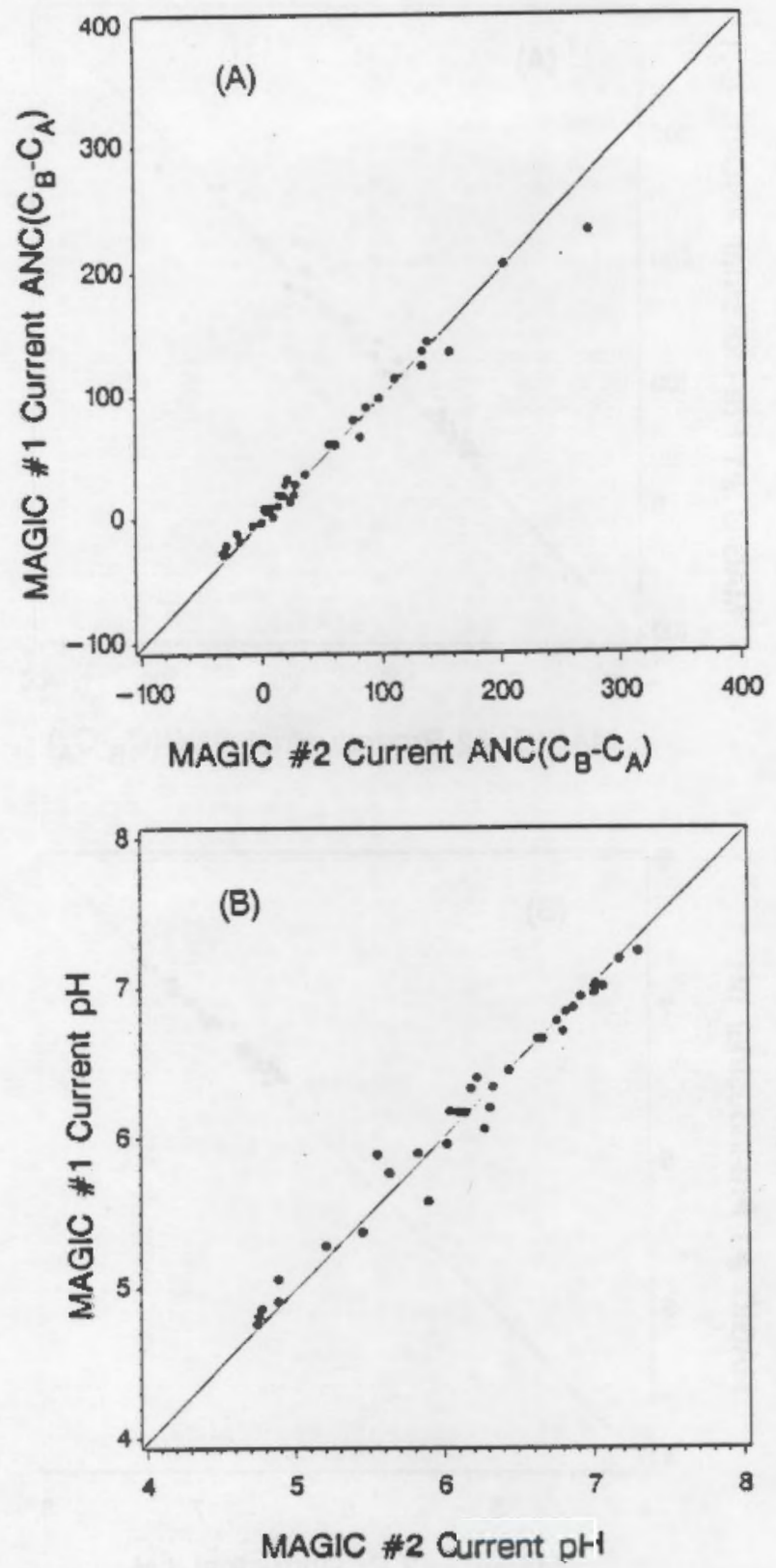

FIGURE 3.13. Comparison Plots of MAGIC Scenarios \#1 and \#2 for (A) ANC $\left(C_{B}-C_{A}\right)$ and $(B) \mathrm{pH}$. The $y$-axis is simulated current $A N C\left(C_{B}-C_{C}\right)$ for $(A)$ and current $\mathrm{pH}$ for (B) using MAGIC Scenario \#1 (DDRP). The $x$-axis is simulated current $A N C\left(C_{B}-C_{C}\right)$ for (A) and current $\mathrm{pH}$ for (B) using MAGIC Scenario ${ }_{2}$ (Husar-based background $\mathrm{SO}_{4}$ ). 

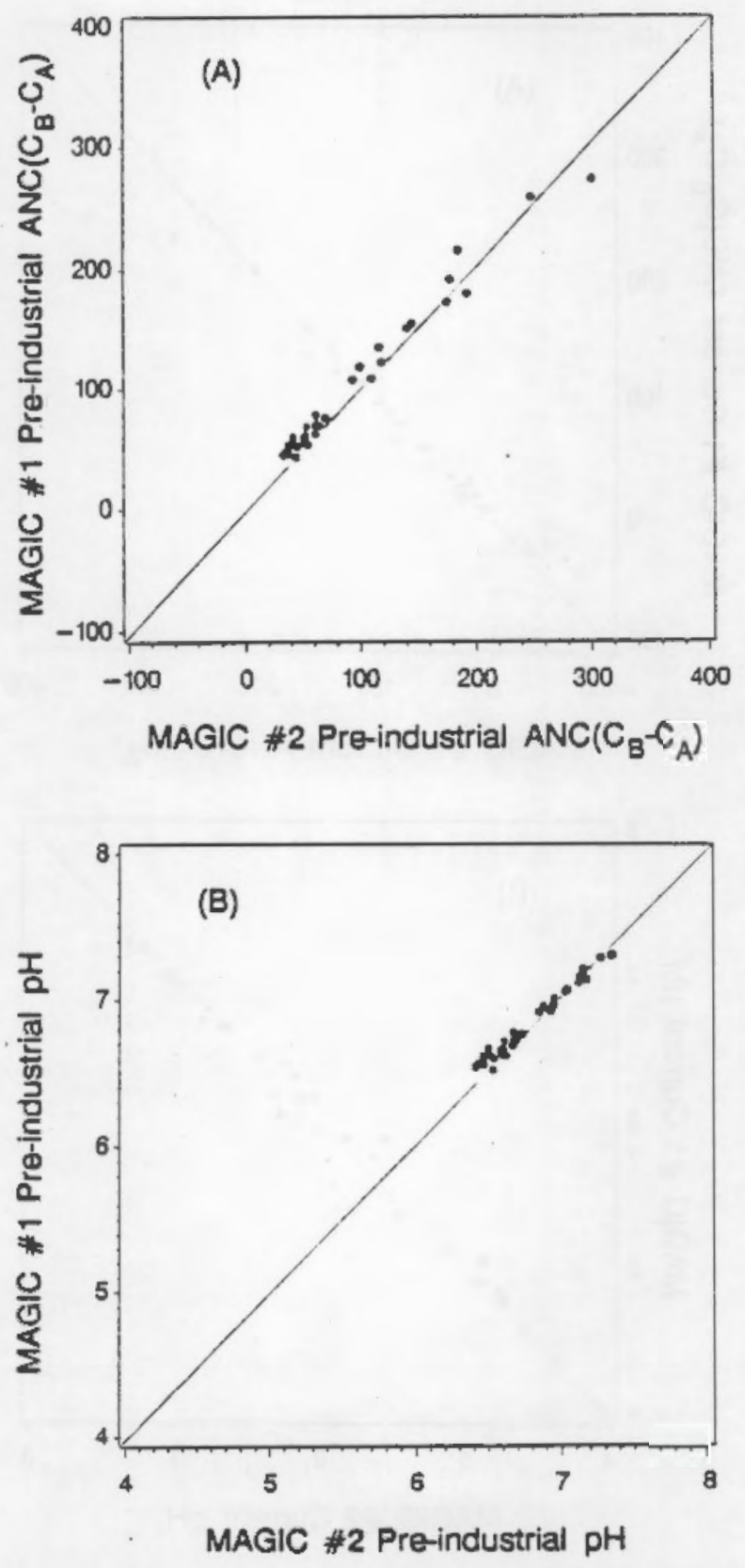

FIGURE 3.14. Comparison Plots of MAGIC Scenarios $\# 1$ and \#2 for (A) ANC $\left(C_{B}-C_{A}\right)$ and (B) $\mathrm{pH}$. The $y$-axis is simulated preindustrial $A N C\left(C_{B}-C_{A}\right)$ for $(A)$ and $\mathrm{pH}$ for (B) using MAGIC Scenario \#1. The $x$-axis is simulated pre-industrial $\operatorname{ANC}\left(C_{B}-C_{A}\right)$ for $(A)$ and $\mathrm{pH}$ for (B) using MAGIC Scenario \#2 (Husar-based background $\mathrm{SO}_{4}$ ). 
than \#2 (Figure 3.14). The uncertainty in sulfur deposition assumption is unlikely to introduce bias as large as that found between MAGIC Scenarios \#1 and $\# 2$ since it is generally accepted that pre-industrial sulfur deposition was low but above zero, i.e., in the range of 10-20 $\mu$ eq $\mathrm{L}^{-1}$ (e.g., Galloway et al. 1984, 1987; Brakke, Henriksen and Norton, 1989; Sullivan, in press).

\subsubsection{Reaggregation of Subregional Soils Data}

Reaggregation of the DDRP soils data to the Adirondack subregion, rather than to the northeastern region, did not result in major changes in estimated soil characteristics. Means and standard deviations for the Northeast and Adirondack sampling classes are shown in Table 3.1. Also given in Table 3.1 are the results of a paired $t$-test of the difference between the sampling class estimates based on the Adirondack pedons and the Northeast pedons. The only parameter found to be significantly different between the two aggregation procedures was cation exchange capacity (CEC) in the upper soil horizon. This implies that CEC in the Adirondack $A+B$ horizons is higher than in similar soils in the Northeast as a whole. This difference could bias MAGIC projections because CEC is an important capacity parameter in the model.

Table 3.2 lists the means and standard deviations for the watershed estimates based on the aggregation from the Northeast and Adirondack sampling classes. The results of a paired t-test of the differences in watershed estimates are also shown in this table. Of the sixteen comparisons shown in Table 3.2, nine are significant at the 0.01 level. This was unexpected because most sampling class differences had not been significant. Some of the differences, though statistically significant, probably do not have implications for the modelling results because the differences are so small (e.g., bulk density) or because the parameters are relatively unimportant (e.g., exchangeable $\mathrm{Na}, \mathrm{K}$ ). Differences in important capacity parameters such as CEC and soil thickness could result in differences in model results. However, they may be offsetting; Adirondack soils have higher CEC, but are thinner, so the overall exchangeable base cation pool is probably similar for both aggregations. 
TABLE 3.1. Sampling Class Statistics and Results of Paired t-test of Differences Between Sampling Class Means for Comparing Soils Aggregation Results Between the Northeast and the Adirondacks

\begin{tabular}{|c|c|c|c|c|c|c|c|c|}
\hline \multirow[b]{2}{*}{ Parameter ${ }^{(\mathbf{a})}$} & \multirow{2}{*}{$\begin{array}{c}\text { MAGIC } \\
\text { Horizon } \\
\end{array}$} & \multirow{2}{*}{$\begin{array}{c}\text { No. of } \\
\text { Observations }\end{array}$} & \multicolumn{2}{|c|}{ Northeast } & \multicolumn{2}{|c|}{ Adirondacks } & \multicolumn{2}{|c|}{$\begin{array}{r}\text { Paired } \\
\text { t-test } \\
\end{array}$} \\
\hline & & & Mean & SD & Mean & SD & $t$ & $p>t$ \\
\hline BS_CL & $\underset{C}{A+B}$ & $\begin{array}{l}15 \\
11\end{array}$ & $\begin{array}{l}17.09 \\
30.62\end{array}$ & $\begin{array}{l}18.91 \\
26.43\end{array}$ & $\begin{array}{l}19.63 \\
34.11\end{array}$ & $\begin{array}{l}24.46 \\
24.94\end{array}$ & $\begin{array}{l}-1.12 \\
-1.27\end{array}$ & $\begin{array}{l}0.28 \\
0.23\end{array}$ \\
\hline CEC_CL & $\stackrel{A+B}{C}$ & $\begin{array}{l}16 \\
12\end{array}$ & $\begin{array}{l}5.54 \\
2.31\end{array}$ & $\begin{array}{l}2.21 \\
2.11\end{array}$ & $\begin{array}{l}6.94 \\
2.94\end{array}$ & $\begin{array}{l}3.23 \\
3.97\end{array}$ & $\begin{array}{l}-2.98 \\
-1.00\end{array}$ & $\begin{array}{l}0.01 \\
0.34\end{array}$ \\
\hline $\mathrm{CA}_{-} \mathrm{CL}$ & $\stackrel{A+B}{C}$ & $\begin{array}{l}16 \\
12\end{array}$ & $\begin{array}{l}0.79 \\
1.19\end{array}$ & $\begin{array}{l}0.99 \\
1.74\end{array}$ & $\begin{array}{l}1.11 \\
1.52\end{array}$ & $\begin{array}{l}1.31 \\
2.44\end{array}$ & $\begin{array}{l}-1.98 \\
-1.55\end{array}$ & $\begin{array}{l}0.07 \\
0.15\end{array}$ \\
\hline MG_CL & $\stackrel{A+B}{C}$ & $\begin{array}{l}16 \\
12\end{array}$ & $\begin{array}{l}0.14 \\
0.32\end{array}$ & $\begin{array}{l}0.18 \\
0.49\end{array}$ & $\begin{array}{l}0.20 \\
0.45\end{array}$ & $\begin{array}{l}0.31 \\
0.73\end{array}$ & $\begin{array}{l}-1.62 \\
-1.62\end{array}$ & $\begin{array}{l}0.12 \\
0.13\end{array}$ \\
\hline NA_CL & $\stackrel{A+B}{C}$ & $\begin{array}{l}16 \\
12\end{array}$ & $\begin{array}{l}0.05 \\
0.03\end{array}$ & $\begin{array}{l}0.05 \\
0.02\end{array}$ & $\begin{array}{l}0.04 \\
0.03\end{array}$ & $\begin{array}{l}0.04 \\
0.02\end{array}$ & $\begin{array}{l}0.84 \\
0.28\end{array}$ & $\begin{array}{l}0.41 \\
0.78\end{array}$ \\
\hline K_CL & $\stackrel{A+B}{C}$ & $\begin{array}{l}15 \\
23\end{array}$ & $\begin{array}{l}0.06 \\
0.05\end{array}$ & $\begin{array}{l}0.06 \\
0.04\end{array}$ & $\begin{array}{l}0.06 \\
0.05\end{array}$ & $\begin{array}{l}0.04 \\
0.05\end{array}$ & $\begin{array}{r}0.10 \\
-0.14\end{array}$ & $\begin{array}{l}0.92 \\
0.89\end{array}$ \\
\hline THKM & $\stackrel{A+B}{C}$ & $\begin{array}{l}18 \\
18\end{array}$ & $\begin{array}{l}40.50 \\
45.43\end{array}$ & $\begin{array}{l}23.67 \\
45.43\end{array}$ & $\begin{array}{l}39.95 \\
41.31\end{array}$ & $\begin{array}{l}27.33 \\
35.26\end{array}$ & $\begin{array}{l}0.26 \\
0.70\end{array}$ & $\begin{array}{l}0.80 \\
0.49\end{array}$ \\
\hline SOILDEN & $\stackrel{A+B}{C}$ & $\begin{array}{l}16 \\
12\end{array}$ & $\begin{array}{l}1.15 \\
1.66\end{array}$ & $\begin{array}{l}0.21 \\
0.06\end{array}$ & $\begin{array}{l}1.10 \\
1.68\end{array}$ & $\begin{array}{l}0.21 \\
0.06\end{array}$ & $\begin{array}{r}1.49 \\
-1.58\end{array}$ & $\begin{array}{l}0.16 \\
0.14\end{array}$ \\
\hline
\end{tabular}

(a) BS_CL: Base saturation, $\mathrm{NH}_{4} \mathrm{Cl}$ extraction (percent)

$\mathrm{CE} \bar{C}-\mathrm{CL}$ : Cation exchange capacity, $\mathrm{NH}_{4} \mathrm{Cl}$ extraction (meq $100 \mathrm{~g}^{-1}$ )

CA_CL: Calcium, $\mathrm{NH}_{4} \mathrm{Cl}$ extraction (meq $100 \mathrm{~g}^{-1}$ )

$\mathrm{MG}_{-}^{-} \mathrm{CL}$ : Magnesium, $\mathrm{NH}_{4} \mathrm{Cl}$ extraction (meq $100 \mathrm{~g}^{-1}$ )

$\mathrm{NA}-\mathrm{CL}$ : Sodium, $\mathrm{NH}_{4} \mathrm{Cl}$ extraction (meq $100 \mathrm{~g}^{-1}$ )

$\mathrm{K}-\overline{C L}$ : Potassium, $\mathrm{NH}_{4} \mathrm{Cl}$ extraction (meq $100 \mathrm{~g}^{-1}$ )

THKM: Measured soil thickness $(\mathrm{cm})$

SOILDEN: Bulk density $\left(g \mathrm{~mL}^{-1}\right)$

(b) Northeast mean minus Adirondack reaggregation mean.

Recalibration of MAGIC using Baker and Brezonik (1988) lake $\mathrm{SO}_{4}^{2-}$ coefficients appropriate to the Adirondack subregion apparently resulted in more substantial changes to the MAGIC output than did the reaggregation of soils data for the subregional reaggregation. This conclusion is derived from the 
TABLE 3.2. Watershed Statistics and Results of Paired t-test of Differences Between Watershed Means for Comparing Soils Aggregation Results Between the Northeast and the Adirondacks

\begin{tabular}{|c|c|c|c|c|c|c|c|c|}
\hline \multirow[b]{2}{*}{ Parameter ${ }^{(a)}$} & \multirow{2}{*}{$\begin{array}{l}\text { MAGIC } \\
\text { Horizon }\end{array}$} & \multirow{2}{*}{$\begin{array}{c}\text { No. of } \\
\text { Observations } \\
\end{array}$} & \multicolumn{2}{|c|}{ Northeast } & \multicolumn{2}{|c|}{ Adirondacks } & \multicolumn{2}{|c|}{$\begin{array}{r}\text { Paired } \\
\text { t-test } \\
\end{array}$} \\
\hline & & & Mean & SD & Mean & SD & $t$ & $p>t$ \\
\hline BS_CL & $\stackrel{A+B}{C}$ & $\begin{array}{l}38 \\
38\end{array}$ & $\begin{array}{l}10.06 \\
14.72\end{array}$ & $\begin{array}{l}4.92 \\
9.43\end{array}$ & $\begin{array}{r}8.92 \\
18.92\end{array}$ & $\begin{array}{r}3.70 \\
10.38\end{array}$ & $\begin{array}{r}4.08 \\
-4.75\end{array}$ & $\begin{array}{l}<0.01 \\
<0.01\end{array}$ \\
\hline CEC_CL & $\stackrel{A+B}{C}$ & $\begin{array}{l}38 \\
38\end{array}$ & $\begin{array}{l}6.81 \\
1.41\end{array}$ & $\begin{array}{l}1.17 \\
0.64\end{array}$ & $\begin{array}{l}7.75 \\
1.43\end{array}$ & $\begin{array}{l}1.64 \\
1.65\end{array}$ & $\begin{array}{l}-7.24 \\
-0.10\end{array}$ & $\begin{array}{r}<0.01 \\
0.92\end{array}$ \\
\hline CA_CL & $\stackrel{A+B}{C}$ & $\begin{array}{l}38 \\
38\end{array}$ & $\begin{array}{l}0.53 \\
0.39\end{array}$ & $\begin{array}{l}0.64 \\
0.52\end{array}$ & $\begin{array}{l}0.60 \\
0.42\end{array}$ & $\begin{array}{l}0.41 \\
0.98\end{array}$ & $\begin{array}{l}-1.71 \\
-0.41\end{array}$ & $\begin{array}{l}0.09 \\
0.68\end{array}$ \\
\hline MG_CL & $\stackrel{A+B}{C}$ & $\begin{array}{l}38 \\
38\end{array}$ & $\begin{array}{l}0.08 \\
0.10\end{array}$ & $\begin{array}{l}0.11 \\
0.13\end{array}$ & $\begin{array}{l}0.08 \\
0.13\end{array}$ & $\begin{array}{l}0.12 \\
0.30\end{array}$ & $\begin{array}{r}1.32 \\
-1.24\end{array}$ & $\begin{array}{l}0.19 \\
0.22\end{array}$ \\
\hline NA_CL & $\stackrel{A+B}{C}$ & $\begin{array}{l}38 \\
38\end{array}$ & $\begin{array}{l}0.03 \\
0.02\end{array}$ & $\begin{array}{l}0.01 \\
0.01\end{array}$ & $\begin{array}{l}0.03 \\
0.01\end{array}$ & $\begin{array}{r}<0.01 \\
0.01\end{array}$ & $\begin{array}{l}1.82 \\
5.49\end{array}$ & $\begin{array}{r}0.08 \\
<0.01\end{array}$ \\
\hline K_CL & $\stackrel{A+B}{C}$ & $\begin{array}{l}38 \\
38\end{array}$ & $\begin{array}{l}0.06 \\
0.10\end{array}$ & $\begin{array}{l}0.02 \\
0.53\end{array}$ & $\begin{array}{l}0.04 \\
0.02\end{array}$ & $\begin{array}{l}0.02 \\
0.02\end{array}$ & $\begin{array}{r}16.21 \\
9.52\end{array}$ & $\begin{array}{l}<0.01 \\
<0.01\end{array}$ \\
\hline THKM & $\stackrel{A+B}{C}$ & $\begin{array}{l}38 \\
38\end{array}$ & $\begin{array}{l}50.34 \\
51.65\end{array}$ & $\begin{array}{r}6.27 \\
10.32\end{array}$ & $\begin{array}{l}49.18 \\
32.65\end{array}$ & $\begin{array}{r}8.91 \\
16.87\end{array}$ & $\begin{array}{r}1.16 \\
10.05\end{array}$ & $\begin{array}{r}0.25 \\
<0.01\end{array}$ \\
\hline SOILDEN & $\stackrel{A+B}{C}$ & $\begin{array}{l}38 \\
38\end{array}$ & $\begin{array}{l}1.04 \\
1.66\end{array}$ & $\begin{array}{l}0.05 \\
0.02\end{array}$ & $\begin{array}{l}1.01 \\
1.68\end{array}$ & $\begin{array}{l}0.07 \\
0.01\end{array}$ & $\begin{array}{r}6.45 \\
-8.15\end{array}$ & $\begin{array}{l}<0.01 \\
<0.01\end{array}$ \\
\hline
\end{tabular}

(a) $\mathrm{BS} C \mathrm{CL}$ : Base saturation, $\mathrm{NH}_{4} \mathrm{Cl}$ extraction (percent)

CEC CL: Cation exchange capacity, $\mathrm{NH}_{4} \mathrm{Cl}$ extraction (meq $100 \mathrm{~g} \mathrm{~g}^{-1}$ )

CA_CL: Calcium, $\mathrm{NH}_{4} \mathrm{Cl}$ extraction (meq $100 \mathrm{~g}^{-1}$ )

$\mathrm{MG}_{-}^{-} \mathrm{CL}$ : Magnesium, $\mathrm{NH}_{4} \mathrm{Cl}$ extraction (meq $100 \mathrm{~g}^{-1}$ )

$\mathrm{NA}^{-} \mathrm{Cl}$ : Sodium, $\mathrm{NH}_{4} \mathrm{Cl}$ extraction (meq $100 \mathrm{~g}^{-1}$ )

$\mathrm{K} \overline{\mathrm{CL}}$ : Potassium, $\mathrm{NH}_{4} \mathrm{Cl}$ extraction (meq $100 \mathrm{~g}^{-1}$ )

THKKM: Measured soil thickness $(\mathrm{cm})$

SOILDEN: Bulk density $(\mathrm{g} \mathrm{mL}-1)$.

(b) Northeast mean minus Adirondack reaggregation mean. 


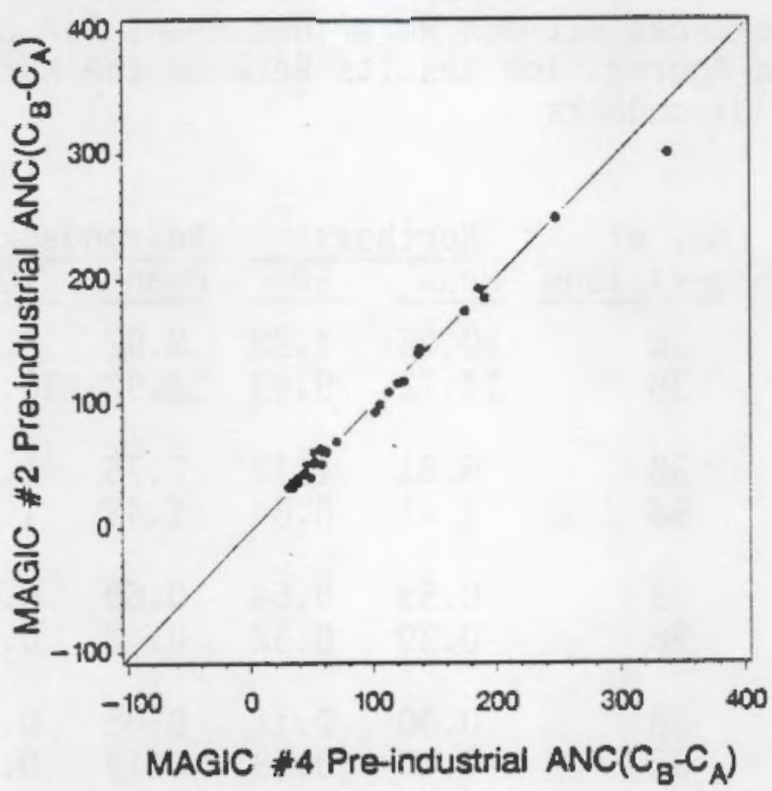

FIGURE 3.15. Comparison Between MAGIC Estimates of Current ANC $\left(C_{B}-C_{A}\right)$ for MAGIC Scenario \#2 (Calibrated to Northeastern Region) and Scenario \#4 (Recalibrated to Adirondack Subregion)

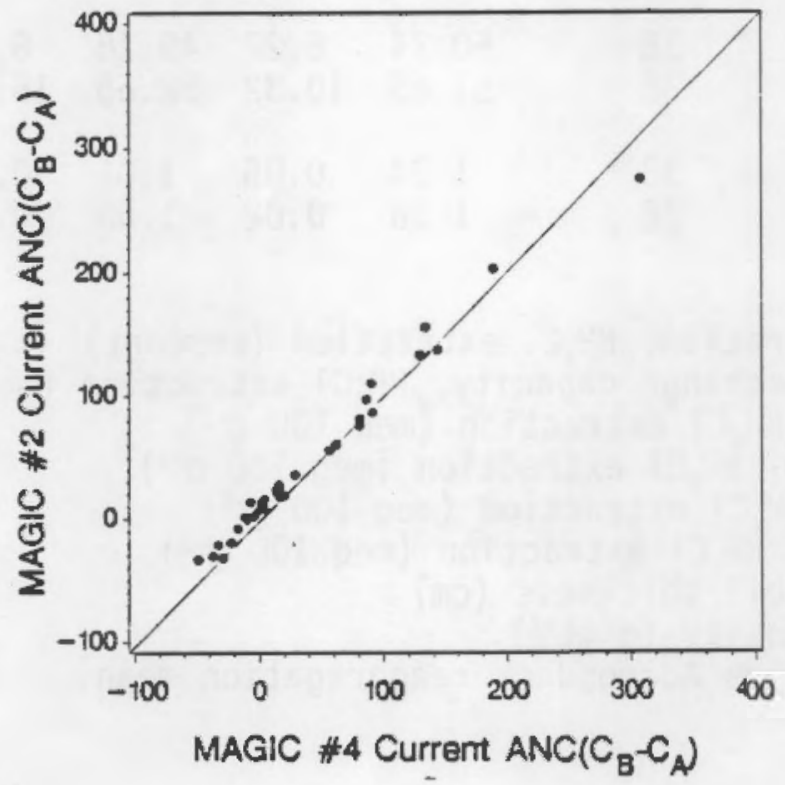

FIGURE 3.16. Comparison of MAGIC Scenario \#2 Simulations of Pre-industrial ANC $\left(C_{B}-C_{A}\right)$ with Simulations Based on Reaggregation of Soils Data and Recalibration of MAGIC to Adirondack Subregion (Rather Than Northeastern Region) (Scenario \#4) 
following two observations. Although pre-industrial ANC remained essentially the same after the recalibration (Scenario \#4) as for the MAGIC Scenario \#2 (Figure 3.15$)$, the recalibration produced approximately $10 \mu \mathrm{eq} \mathrm{L} \mathrm{L}^{-1}$ lower estimates of current ANC (Figure 3.16). This shift was probably caused largely by a bias in predicted versus observed lakewater $\mathrm{SO}_{4}^{2-}$ concentration in the Scenario $\# 2$ simulations (Figure 3.17 a). This bias was removed during the calibration to the Adirondack subregion. Recalculating the in-lake sulfur uptake in the Baker and Brezonik (1988) sulfur retention model to the Adirondack subregion lakes yielded near zero values for this coefficient (Figure 3.17b).

A substantial shift was observed for the pH estimates as a result of the subregional MAGIC recalibration (Figures $3.18,3.19$ ). The recalibration resulted in consistently lower pre-1850 pH values (by about $0.25 \mathrm{pH}$ units; Figure 3.18). A similar bias was observed for current $\mathrm{pH}$ estimates for the lakes having current $\mathrm{pH}$ greater than approximately 5.5 (Figure 3.19), whereas the bias decreased at lower $\mathrm{pH}$ and was not observed for lakes having $\mathrm{pH}$ less than 5.0. This shift is attributable primarily to the higher $\mathrm{pCO}_{2}$ values estimated for Adirondack lakes, compared with the northeastern ELS-I region as a whole. The reason the shift was not apparent for low-pH $(<5.0)$ lakes was that lakewater $\mathrm{pH}$ is generally insensitive to $\mathrm{CO}_{2}$ over-pressure at such low $\mathrm{pH}$ values.

Thus, the MAGIC calibration (Scenario \#1) to the Northeast region did not appear to bias results for the Adirondack subregion as a consequence of differences in soil characteristics within the northeast region. The MAGIC calibration, however, was apparently sensitive to differences between the Adirondack subregion and the Northeast as a whole, particularly in terms of in-lake sulfur uptake and lakewater $\mathrm{pCO}_{2}$. The Adirondack lakes tend to be located at higher elevation, are more often headwater lakes, and have shorter retention times than northeastern lakes in general, which results in little in-lake sulfur retention. These subregional characteristics tend to produce smaller effects of in-lake sulfur retention on lakewater ANC and $\mathrm{pH}$ and larger $\mathrm{pH}$ effects from $\mathrm{CO}_{2}$ oversaturation. Such expected differences appear to have 

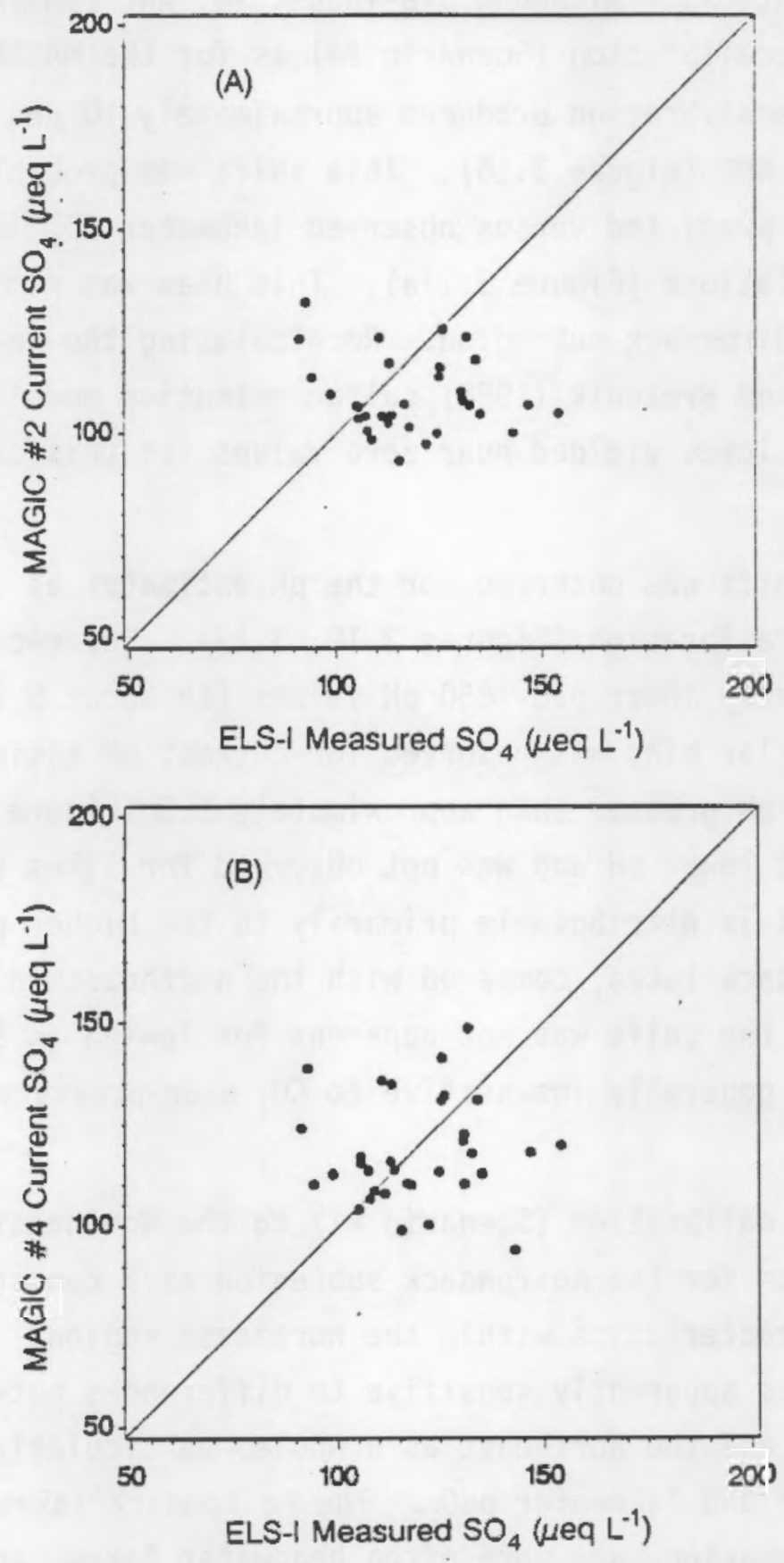

FIGURE 3.17. Sulfate Calibration data for (A) MAGIC Scenario \#2 Simulations and (B) Recalibration for Adirondack Subregion (Scenario \#4). The recalibration removed the bias associated with $\mathrm{SO}_{4}^{2-}$ simulated values in Scenario \#2. The mean and (standard deviation) for simulated minus observed $\mathrm{SO}_{4}^{2-}$ concentration was -9.7 (19.4) $\mu \mathrm{eq} \mathrm{L}^{-1}$ for the upper plot and -0.8 (19.7) $\mu \mathrm{eq} \mathrm{L} \mathrm{L}^{-1}$ for the lower plot. 


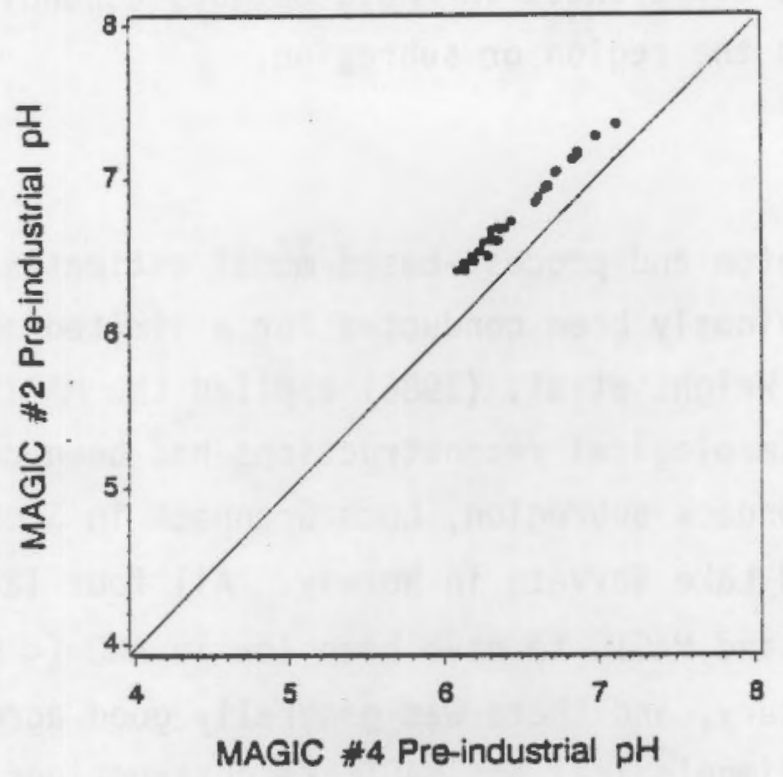

FIGURE 3.18. MAGIC Pre-industrial pH Versus Diatom-inferred Pre-industrial $\mathrm{pH}$. MAGIC simulations were based on reaggregation and recalibration to the Adirondack subregion (Scenario \#4).

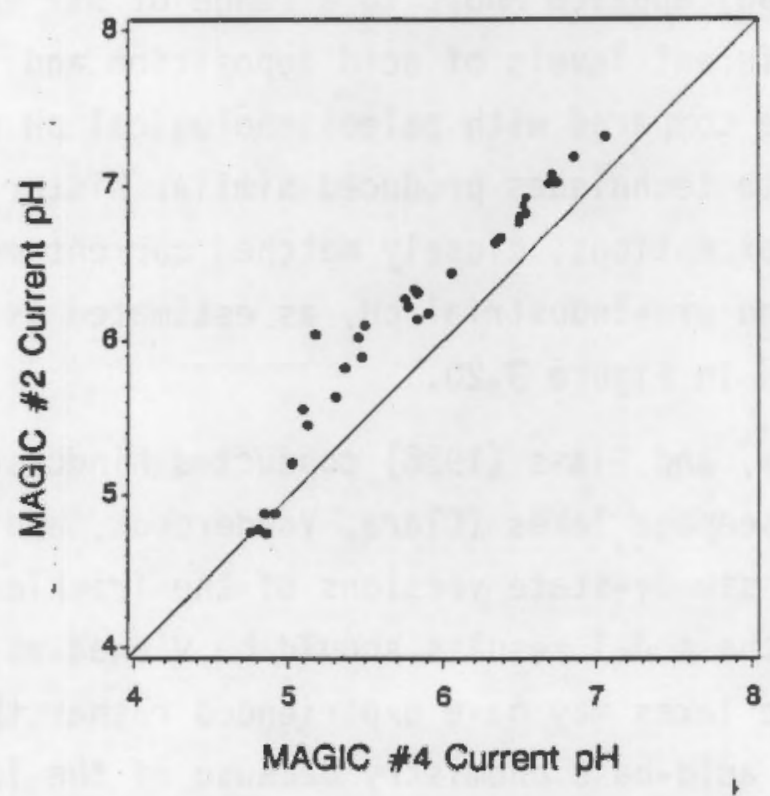

FIGURE 3.19. MAGIC Current pH Versus Diatom-inferred Current pH. MAGIC simulations were based on reaggregation and recalibration to the Adirondack subregion (Scenario \#4). 
resulted in appreciable differences in MAGIC output, depending on whether the model was calibrated to the region or subregion.

\subsection{SYNTHESIS}

Comparisons of Diatom and process-based model estimates of historical acidification have previously been conducted for a limited number of aquatic systems. For example, Wright et al. (1986) applied the MAGIC model to four lakes for which paleolimnological reconstructions had been constructed: Big Moose Lake in the Adirondack subregion, Loch Grannoch in Scotland, Lake Gårdsjon in Sweden, and Lake Hovvatn in Norway. All four lakes were inferred by both paleolimnology and MAGIC to have been low in ANC $(<50 \mu$ eq L-1) prior to the turn of the century, and there was generally good agreement between the two approaches. Paleolimnological and MAGIC reconstructions of the pH history of Round Loch of Glenhead, Scotland, also showed close agreement (Neal, Whitehead, and Jenkins 1988). Both approaches suggested that the lakewater $\mathrm{pH}$ in Round Loch of Glenhead decreased roughly from 5.7 to 4.8 since 1800 .

Jenkins et al. (1990) applied MAGIC to a range of six catchments in Scotland subject to different levels of acid deposition and land use. Simulated trends in $\mathrm{pH}$ were compared with paleolimnological $\mathrm{pH}$ reconstructions for the same sites. Both techniques produced similar historical acidification trends, and, with some exceptions, closely matched current measured $\mathrm{pH}$. A comparison of current and pre-industrial pH, as estimated using the two approaches, is presented in Figure 3.20 .

Schnoor, Nikolaidis, and Glass (1986) conducted hindcast simulations for three upper Midwestern seepage lakes (Clara, Vandercook, and McNearney Lakes) using time-variable and steady-state versions of the Trickle-Down model. The authors cautioned that the model results should be viewed as indications of the types of changes the lakes may have experienced rather than as firm reconstructions of lake acid-base chemistry because of the large uncertainties in historical deposition and in the response of weathering to increased strong mineral acids. The model reconstructions suggested that Lakes Clara and Vandercook had acidified by approximately 10-15 $\mu \mathrm{eq} \mathrm{\textrm {L } ^ { - 1 }}$ of ANC. The modelprojected acidification of McNearney Lake by $60 \mu \mathrm{eq} \mathrm{\textrm {L } ^ { - 1 }}$ was inconsistent with 

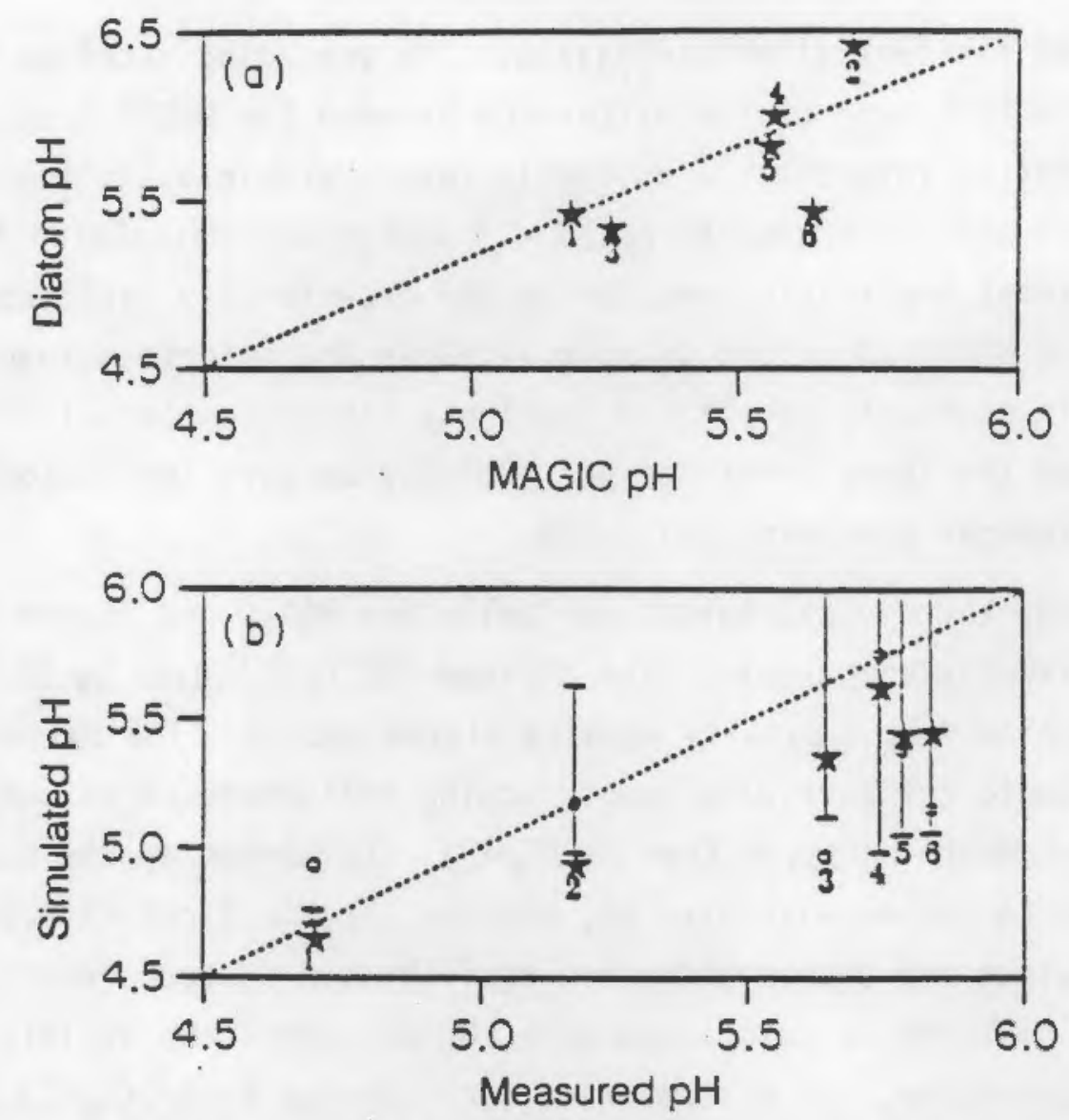

FIGURE 3.20. Comparisons of (A) Diatom Inferences and MAGIC Model Hindcasts of Pre-industrial (ca. 1850) Lakewater $\mathrm{pH}$ at Round Loch of Glenhead (1), Loch Chon (2), Loch Dubh (3), Loch Tinker (4), Loch Doilet (5), and Loch Uaine (6) in Scotland and (B) Simulated Present-day $\mathrm{pH}$ from Diatom (o) and MAGIC (*) Versus Measured pH. Solid bars represent the range of present-day measured $\mathrm{pH}$ values at each site. (Source: Jenkins et al. 1990)

paleolimnological data that suggest this lake (current ANC $=-38 \mu \mathrm{eq} \mathrm{L}^{-1}$ ) has been acidic for at least the last 4000 years (Cook et al. in press). The Trickle-Down model did not account for Al, which is present in high concentrations $\left(248 \mu \mathrm{g}^{-1}\right)$ in McNearney Lake. This may account, at least in part, for the discrepancy.

Thus, earlier studies that compared process-based model and paleolimnological estimates of historical acidification generally showed good agreement, primarily for comparisons between MAGIC and paleolimnology for lakes that have 
experienced substantial acidification. The preceding sections of this report demonstrate that much of the difference between the MAGIC hindcast results and Diatom model in inferences are readily interpretable as follows. First, the MAGIC model was calibrated to $\operatorname{ANC}\left(C_{B}-C_{A}\right)$ and $\mathrm{pH}$ was calculated from the ANC output without explicitly considering the organic-acid influence on $\mathrm{pH}$. As a result, the MAGIC pH output is more variable and uncertain than is the ANC output. In contrast, the Diatom model was independently calibrated to $\mathrm{pH}$ and ANC but had the lower error for $\mathrm{pH}$, probably because the Diatom $\mathrm{pH}$ response has the stronger physiological basis.

Second, the typical output variables for MAGIC and Diatom reconstructions are not directly comparable. The defined ANC $\left(C_{B}-C_{A}\right)$ used by MAGIC differs from titration $\mathrm{ANC}_{\mathrm{g}}$ typically used in Diatom models. The differences in output are due to the partially counteracting influences of $A l$ and organic acids on $A_{N C}$ and their omission from $A N C\left(C_{B}-C_{A}\right)$. Furthermore, the Diatom model was calibrated to air-equilibrated $\mathrm{pH}$, whereas the MAGIC output was derived from the ANC output and approximates non-equilibrated pH measurements. To eliminate the differences associated with the different ANC definitions used in the two approaches, the diatoms were recalibrated to $\operatorname{ANC}\left(C_{B}-C_{A}\right)$. The $\mathrm{pH}$ differences should be insignificant for lakes that have $\mathrm{pH}$ values less than about 5.5, but they become increasingly important for high-pH lakes. The Diatom inferences should yield higher $\mathrm{pH}$ for these lakes because of $\mathrm{CO}_{2}$ degassing effects on $\mathrm{pH}$.

Third, results may have been biased for the MAGIC simulations calibrated to the Northeast region of the United States, for a subregion such as the Adirondacks, by the extent to which the subregion differs from the Northeast in important model-input parameters. Subregional reaggregation of physical and chemical soils data and recalibration of MAGIC to Adirondack lake water chemistry resulted in better agreement between MAGIC-predicted and observed current lakewater chemistry. The most significant subregional differences appeared to be the $\mathrm{pCO}_{2}$ of lakewater (and consequent $\mathrm{pH}$ effects) and in-lake sulfur uptake. Results of the recalibration to the Adirondack subregion suggested that Adirondack lakes had less sulfur retention and higher $\mathrm{PCO}_{2}$ values than the Northeast as a whole. Such differences seem reasonable in view of 
the lakes' generally high elevations, their short water-residence times, and the headwater location of many of the lakes.

Fourth, the use of MAGIC, or any process-based model, for hindcasting requires assumptions regarding the historical deposition of all major ions. Differences in results between Scenario $\# 1$ and Scenario $\# 2$ illustrate that MAGIC estimates of pre-industrial lakewater chemistry are sensitive to the estimated historical sulfur deposition. The use of the Husar et al. (in press) historical deposition pattern is unlikely to result in major bias in the results for most Adirondack lakes, because of the general agreement that pre-industrial lakewater $\mathrm{SO}_{4}^{2-}$ concentration was likely in the range of 10-20 $\mu$ eq $L^{-1}$, but not zero.

In addition, other issues (e.g., seasonal sampling differences, watershed disturbance, and organic acid influence on pre-industrial lakewater chemistry) could potentially bias results of the comparison between Diatom and MAGIC results. Although the PIRLA data were calibrated to summer chemistry data, whereas the MAGIC data were calibrated to fall index chemistry, these differences apparently had little effect on the comparison. Watershed disturbance should, in general, have increased current lakewater ANC and $\mathrm{pH}$. Accordingly, of the eight samples with MAGIC-estimated $\operatorname{ANC}\left(C_{B}-C_{A}\right)>80 \mu e q L^{-1}$, six are rated as disturbed or moderately disturbed. Analyses of limited land-use data did not support the contention, however, that such an effect had introduced substantial bias into this model comparison.

Organic acids may have exerted greater influence on lakewater pH during pre-industrial times than they do currently. There are two principal reasons why organic-acid effects may have declined in response to acidic deposition:

1. DOC and organic acid anion concentrations in soil solutions and surface water may have decreased in response to acidic deposition as a result of increased organic-acid protonation and increased concentrations of $\mathrm{Fe}$ and $\mathrm{Al}$ (Almer et al. 1974; Krug and Frink 1983; Davis, Anderson, and Berge 1985; Marmorek et al. 1988).

2. Acidic deposition has caused an increase in base cation concentrations in lakewater. The lower $\left[C_{\beta}\right]$ during pre-industrial times would have resulted in a larger pH effect from a given quantity and quality of organic acids. 
Both issues described above are likely to exert some influence on the evaluation of change in $\mathrm{pH}$ or $\mathrm{ANC}_{\mathrm{G}}$, but data are lacking with which to quantify the effect. Diatom-inferred changes in DOC for the Adirondack lakes (Kingston and Birks 1990; B. F. Cumming and J. C. Kingston, personal communication) suggest, however, that the DOC changes have generally been small (less than the standard error of the inference equation, $55 \mu \mathrm{M}$ or $\approx 0.6 \mathrm{mg} \mathrm{L}^{-1} \mathrm{DOC}$ ) (Table 3.3). Although organic effects on $A_{N C}$ can be substantial (Sullivan et al. 1989), such effects should be minimal on $A N C\left(C_{B}-C_{A}\right)$, because such a definition excludes organic anions. Data are lacking with which to quantify the extent to which the influence of organic acids on pre-industrial lakewater chemistry may bias the comparison between Diatom-inferred and MAGIC-simulated pre-industrial $\mathrm{pH}$. Analyses presented in the Appendix suggest, however, that failure to include organic acids in the MAGIC simulation presented in this study may have substantially biased the $\mathrm{pH}$ comparison results.

The most reasonable comparison available between the MAGIC and paleolimnological hindcasts includes MAGIC Scenario \#4 (based on the subregional reaggregation and recalibration) and the paleolimnological inferences of ANC defined as $\operatorname{ANC}\left(C_{B}-C_{A}\right)$. This comparison removed the biases associated with the ANC definition used and the regional (rather than subregional) nature of the other MAGIC scenarios. Results of this comparison showed good agreement for the estimates of current chemistry (Figure 3.21) but substantial differences between the MAGIC and paleolimnological estimates of pre-industrial chemistry (Figure 3.22). The MAGIC model estimates of pre-1850 pH and ANC were generally higher than the Diatom estimates. MAGIC results therefore imply that the lakewater acid-base status had been more responsive to historical increases in acidic deposition (Figure 3.23). The extent to which the model estimates "agree" or "disagree" depends largely on one's perspectives and expectations. A decade ago, most scientists believed that $60-100 \%$ of the atmospheric sulfate input caused a stoichiometric decrease in ANC (e.g., Henriksen 1979, 1980; Wright 1983). Compared to these earlier estimates, the Diatom and MAGIC hindcast estimates are in relatively good agreement, and imply that the above percentage has been $0-50 \%$. Nevertheless, the MAGIC estimates of historical 
TABLE 3.3. Measured and Diatom-inferred Dissolved Organic Carbon Concentrations for Lakes Included in the Diatom/MAGIC Comparison

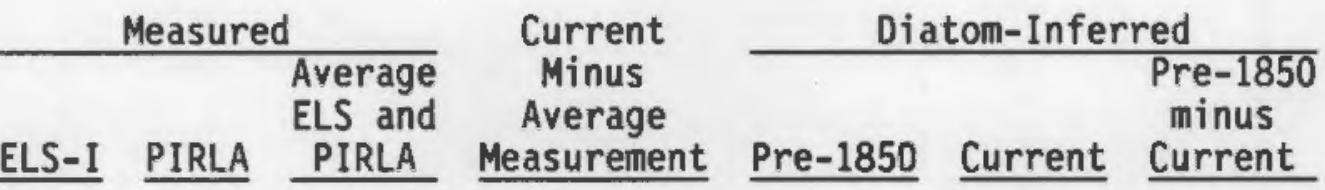

$\begin{array}{lrrrrrrr}1 A 1-003 & 131 & 278 & 205 & -47 & 331 & 158 & 173 \\ 1 A 1-012 & 213 & 204 & 209 & 22 & 251 & 230 & 21 \\ \text { 1A1-014 } & 182 & 182 & 182 & 81 & 236 & 263 & -27 \\ \text { 1A1-017 } & 291 & 354 & 323 & -118 & 263 & 205 & 58 \\ \text { 1A1-020 } & 347 & 347 & 347 & 51 & 311 & 398 & -87 \\ \text { 1A1-028 } & 327 & 305 & 316 & -74 & 222 & 242 & -20 \\ \text { 1A1-029 } & 497 & 538 & 518 & 50 & 434 & 567 & -133 \\ \text { 1A1-033 } & 317 & 312 & 315 & 5 & 334 & 319 & 15 \\ \text { 1A1-039 } & 56 & 101 & 79 & 99 & 176 & 177 & -1 \\ \text { 1A1-046 } & 425 & 425 & 425 & -112 & 264 & 313 & -49 \\ \text { 1A1-049 } & 75 & 199 & 137 & 94 & 261 & 231 & 30 \\ \text { 1A1-057 } & 427 & 498 & 463 & -55 & 349 & 408 & -59 \\ \text { 1A1-061 } & 486 & 531 & 509 & -10 & 350 & 499 & -149 \\ \text { 1A1-064 } & 223 & 212 & 218 & 74 & 215 & 291 & -76 \\ \text { 1A1-066 } & 148 & 155 & 152 & 192 & 325 & 343 & -18 \\ \text { 1A1-073 } & 176 & 278 & 227 & -8 & 274 & 219 & 55 \\ \text { 1A2-002 } & 147 & 143 & 145 & -27 & 198 & 118 & 80 \\ \text { 1A2-006 } & 382 & 339 & 361 & -98 & 292 & 263 & 29 \\ \text { 1A2-037 } & 463 & 463 & 463 & -37 & 410 & 426 & -16 \\ \text { 1A2-041 } & 687 & 548 & 618 & -245 & 271 & 373 & -102 \\ \text { 1A2-042 } & 409 & 399 & 404 & -3 & 328 & 401 & -73 \\ \text { 1A2-045 } & 173 & 170 & 172 & 51 & 240 & 222 & 18 \\ \text { 1A2-046 } & 161 & 161 & 161 & -26 & 46 & 135 & -89 \\ \text { 1A2-048 } & 446 & 446 & 446 & -52 & 378 & 394 & -16 \\ \text { 1A2-052 } & 394 & 415 & 405 & -55 & 360 & 350 & 10 \\ \text { 1A2-054 } & 410 & 400 & 405 & -105 & 296 & 300 & -4 \\ \text { 1A3-001 } & 360 & 354 & 357 & -116 & 211 & 241 & -30 \\ \text { 1A3-040 } & 212 & 205 & 209 & -5 & 199 & 204 & -5 \\ \text { 1A3-042 } & 427 & 346 & 387 & 21 & 410 & 407 & 3 \\ \text { 1A3-043 } & 579 & 537 & 558 & -149 & 387 & 409 & -22 \\ \text { 1A3-046 } & 234 & 247 & 241 & 34 & 222 & 274 & -52 \\ \text { 1A3-048 } & 389 & 345 & 367 & -34 & 314 & 333 & -19 \\ \text { 1A3-065 } & 139 & 143 & 141 & 84 & 273 & 225 & 48\end{array}$

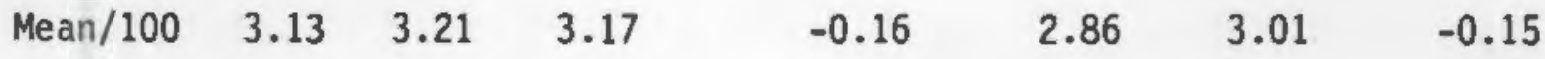



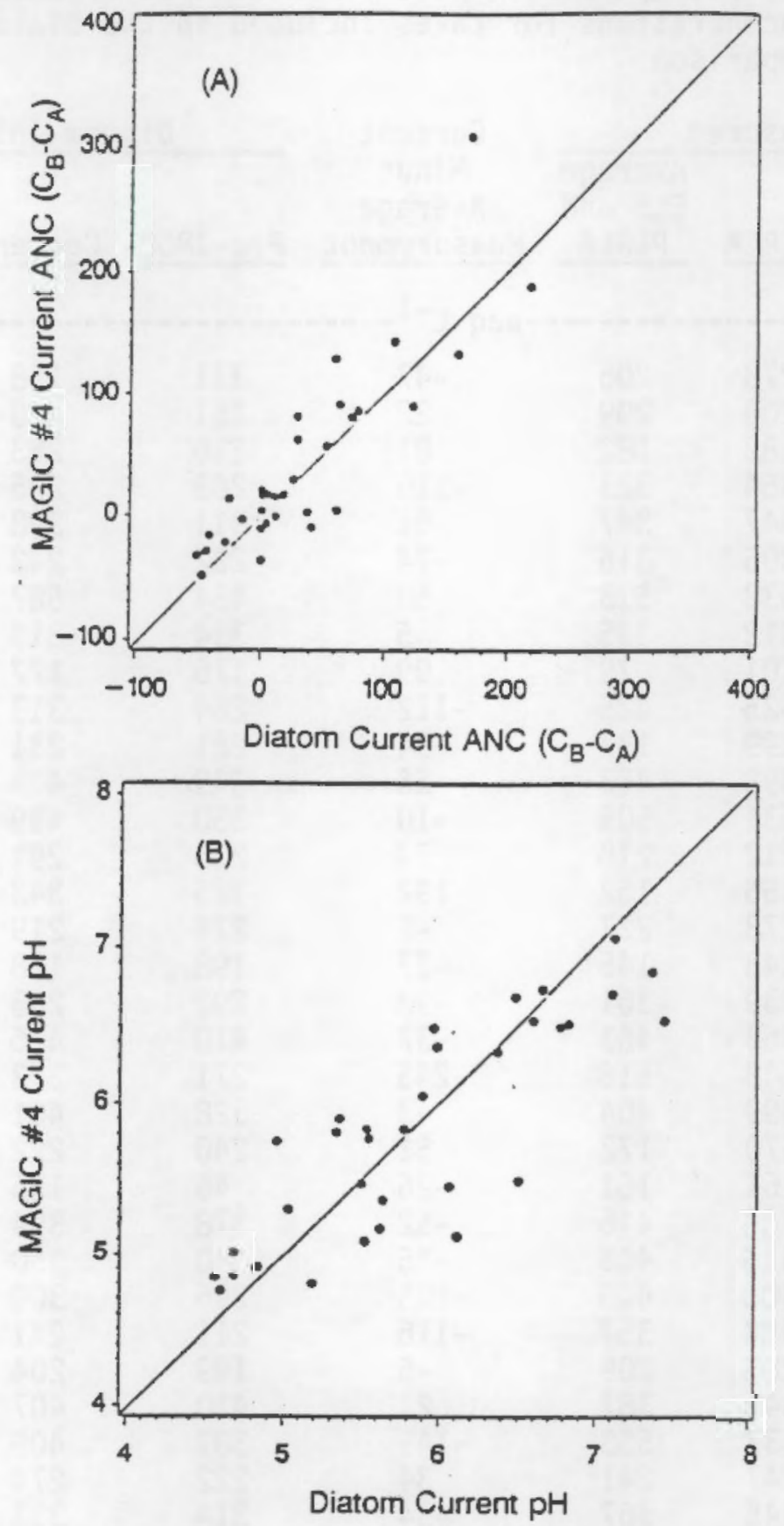

FIGURE 3.21. Comparison Plot of (A) Current ANC Estimates Between the MAGIC Scenario \#4 Simulations of ANC $\left(C_{B}-C_{A}\right)$ and the Diatom Inferences of $\operatorname{ANC}\left(C_{B}-C_{A}\right)$ and $(B)$ Current $\mathrm{pH}$ Estimates Between the MAGIC Scenario \#4 Simulations and Diatom Inferences 

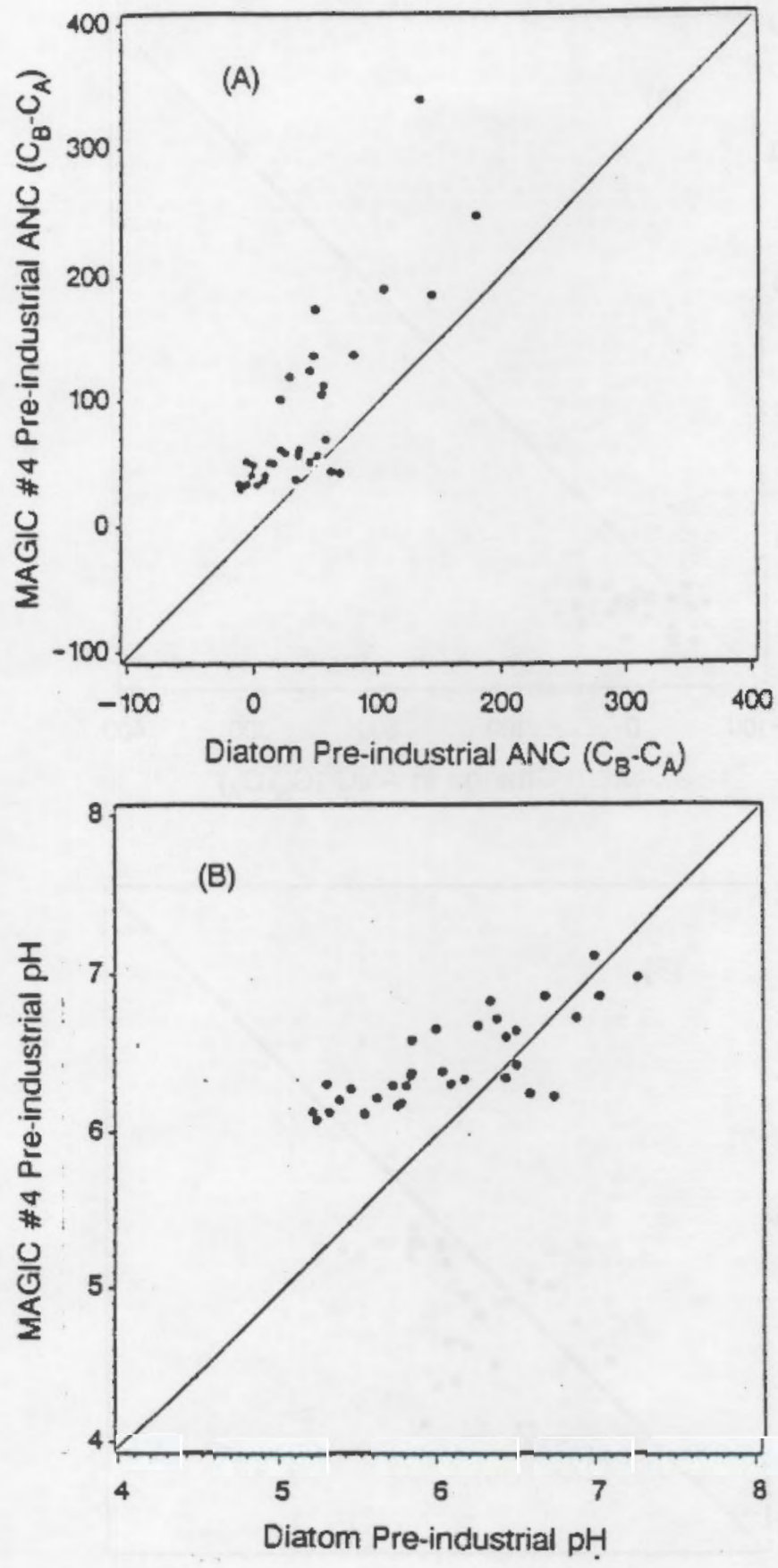

FIGURE 3.22. Comparison Plot of (A) Pre-industrial ANC Estimates Between the MAGIC Scenario \#4 Simulations of ANC $\left(C_{B}-C_{A}\right)$ and the Diatom Inferences of ANC $\left(C_{B}-C_{A}\right)$ and (B) Comparison Plot of Pre-industrial pH Estimates Between the MAGIC Scenario \#4 Simulations and Diatom Inferences 

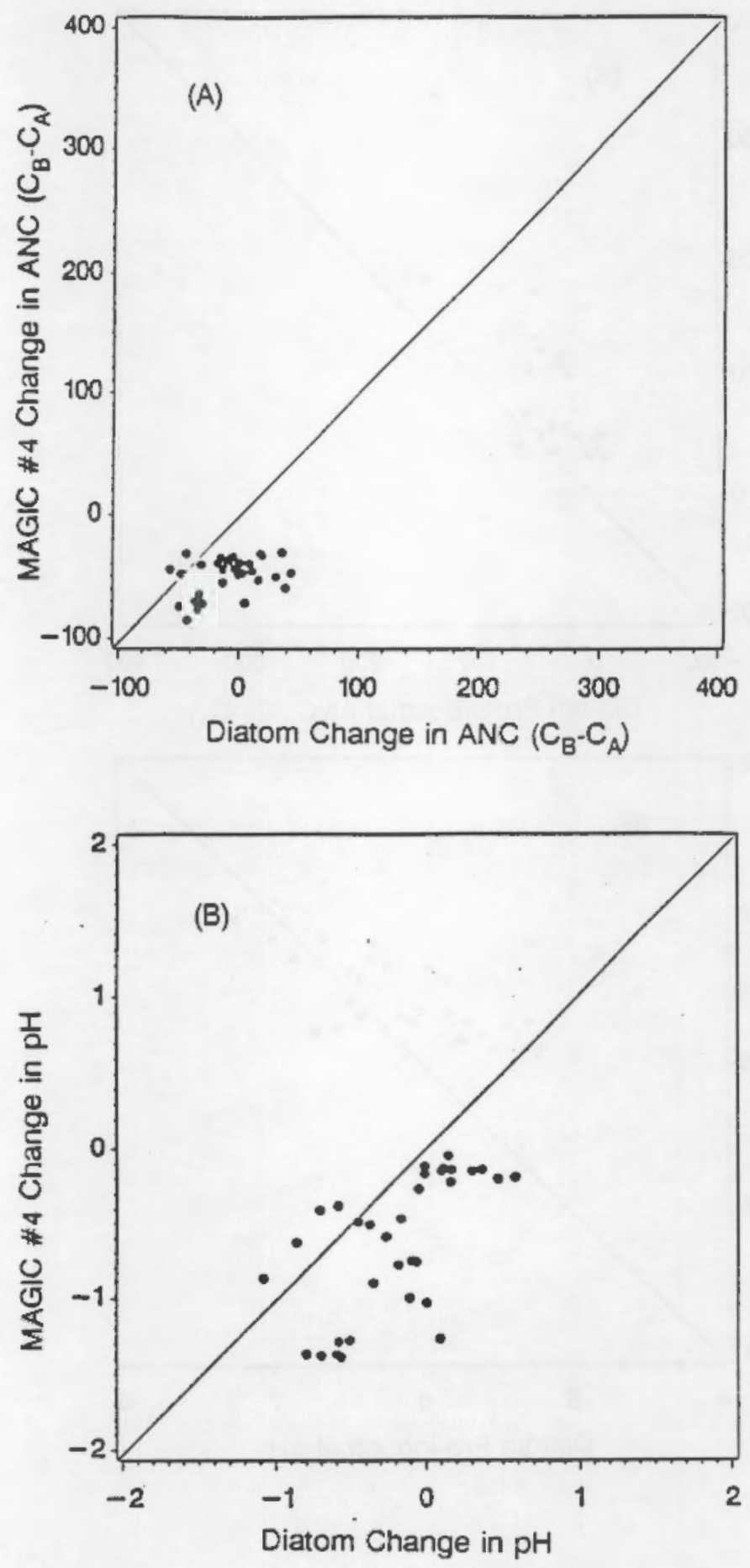

FIGURE 3.23. Estimates of Change From Pre-industrial Time to the Present Using the MAGIC Model Scenario \#4 Simulations versus Diatom Inferences of Change in (A) $\operatorname{ANC}\left(C_{B}-C_{A}\right)$ and $(\mathrm{B}) \mathrm{pH}$ 
acidification presented here imply that the acidification since pre-industrial times has been substantially greater than the acidification inferred from the Diatom model. 



\subsection{CONCLUSIONS}

Results of these analyses indicate that differences in ANC definition and deposition assumption between a Diatom model and MAGIC, a process-based watershed model, confound a comparison of estimates of historical acidification made with these models. Nevertheless, the comparisons made suggest that there are both similarities and differences between the two hindcast approaches, as follows:

\section{Similarities}

- Both approaches indicate acidification of low-ANC lakes in the Adirondacks since pre-industrial times

- Both approaches suggest that lake acidification has been of lesser magnitude than was generally believed prior to NAPAP and that neutralization of acidic inputs (e.g., via base-cation release) has been substantial

\section{Differences}

- Diatom paleolimnological estimates suggest that lake acidification has been restricted to low-ANC $\left(<50 \mu\right.$ eq $\left.L^{-1}\right)$ lakes, whereas MAGIC infers acidification of higher-ANC lakes as well

- Inferred historical changes in pH and ANC are greater using MAGIC than using diatom paleolimnology. 
$\bullet$
$\bullet$ 


\subsection{REFERENCES}

Almer, B., W. Dickson, C. Ekstrom, E. Hórnstrom, and U. Miller. 1974. "Effects of Acidification on Swedish Lakes." Ambio 3:30-36.

Altshuller, A. P., and R. A. Linthurst, eds, 1984. The Acidic Deposition Phenomenon and its Effects: Critical Assessment Review Papers.

EPA-600/8-83-016-BF, Vol. 2, U.S. Environmental Protection Agency, Washington, 0.C.

Arzet, K., D. Krause-Dellin, and C. Steinberg. 1986. "Acidification of Four Lakes in the Federal Republic of Germany as Reflected by Diatom Assemblages, Cladoceran Remains, and Sediment Chemistry." In Diatoms and Lake Acidity, eds. J. P. Smol, R. H. Battarbee, R. B. Davis, and J. Meriläinen, Pp. 227250. Dr. W. Junk, Oordrecht, The Netherlands.

Ashbury, C. E., M. D. Mattson, F. A. Vertucci, and G. E. Likens. 1990. "Coment on "Acidification of Adirondack Lakes." Environ. Sci. Technol. $24: 387-390$.

Baker, L. A., and P. L. Brezonik. 1988. "Dynamic Model of In-Lake Alkalinity Generation." Water Resour. Res, 24:65-74.

Baker, L. A., P. L. Brezonik, and C. D. Pollman. 1986. "Model of Internal Alkalinity Generation in Softwater Lakes: Sulfate Component." Woter Air Soil Pollut. 31:89-94.

Baker, L. A., C. D. Pollman, and J. M. Eilers. 1988. "Mechanisms of Alkalinity Regulation in Softwater Florida Lakes." Woter Resour. Res. 24:1069-1082.

Bard, Y. 1974. Nonlinear Parometer Estimotion. Academic Press, New York.

Battarbee, R. W. 1984. "Diatom Analysis and the Acidification of Lakes." Phil. Trans. R. Sac. Land. B. 305:451-477.

Beven, K. J., and M. J. Kirkby, 1979. "A Physically Based, Variable Contributing Area Model of Basin Hydrology." Hydro. Sci. Bull. 24:43-69.

Birks, H. J. B., J. M. Line, S. Juggins, A. C. Stevenson, and C. J. F. ter Braak. 1990. "Diatons and pH Reconstruction." Phil. Trons. R. Soc. Lond. B. $327: 263-278$.

Brakke, D. F., A. Henriksen, and S. A. Norton. 1989. "Estimated Background Concentrations of Sulfate in Dilute Lakes." Woter Resour. Bull. 25:247-253.

Brezonik, P. L., L. A. Baker, and T. E. Perry. 1987. "Mechanisms of Alkalinity Generation in Acid-Sensitive Softwater Lakes." In Sources and Fates of Aquotic Pollutonts, Adv. Chem. Ser. 216, Eds. R. Hites and S. J. Eisenreich, pp. 229-262. American Chemical Society, Washington, D.C. 
Brook, G. A., M. E. Polkoff, and E. 0. Box. 1983. "A World Model of Carbon Dioxide." Earth Surf. Process, and Landforms 8:79-88.

Charles, D. F. 1984. "Recent pH History of Big Moose Lake (Adirondack Mountains, New York, USA) Inferred from Sediment Diatom Assemblages." Verh.

Internat. Verein. Limnol. 22:559-566.

Charles, D. F. 1985. "Relationships Between Surface Sediment Diatom Assernblages and Lakewater Characteristics in Adirondack Lakes." Ecology $66: 994-1011$.

Charles, D. F. 1987. "Diatom Counts of Adirondack Lake Surface Sediment Samples." PIRLA Unpublished Report Series, Report no. 12, Department of Biology, Indiana University, Bloomington, Indiana.

Charles, D. F., and S. A. Norton. 1986. "Paleolimnological Evidence for Trends in Atmospheric Deposition of Acids and Metals." In Acid Deposition: Long-term Trends, pp. 335-435. Committee on Monitoring and Assessment of Trends in Acid Deposition, National Academy Press, Washington, D.C.

Charles, D. F., and J. P. Smol. 1988. "New Methods for Using Diatoms and Chrysophytes to Infer Past pH of Low-Alkalinity Lakes." Limnol. Oceonogr. $33: 1451-1462$.

Charles, D. F., and D. R. Whitehead. 1986a. Paleoecological Investigation of Recent Lake Acidification (PIRLA): Methods and Project Description. EPRI EN-4906, Electric Power Research Institute, Palo Alto, California.

Charles, D. F., and D. R. Whitehead. 1986b. "The PIRLA Project: PaleoecoIogical Investigations of Recent Lake Acidification." Hydrobiologia $143: 13-20$.

Charles, D. F., D. R. Whitehead, D. S. Anderson, R. Bienert, X. E. Camburn, R. B. Cook, T. L. Crisman, R. B. Davis, B. D. Fry, R. A. Hites, J. S. Kahl, J. C. Kingston, R. G. Kreis, Jr., M. J. Whiting, and R. J. Wise. 1986. "The PIRLA Project (Paleoecological Investigation of Recent Lake Acidification): Preliminary Results for the Adirondacks, New England, N. Great Lake States, and N. Florida." Water Air Soil Pollut. 30:355-365.

Charles, D. F., D. R. Whitehead, D. R. Engstrom, B. D. Fry, R. A. Hites, S. A. Norton, J. S. Owen, L. A. Roll, S. C. Schindier, J. P. Smol, A. J. Uutala, J. R. White, and R. J. Wise. 1987. "Paleolimnological Evidence for Recent Acidification of Big Moose Lake, Adirondack Mountains, N.Y. (USA)." Biogeochemistry 3:267-296.

Chen, C. W., S. A. Gherini, R.J.M. Hudson, and J. D. Dean. 1983. "Model Principles and Application Procedures." Vol. 1 of The Integrated LakeWatershed Acidification Study. EPRI EA-3221, Project 1109-5, Electric Power Research Institute, Palo Alto, California. 
Chen, C. W., S. A. Gherini, R. K. Munson, L. Gomez, and C. Donkers. 1988. "Sensitivity of Meander Lake to Acid Deposition." J. Environ. Eng. $114: 1200-1216$.

Christophersen, N., H. M. Seip, and R. F. Wright. 1982. "A Model for Streamwater Chemistry at Berkenes, Norway." Woter Resour. Res. 18:977-997.

Church, M. R., C. L. Schofield, J. N. Galloway, and B. J. Cosby. 1984. "Method of Measuring Alkalinity." Vol. 3 of The Integrated Lake-watershed Acidification Study. EPRI EA-3221, Project 1109-5, Electric Power Research Institute, Palo Alto, California.

Church, M. R., K. H. Thorton, P. H. Shaffer, D. L. Stevens, B. P. Rochelle, R. G. Holdren, M. G. Johnson, J. J. Lee, R. S. Turner, D. L. Cassell, D. A. Lanmers, W. G. Campbell, C. I. Liff, C. C. Brandt, L. H. Liegel, G. D. Bishop, D. C. Mortenson, and S. M. Pierson. 1989. Future Effects of Long-Term Sulfur Deposition on Surface water Chemistry in the Northeast and Southern Blue Ridge Province (Results of the Direct/Delayed Response Project). EPA 4600/3-89/061 U.S. Environmental Protection Agency, Washington, D.C.

Cook, R. B., R. G. Kreis, Jr., J. C. Kingston, K. E. Camburn, S. A. Norton, M. Mitchell, B. Fry, and L. L. Shane. 1990. "Paleolimnology of McNearney Lake: An Acidic Lake in Northern Michigan." J. Paleolimnol. 3:13-34.

Cosby, B. J., G. M. Hornberger, and R. F. Wright. 1989. "A Regional Model of Surface Water Acidification in Southern Norway: Calibration and Validation Using Survey Data." In Proceedings of the IIASA-IMGW Tosk Force Meeting on Environmental Impact Models to Assess Regional Acidificotion, ed. J. Kamari. Reidel Publishing. Dr. H. Junk, Dordrecht, The Netherlands.

Cosby, B. J., G. M. Hornberger, P. F. Ryan, and D. M. Wolock. 1989. MAGIC/ DDRP Final Report: Vol. I. Models, Colibration, Results, Uncertainty Analysis, $Q A / Q C$. Environmental Sciences Department, University of Virginia, Charlottesville, Virginia.

Cosby, B. J., G. M. Hornberger, R. F. Wright, E. B. Rastetter and J. N. Galloway. 1986. "Estimating Catchment Water Quality Response to Acid Deposition Using Mathematical Models of Soil Ion Exchange Processes." Geoderma $38: 77-95$.

Cosby, B. J., G. M. Hornberger, J. N. Galloway, and R. F. Wright. 1985a. "Time Scales of Catchment Acidification: A Quantitative Model for Estimating Freshwater Acidification." Environ. Sci. Technol. 19:1144-1149.

Cosby, B. J., R. F. Wright, G. M. Hornberger, and J. N. Galloway, $1985 b$. Modelling the Effects of Acid Deposition: Assessment of a Lumped Parameter Model of Soil Water and Streamwater Chemistry." Woter Resour. Res. 21:51-63. 
Cosby, B. J., R. F. Wright, G. M. Hornberger, and J. N. Galloway. 1985c. Modelling the Effects of Acid Deposition: Estimation of Long-Tern Water Quality Responses in a Small Forested Catchment." Water Resour. Res. $21: 1591-1601$.

Davidson, G. A. 1984. Poleolimnological Reconstruction of the Acidification History of an Experimentally Acidified Lake. Master's Thesis, University of Manitoba.

Davis, R. B., and D. S. Anderson. 1985. "Methods of pH Calibration of Sedimentary Diatom Remains for Reconstructing History of pH in Lakes." Hydrobiologia 120:69-87.

Davis, R. B., D. S. Anderson, and F. Berge. 1985. "Loss of Organic Matter, a Fundamental Process in Lake Acidification: Paleolimnological Evidence." Nature 316:436-438.

Davis, R. B., and F. Berge. 1980. "Atmospheric Deposition in Norway During the Last 300 Years as Recorded in SNSF Lake Sediments II. Diatom Stratigraphy and Inferred $\mathrm{pH} . "$ In Ecological Impoct of Acid Precipitation. Proceedings of an Internotional Conference, eds. D. Drablos and A. Tollan, pp. 270-271.

Sandefjord, Norway. SNSF Project, 0slo.

Davis, R. B., S. A. Norton, C. T. Hess, and D. F. Brakke. 1983. "Paleolimnological Reconstruction of the Effects of Atmospheric Deposition of Acids and Heavy Metals on the Chemistry and Biology of Lakes in New England and Norway." Hydrobiologia 103:113-123.

Del Prete, A., and C. Schofield. 1981. "The Utility of Diatom Analys is of Lake Sediments for Evaluating Acid Precipitation Effects on Dilute Lakes." Archiv. Hydrobiol. $91: 332-340$.

DeNicola, D. M. 1986. "The Representation of Living Diatom Communities in Deep-Water Sedimentary Diatom Assemblages in Two Maine (U.S.A.) Lakes." In Diotoms and Lake Acidity, eds. J.P. Smol et al., pp. 73-85. Dr. W. Junk, Dordrecht, The Netherlands.

Dixit, S. S. 1983. The Utility of Sedimentary Diatons as a Measure of Historical Loke pH. Master's Thesis, Brock University, Ontario.

Dixit, S. S., A. S. Dixit, and R. D. Evans. 1987, "Paleolimnological Evidence of Recent Acidification in Two Sudbury (Canada) Lakes." Sci. Totol Environ. 67:53-67.

Dixit, S. S., A. S. Dixit, and J. P. Smol. 1989a. "Acidification and Recovery of Baby Lake, Sudbury, Ontario, Canada." Presented at the Fifth International Symposium on Paleolimnology, September 1-6, 1989, Cumbria, United Kingdom. 
Dixit, S. S., A. S. Dixit, and J. P. Smol. 1989b. "Lake Acidification Recovery Can Be Monitored Using Chrysophycean Microfossils." Con. J. Fish. Aquat. Sci. 46:1309-1312.

Driscoll, C. T., and J. J. Bisogni. 1984. "Weak Acid/Base Systems in Dilute Acidified Lakes and Streams of the Adirondack Region of New York State." In Modeling of Total Acid Precipitation, ed. J. L. Schnoor, pp. 53-72. Butterworth, Boston.

Driscoll, C. T., G. E. Likens, L. O. Hedin, J. S. Eaton, and F. H. Bormann. 1989. "Changes in the Chemistry of Surface Waters." Environ. Sci. Technol. $23: 137-143$.

Driscol1, C. T., and R. M. Newton. 1985. "Chemical Characteristics of Adirondack Lakes." Environ. Sci. Technol. 19:1018-1024.

Efron, B. 1983. "Estimating the Error Rate of a Prediction Rule: Improvement on Cross-Validation." J. Amer. Stot. Assoc. 78:316-331.

Eshleman, K. N., and H. F. Hemond. 1985. "The Role of Organic Acids in the Acid-Base Status of Surface Waters at Bickford Watershed, Massachusetts." Woter Resour. Res. 21:1503-1510.

Felmy, A. R., D. C. Girvin, and E. A. Jenne. 1984. MINTEQ: A Computer Program for Calculating Aqueous Geochemical Equilibria. NTIS PB 84157148, National Technical Information Service, Springfield, Virginia.

Flower, R. J., and R. W. Battarbee. 1983. "Diatom Evidence for Recent Acidification of Two Scottish Lochs." Nature 305:130-133.

Flower, R. J., R. W. Battarbee, and P. G. Appleby. 1987. "The Recent Paleol imnology of Acid Lakes in Galloway, South-West Scotland: Diatom Analysis, $\mathrm{pH}$ Trends, and the Role of Afforestation." J. Ecol. 75:797-824.

Galloway, J. N., Z. Dianwu, X. Jiling, and G. E. Likens. 1987. "Acid Rain: China, United States, and a Remote Area." Science 236:1559-1562.

Galloway, J. N., G. E. Likens, W. C. Keene, and J. M. Miller. 1984. "The Composition of Precipitation in Remote Areas of the World." $J$. Geophys. Res. $87: 8771-8776$.

Galloway, J. N., S. A. Norton, and M. R. Church. 1983. "Freshwater Acidification from Atmospheric Deposition of Sulfuric Acid: A Conceptual Model." Environ. Sci. Technol. 17:541A-545A.

Gasse, F., and F. Tekaia. 1983. "Transfer Functions for Estimating Paleoecological Conditions (pH) from East African Diatoms." Hydrobiologio $103: 85-90$. 
Gherini, S. A., L. Mok, R. J. Hudson, G. F. Davis, C. W. Chen, and R. A. Goldstein. 1985. "The ILWAS Model: Formulation and Application." Water Air Soil Pollut. 26:425-459.

Goldstein, R. A., and S. A. Gherini, eds. 1984. "Summary of Major Results." Vol. 4 of The Integrated Lake-Watershed Acidification Study. EPRI EA-3221, Project 1109-5, Electric Power Research Institute, Palo Alto, California.

Goldstein, R. A., S. A. Gherini, C. W. Chen, L. Mok, and R.J.M. Hudson. 1984. "Integrated Lake Watershed Acidification Study (ILWAS): A Mechanistic Ecosysten Analysis." Phil. Trans. R. Soc. Land. 8 305:409-425.

Goldstein, R. A., S. A. Gherini, C. T. Driscoll, R. April, C. L. Schofield, and C. W. Chen. 1987. "Lake-Watershed Acidification in the Morth Branch of the Moose River." Biogeochemistry 3:5-20.

Gran, G. 1952. "Determination of the Equivalence Point in Potentiometric Titrations." Analyst 77:661-671.

Henriksen, A. 1979. "Regional Survey of Large Lakes in Southern Norway, Winter 1979." TN 50/79, SNSF-Project.

Henriksen, A. 1980. "Acidification of Freshwaters - A Large Scale Titration." Pp. 68-74, in Ecological Impact of Acid Precipitation, Orab1 $s$ and A. Tollan (eds), SNSF-Project, Oslo, Norway.

Hicks, B. B., R. P. Hosker, Jr., and J. D. Womack. 1986. "Comparisons of Wet and Dry Deposition Derived from the First Year of Trial Dry Deposition Monitoring." In Symposium on Acid Rain: 1. Source and Atmospheric Processes, pp. 486-490. Division of Petroleum Chemistry, American Chemical Society, New York.

Hornberger, G. M., B. J. Cosby, and J. N. Galloway. 1986. "Modeling the Effects of Acid Deposition: Uncertainty and Spatial Variability in Estimation of Long-Term Sulfate Dynamics in a Region." Wot. Resour. Res. 22:1293-1302.

Hosker, R. P., and J. D. Womack. 1986. "Simple Meteorological and Chemical Filterpak Monitoring System for Estimating Dry Deposition of Gaseous Pollutants." In Proceedings of the Fifth Annual National Symposium on Recent Advances in Pollutant Monitoring of Ambient Air and Stationary Sources. pp. 23-29. EPA/600/9-85/029, Atmospheric Turbulence and Diffusion Division, NOAA/ERL/Air Resources Laboratory, Oak Ridge, Tennessee.

Huttenen, P., and J. Meriläinen. 1986. "Diaton Response to pH and Humic Matter of the Water." In Proceedings of the Finnish-Soviet Symposium on Methods in Paleoecology and the Nordic Meeting of Diatomologists, ed. H. Simola, pp. 47-54. Karelian Institute, Joensuu, Finland. 
Jenkins, A., P. G. Whitehead, B. J. Cosby, and H. J. B. Birks. 1990. "Modelling Long Term Acidification: a Comparison With Diatom Reconstructions and the Implications for Reversibility." Phil. Trons. R. Soc. Lond. $B$. $327: 435-440$.

Jenne, E. A., L. E. Eary, L. W. Vai1, D. C. Girvin, A. M. Liebetrau, L. F. Hibler, T. B. Miley, and M. J. Monsour. 1989. An Evaluation and Analysis of Three Dynamic Wotershed Acidification Codes (MAGIC, ETD, and ILWAS).

PNL-6687, Pacific Northwest Laboratory, Richland, Washington.

Jones, V. J., and R. J. Flower. 1986. "Spatial and Temporal Variability in Periphytic Diatom Communities: Paleoecological Significance in an Acidified Lake." In Diatoms and Lake Acidity, eds. J. P. Smol et al., PP. 87-94.

Dr. W. Junk, Oordrecht, The Netherlands.

Kanciruk, P., J. M. Eilers, R. A. McCord, D. H. Landers, D. F. Brakke, and R. A. Linthurst. 1986. Data Compendium of Site Characteristics and Chemical Variables. Vol. III of Characteristics of Lakes in the Eastern United States. EPA/600/4-86/007c, U.S. Environmental Protection Agency, Washington, D.C.

Kelly, C. A., J. W. M. Rudd, R. H. Hesslein, C. T. Driscoll, S. A. Gherini, and R. E. Hecky. 1987. "Prediction of Biological Acid Neutralization in Acid-Sensitive Lakes." Biageochemistry 3:129-140.

Kingston, J. C., and H. J. B. Birks. 1990. "Dissolved Organic Carbon Reconstruction from Diatom Assemblages in PIRLA Project Lakes, North America." Phil. Trans. R. Soc. Lond. B. 327:279-288.

Kramer, J. R. 1990. "Comment on 'Acidification of Adirondack Lakes." Environ. Sci. Technol. 24:385-387.

Krug, E. C., and C. R. Frink. 1983. "Acid Rain on Acid Soil: A New Perspective." Science 221:520-525.

Lin, J. C., and J. L. Schnoor. 1986. "Acid Precipitation Model for Seepage Lakes." J. Environ. Eng. 112:677-694.

Linthurst, R. A., D. H. Landers, J. M. Eilers, D. F. Brakke, W. S. Overton, E. P. Meier, and R. E. Crowe. 1986. Population Descriptions and PhysicoChemical Relationships. Vol. 1 of Characteristics of Lakes in the Eastern United States. EPA/600/4-86/007a, U.S. Environmental Protection Agency, Washington, D.C.

Marmorek, D. R., D. P. Bernard, M. L. Jones, L. P. Rattie, and T. J. Sullivan. 1988. The Effects of Mineral Acid Deposition on Concentrations of Dissolved Orgonic Acids in Surfoce Woters. ERL-COR-500 AP, U.S. Environmental Protection Agency, Environmental Research Laboratory, Corvallis, Oregon. 
Mattigod, S. V., and G. Sposito. 1979. "Chemical Modeling of Trace Metal Equilibria in Contaminated Soil Solutions Using the Computer Program GEOCHEM." In Chemical Modeling in Aqueous Systems, ed. E. A. Jenne, pp. 837-856. Amer. Chem. Soc. Symp. Series 93.

Metcalf, R. C., and R. H. Gerlack. 1990. "Comment on 'Acidification of Adirondack Lakes." Environ. Sci. Technol.

Neal, C., P. Whitehead, and A. Jenkins. 1988. "Reversal of Acidification." Noture 334:109-110.

Oksanen, J., E. Läära, P. Huttunen, and J. Meriläinen. 1988. "Estimation of $\mathrm{pH}$ Optima and Tolerances of Diatoms in Lake Sediments by the Methods of Weighted Averaging, Least Squares, and Maximum Likelihood, and Their Use for the Prediction of Lake Acidity." J. Poleolimnol. 1:39-49.

Oliver, B. G., E. M. Thuman, and R. L. Malcolm. 1983. "The Contribution of Humic Substances to the Acidity of Colored Natural Waters." Geochim. Cosmochim. Acta 47:2031-2035.

Omernik, J. M., and C. S. Powers. 1982. Total Alkalinity of Surface Waters National Map. U.S. Environmental Protection Agency, Environmental Research Laboratory, Corvallis, Oregon.

Parkhurst, D. L., D. C. Thorstenson and L. N. Plumer. 1980. "PHREEQE - A Computer Program for Geochemical Calculations." N.S. Geol. Survey Water Res. Invest. 80-96.

Perdue, E. M., K. C. Beck, and J. H. Reuter. 1976. "Organic Complexes of Iron and Aluminum in Natural Haters." Nature 260:418-420.

Renberg, I., and T. Hellberg. 1982. "The pH History of Lakes in Southwestern Sweden, as Calculated from the Subfossil Diatom Flora of the Sediments."

Ambio $11: 30-33$.

Renberg, I., and J. E. Wallin. 1985. "The History of the Acidification of Lake Gärdsjon as Deduced from Diatoms and Sphagnum Leaves in the Sediment." In Lake Gärdsjon: An Acid Forest and Its Catchment, eds. F. Andersson and B. 01sson, Pp. 47-52. Ecological Bulletin No. 37. Publishing House of Swedish Research Councils, Stockholm.

Reuss, J. O., N. Christopherson, and H. M. Seip. 1986. "A Critique of Models for Freshwater and Soil Acidification." Water Air Soil Pollut, 30:909-930.

Reuss, J. 0., and D. W. Johnson. 1985. "Effect of Soil Processes on the Acidification of Water by Acid Deposition." J. Environ. Qual. 14:26-31.

Rochelle, B. P., and M. R. Church. 1987. "Regional Patterns of Sulfur Retention in Watersheds of the Eastern U.S." Water Air Soil Pollut. 36:61-73. 
Rochelle, B. P., M. R. Church, and M. B. David. 1987. "Sulfur Retention at Intensively Studied Sites in the U.S. and Canada." Woter Air Soil Pollut. $33: 73-83$.

Rosenbrock, H. H. 1960. "An Automatic Method for Finding the Greatest or Least Value of a Function." Computer J. 3:175-184.

Rudd, J. W. M., ed. 1987. "Acidification of the Moose River System in the Adirondack Mountains of New York State." Biogeochemistry 3:1-296.

Rudd, J. H. M., C. A. Kelly, and A. Furutani. 1986. "The Role of Sulfate Reduction in Long Term Accumulation of Organic and Inorganic Sulfur in Lake Sediments." Limnol. Oceanogr. 31:1281-1291.

Rustad, S., N. Christophersen, H. M. Seip, and D. Dillon. 1986. "Model for Streamwater Chemistry of a Tributary to Harp Lake, Ontario." Can. J. Fish. Aquot. Sci. 43:625-633.

Schecher, W. D., and C. T. Driscoll. 1988. "An Evaluation of the Equilibrium Calculations Within Acidification Models: The Effect of Uncertainty in Measured Chemical Components." Water Resour. Res. 24:533-540.

Schindler, D. H. 1988. "The Effects of Acid Rain on Freshwater Ecosystems." Science 239:149-157.

Schindler, D. H., M. A. Turner, M. P. Stainton, and G. A. Linsey. 1986. "Natural Sources of Acid Neutralizing Capacity in Low Alkalinity Lakes of the Precambrian Shield." Science 232:844-847.

Schnoor, J. L., and H. Stumn. 1985. "Acidification of Aquatic and Terrestrial Systems." In Chemical Processes in Lakes, ed. H. Stumun, pp. 311-338. Wiley, New York.

Schnoor, J. L., N. P. Nikolaidis, and G. E. Glass. 1986. "Lake Resources at Risk to Acidic Deposition in the Upper Midwest." J. Water Pollut. Control Fed. 58:139-148.

Schofield, C. L., J. N. Galloway, and G. R. Hendry, 1985. "Surface Hater Chemistry in the ILWAS Basin." Water Air Soil Pollut. 26:403-423.

Seip, H. M. 1980. "Acidification of Freshwater - Sources and Mechanisms." In Ecological Impoct of Acid Precipitation. Proceedings of an Internatianal Conference, eds. D. Drablos and A. Tollan, pp. 358-365. Sandefjord, Norway. SNSF Project, Oslo.

Seip, H. M., N. Christophersen, and T. J. Sullivan. 1989. "Episodic Variations in Streamwater Aluminum Chemistry at Birkenes, Southernmost Norway." In Environmental Chemistry and Toxicology of Aluminum, ed. T. E. Lewis, pp. 159-169. Lewis Publishers, Chelsea, Michigan. 
Shaffer, P. W. and M. R. Church. 1989. "Terrestrial and In-Lake Contributions to Alkalinity Budgets of Drainage Lakes: An Assessment of Regional Differences." Con. J. Fish. Aquat. Sci. 46:509-515.

Smith, G. B., F. Newhal1, L. H. Robinson, and D. Swanson, 1964. "SoilTemperature Regimes, Their Characteristics and Predictability." Doc. \#SCS-TP144, Soil Conservation Service, U.S. Department of Agriculture, Washington, D.C.

Smith, R. A., E. B. Alexander, and M. G. Wolman. 1987. "Water-Quality Trends in the Nation's Rivers." Science 235:1607-1615.

Smol, J. P., D. F. Charles, and D. R. Whitehead. 1984. "Mallomonadacean (Chrysophyceae) Assemblages and Their Relationships with Limnological Characteristics in 38 Adirondack (New York) Lakes." Con. J. Bot. 62:911-923.

Smol, J. P., R. W. Battarbee, R. B. Davis, and J. Merilïinen, eds, 1986. Diatoms and Loke Acidity. Dr. W. Junk, Dordrecht. The Netherlands.

Stevenson, F. J. 1982. Humus Chemistry. Wiley, New York.

Stone, A., and H. M. Seip. 1989. "Mathematical Models and Their Role in Understanding Water Acidification: An Evaluation Using the Birkenes Model as an Example." Anbio 18:192-199.

Stumm, W., and J. J. Morgan, 1981. Aquatic Chemistry. Wiley, New York.

Stumm, W., J. J. Morgan, and J. L. Schnoor. 1983. "Saurer Regen, Eine Folgeder Storung Hydrogeochemischer Kreisläufe." Naturwissenschaften

$70: 216-223$.

Sullivan, T. J., D. F. Charles, J. P. Smol, B. F. Cumming, A. R. Selle, D. R. Thomas, J. A. Bernert, and S. S. Dixit. 1990. "Quantification of Changes in Lakewater Chemistry in Response to Acidic Deposition." Nature 345:54-58.

Sullivan, T. J., C. T. Driscoll, J. M. Eilers, and D. H. Landers. 1988. "Evaluation of the Role of Sea Salt Inputs in the Long-Term Acidification of Coastal New England Lakes." Environ. Sci. Technol. 22:185-190.

Sullivan, T. J., C. T. Driscoll, S. A. Gherini, R. K. Munson, R. B. Cook, D. F. Charles, and C. P. Yatsko. 1989. "The Influence of Organic Acid Anions and Aqueous Aluminum on Measurements of Acid Neutralizing Capacity in Surface Waters." Noture 338:408-410.

ter Braak, C. J. F. 1985. "Correspondence Analysis of Incidence and Abundance Data: Properties in Terms of a Unimodal Response Model." Biometrics $41: 859-873$. 
ter Braak, C. J. F. 1986. "Canonical Correspondence Analysis: A New Eigenvector Technique for Multivariate Direct Gradient Analysis." Ecology $67: 1167-1179$.

ter Braak, C. J. F. 1987. "The Analys is of Vegetation-Environment Relationships by Canonical Correspondence Analysis." Vegetatio 69:79-87.

ter Braak, C. J. F. 1988. "Partial Canonical Correspondence Analysis." In Class ification and Related Methods of Data Analysis, ed. H.H. Bock, pp. 551-558. North-Holland, Ansterdam.

ter Braak, C. J. F., and L. G. Barendregt. 1986. "Weighted Averaging of Species Indicator Values: Its Efficiency in Environmental Calibration." Mathemat. Biosci. 78:57-72.

ter Braak, C. J. F., and N. J. M. Gremmen. 1987. "Ecological Amplitudes of Plant Species and the Internal Consistency of Ellenberg's Indicator Values for Moisture." Vegetatio 69:79-87.

ter Braak, C. J. F., and C. W. N. Looman. 1986. "Weighted Averaging, Logistic Regression and the Gaussian Response Model." Vegetatio 65:3-11.

ter Braak, C. J. F., and I. C. Prentice. 1988. "The Theory of Gradient Analysis." Advan. Ecolog. Res. 18:271-317.

ter Braak, C. J. F., and H. van Dam. 1989. "Inferring pH from Diatoms: A Comparison of Old and New Calibration Methods." Hydrobiologia 178:209-223.

Tolonen, K., and T. Jaakkola. 1983. "History of Lake Acidification and Air Pollution Studied on Sediments in South Finland." Annales Botanici Fennici 20:57-78.

Truesdell, A. H., and B. F. Jones. 1974. "WATEQ, A Computer Program for Calculating Chemical Equilibria of Natural Haters." Jour. Res. U.S. Geol. Survey $2: 233-248$.

van Dam, H., B. van Geel, A. van der Hijk, J. F. M. Geelen, R. van der Heijden, and M. D. Dickman. 1988. "Palaeolimnological and Documented Evidence for Alkalization and Acidification of Two Moorland Pools (The Netherlands)." Rev. Paleobot. Palynol. 55:273-316.

Wright, R. F. 1983. "Predicting Acidification of North American Lakes." Acid Rain Research Report 4/83, Norwegian Institute for Hater Research, 0slo, Norway.

Wright, R. F., E. T. Gjessing, N. Christophersen, E. Lotse, H. M. Seip, A. Semb, B. Sletaune, R. Storhaug, and K. Hedum. 1986. "Project Rain: Changing Acid Deposition to Whole Catchments. The First Year of Treatment." Water Air Soil Pollut. 30:47-64. 
Wright, R. F., E. Lotse, and A. Semb, 1988. "Reversibility of Acidification Shown by Whole-Catchment Experiments." Noture 334:670-675. 


\section{APPENDIX}

ORGANIC ACID INFLUENCE 
APPENDIX

ORGANIC ACID INFLUENCE

In addition to the evaluation and quantification of differences between paleolimnological and MAGIC model estimates of current and pre-industrial chemisty, an important objective of the research described in this report was to explore alternative explanations for observed discrepancies between the two models. The lack of adequate organic acid representation in the MAGIC hindcast simulations may have been an important factor contributing to the observed discrepancy, particularly for pH. Organic acids often exert a large influence on surface water acid-base chemisty, particularly in waters having low jonic strength. To investigate the potential role of organic acids in influencing the comparison results, a MAGIC model scenario was conducted that included a "reasonable" organic acid representation. Results of the additional scenario are presented in this appendix, and constitute an approximation of the potential importance of organic acids as an influence on the comparison results discussed in the body of the report.

Although organic substances have been well studied in recent years (e.g., Thumnan 1985; Aiken et al. 1985), quantitative evaluation of organic acidity is difficult. A direct measurement technique is not available for organic acid anions, and the influence of organic matter on the PH and ANC of natural water is an area of considerable uncertainty. Dissolved organic carbon (DOC) is commonly measured as a surrogate for organic acidity, and it includes a large variety of organic compounds that differ in molecular weight and degree of dissociation. DOC contains many types of functional groups, including carboxylic acids, phenols, thiols, and alcohols (Perdue 1985). It is difficult to characterize the complex and heterogeneous mixture of organic solutes present in natural waters. The contribution of $\mathrm{H}^{*}$ from organic matter to surface waters depends on the number and type of functional groups present, and the degree to which those functional groups dissociate.

It is well established that organic acids make significant contributions to surface water acidity in some instances. For example, bogs and dystrophic lakes containing high concentrations of organic matter can have $\mathrm{pH}$ values 
below 4.0 (0liver et al. 1983; Linthurst et a]. 1986). Most organic acids in surface waters are relatively strong acids. Average $\mathrm{pK}$ values have been estimated to be near 4.0 (Perdue, Reuter, and Parrish 1984; Perdue 1985; Kramer and Davies 1988). Even low to moderate concentrations of these organic acids can potentially depress dilute surface water $\mathrm{pH}$ below 5.0. An average surface water DOC value of $5 \mathrm{mg} \mathrm{L}^{-1}(400 \mathrm{\mu M})$ would exhibit a $\mathrm{pH}$ level of 4.4 to 4.5 in the absence of inorganic buffering (Kramer et al. 1989). Calculations using ELS titration data by Kramer and Davies (1988) suggested that $4 \mathrm{mg} \mathrm{L-1}(300 \mu \mathrm{M})$ of an "average organic cocktail" could reduce pH below 5.0 in systems with bicarbonate alkalinity of 50-100 $\mu$ eq $\mathrm{L}^{-1}$. Kramer et al. (1989) also emphasized that, because of the low pk, values of many surface water organic acids, small concentrations of DOC can lower pH below 5.0 in poorly buffered solutions. An important consideration is the ionic strength of the waters in the absence of this DOC contribution. Waters with little inorganic buffering will exhibit a greater $\mathrm{pH}$ depression in response to a given concentration of DOC. Naturally occurring organic acids have a major effect on $\mathrm{pH}$ at ANC values near zero, because of limited buffering capacity in this range of ANC. In negative ANC solutions, however, organic acids are less likely to donate protons because of the high concentration of $\mathrm{H}^{+}$in solution. Therefore, organic acids have a smaller pH effect in highly acidic waters.

An evaluation of past changes in acid-base status in response to acidic deposition must consider not only current organic acidity, but also the extent to which organic acidity may have changed in response to acidic deposition. It has been hypothesized that surface water acidification from acidic deposition has been accompanied by a loss of DOC and color (Almer et al. 1974; Krug and Frink 1983; Davis et al. 1985). Data with which to directly evaluate this hypothesis are generally lacking, but a variety of indirect evidence is available and has been summarized in the review of Marmorek et a1. (1988). Marmorek and coworkers evaluated data from laboratory studies, paleolimnological reconstructions, theoretical considerations, and limited field observations of temporal and spatial trends in lakewater chemisty. They concluded that there were a number of inconsistencies in the avajlable data, but most data suggested that organic acids have been lost from lake water as a consequence of acidic deposition. Hypothesized mechanisms included: 
1. Decreased mobility of organic materials from soils and wetlands because of increased $\left[\mathrm{H}^{*}\right]$.

2. Reduced microbial decomposition of organic materials,

3. Changes in dissociation and/or physical structure of humics,

4. Increased loss from solution to sediments through chelation with metals (e.g., $\mathrm{Al}, \mathrm{Fe}$ ) mobilized by increased $\left[\mathrm{H}^{*}\right]$, and subsequent precipitation of the metal-organic complex.

Of the above mechanisms, complexation of organic acids by metals (Almer et al. 1974; Lind and Hem 1975; Dickson 1978; Cronan and Aiken 1985) and pH dependent changes in dissociation of organic acids (0liver et al. 1983; Wright et al. 1988) appeared most likely to be significant. Quantitative estimates of change in DOC were not possible, but, based on the available data, Marmorek et a]. (1988) concluded that potential DOC losses of up to $3 \mathrm{mg} \mathrm{L}^{-1}$ were not unreasonable. Subsequent research has suggested, however, that decreases in DOC concentrations in surface water in response to acidic deposition have probably been much less than $3 \mathrm{mg} \mathrm{L}^{-1}$ (Wright, Lotse and Sem 1988; Kingston and Birks 1990; Hedin et al. 1990).

Kingston and Birks (1990) presented paleolimnological reconstructions of DOC for the four regional data sets in the PIRLA-I project. Species optima and tolerances along the DOC gradient were estimated using maximum likelihood and weighted averaging regression. The cumulative fit per taxon as a fraction of the taxon's total variance revealed that few taxa were consistent in terms of their explanation of the DOC gradient from region to region. DOC explained a smal1, but significant, amount of taxon variance in the Adirondacks, northern Florida, and the northern Great Lakes States, but the signal was much weaker in northern New England. Calculated species optima were not consistent among regions and the best indicators of DOC in the PIRLA data sets were not always in good agreement with those found in Norway and Canada (e.g. Davis et al. 1985; Anderson, Davis, and Berge 1986; Taylor, Duthie, and Smith 1988). The authors therefore cautioned that indicators from one region may not be applicable for other regions. Example reconstructions were provided for Big Moose Lake in the Adirondacks and Brown Lake in northern Wisconsin. The magnitude of inferred $D O C$ changes were small relative to the mean square error of the relation in each region (98 and $80 \mu \mathrm{M}$, respectively), but in each case 
DOC declined coincident with lakewater $\mathrm{pH.} \mathrm{For} \mathrm{the} \mathrm{recently} \mathrm{acidified} \mathrm{PIRLA-I}$ lakes in general, DOC also declined coincident with recent acidification. Although the magnitude of DOC change was typically small $(<100 \mu M)$, the acid-base character of the DOC may also have changed.

In addition to potential changes in DOC concentrations in response to acidic deposition, acidification or recovery can alter the charge density of organic solutes and thus influence organic contributions to acidity (e.g., Wright et al. 1988). Loss of DOC in response to acidic deposition can also cause a shift in Al species composition towards lesser complexation with organic ligands. Such a shift from organic to inorganic Al increases toxicity of the Al to aquatic biota.

Hedin et al. (1990) artificially acidified a small, moderately high-DOC (8.7 $\mathrm{mg} \mathrm{L}^{-1}$ ) stream with sulfuric acid at the Hubbard Brook Experimental Forest (HBEF) in New Hampshire. The ambient streamwater $\mathrm{PH}$ (4.4) was in the range of reported average $\mathrm{pK}$ values for organic acids, suggesting that the capacity of organic acids to buffer mineral acidity should be high. The loading rate of sulfuric acid was adjusted to achieve an increased streamwater [ $\mathrm{SO}_{4}^{2-}$ ] of $150 \mu \mathrm{eq} \mathrm{L}^{-1}$ at the downstream sampling point $108 \mathrm{~m}$ below the point of acid addition, and LiBr was added as a conservative tracer to adjust measured concentrations for dilution by soil water or inflow from small tributaries. Although streamwater $D O C$ did not change significantly, the concentration of organic anions (as calculated from the charge balance) decreased by $17 \mu \mathrm{eq} \mathrm{L}^{-1}$. Thus the overall capacity of organic anions to neutralize mineral acid inputs accounted for about $11 \%$ of the added $\mathrm{H}_{2} \mathrm{SO}_{4}$ concentration (Hedin et al. 1990).

The extent of organic anion buffering of mineral acid input should increase with increasing $D O C$. Indeed, acidic deposition exclusion experiment at the Risdalsheia catchment in southern Norway (Wright et al. 1988) resulted in slightly higher in both DOC and the degree of organic acid buffering as compared to results obtained by Hedin et al. (1990) at HBEF. The increase in organic anions at Risdalsheia accounted for about 198 of the decrease in mineral acids in a sma11 stream with DOC of about $15 \mathrm{mg} \mathrm{L}^{-1}$. As was observed at HBEF, the organic buffering was primarily due to changes in organic anion protonation, rather than changes in $D O C$ concentration. 
Even in the absence of appreciable changes from pre-industrial times to the present in either DOC or organic acid charge density, the presence of organic acids could have a significant influence on the comparison between paleolimnological and MAGIC model hindcast results. This is because acidic deposition has caused a large increase in the base cation concentrations of even the most sensitive Adirondack systems. The lower $\left[\mathrm{C}_{\mathrm{B}}\right]$ during pre-industrial times would have resulted in a larger $\mathrm{pH}$ effect from the organic acids that were present at that time because of the lower preindustrial ionic strength of the lakewater.

In order to evaluate the potential importance of organic acids on the comparison between paleolimnological and MAGIC model hindcast results for Adirondack lakes, a MAGIC model scenario was constructed that included a uniform organic acid representation in all study lakes. MAGIC scenario \#4, which included no organic representation, was modified by adding a concentration of diprotic organic acid sufficient to produce $20 \mu \mathrm{eq} \mathrm{L}^{-1}$ of organic anion charge in each lake at $\mathrm{pH}=5.0$. The diprotic acid was modeled using pK values of 4.0 and 10.0 . No attempt was made to adjust the added organic acid anions to measured lakewater DOC, and therefore results of this new scenario (MAGIC scenario $4 A$ ) should be viewed as a first approximation of the magnitude of organic effect that might be observed, given a more rigorous treatment of organic acid influence in the MAGIC model simulations. The lower pK value selected $(4.0)$ is in agreement with previous estimates (e.g., Perdue, Reuter, and Parrish 1984; Perdue 1985; Kramer and Davies 1988), and the higher value $(10.0)$ is too high to have any appreciable influence on the model results for the study lakes of interest.

Considering a diprotic organic acid, with pK values of 4.0 and 10.0 , essentially a monoprotic acid, and where total organic acid is given by HTOT:

$$
\begin{aligned}
& \text { HTOT }=\mathrm{H}_{2} A+H A^{-} \\
& H_{2} A \stackrel{K}{\Leftrightarrow} H^{-}+H^{+} \\
& \begin{aligned}
K & =\left(H A^{-}\right)\left(H^{+}\right) /\left(H_{2} A\right) \\
& =\left(H A^{-}\right)\left(H^{+}\right) /\left(H T O T-H A^{-}\right) .
\end{aligned}
\end{aligned}
$$

Given $\mathrm{pK}=4.0(\mathrm{k}=0.0001)$ and $\mathrm{pH}=5.0\left(\mathrm{H}^{*}=0.00001\right)$, and rearranging the 
equations:

$$
\begin{aligned}
\text { HTOT } & =\left(\mathrm{HA}^{-}\right) 0.00001 / 0.0001+\left(\mathrm{HA}^{-}\right) \\
& =1.1\left(\mathrm{HA}^{-}\right) .
\end{aligned}
$$

Thus, $22 \mathrm{mmol} \mathrm{L}^{-1}$ of total organic acid was added to each lake in the simulations in order to produce $20 \mu \mathrm{eq} \mathrm{L}^{-1}$ of organic anion charge at $\mathrm{pH}=5.0$.

The results of the new MAGIC scenario ( $\$ 4 A)$ are presented in Figures A.I and A.2 for current and pre-industrial acid-base chemistry, respectively. The MAGIC results for simulated current $\mathrm{pH}$ were in slightly poorer agreement with diatom $\mathrm{pH}$ estimates (Figure A.1), as compared with MAGIC scenario \#4, which did not include an organic acid representation (Figure 3.21). The change in agreement was fairly small and was likely attributable to not recalibrating the model $\mathrm{pH} / \mathrm{ANC}$ relationship with the added organic acids. The end result of a recalibration of this relationship would be to adjust the calibrated $\mathrm{CO}_{2}$ overpressure in lakewater. In the calibration procedure for scenario \#4, it was assumed that $\mathrm{CO}_{2}$ overpressure accounted for all of the discrepancy between measured and calculated $\mathrm{pH}$. This relationship was altered by the addition of organic acids in Scenario \#4A, but time and resource constraints precluded further calibration for the purposes of the research described in this appendix.

MAGIC results for simulated current $A N C\left(C_{B}-C_{A}\right)$ were not appreciably different between scenario \#4A (Figure A.1) and scenario \#4 (Figure 3.21). Inclusion of an organic acid representation in Scenario $\$ 4 A$ did not have a major effect on ANC estimates because a defined ANC was used that excludes organic anions (see Section 2.4.3).

The MAGIC results for simulated pre-industrial ANC $\left(C_{B}-C_{A}\right)$ were also similar between the MAGIC Scenarios $\# 4$ and $\# 4 A$ (Figures 3.22 and A.2), again because a defined ANC was used that excluded organic influence. Results for simulated $\mathrm{pH}$ were in much better agreement with diatom estimates for the scenario that included an organic representation (Scenario \#4A, Figure A.2) than for the otherwise similar scenario that excluded organic acids 

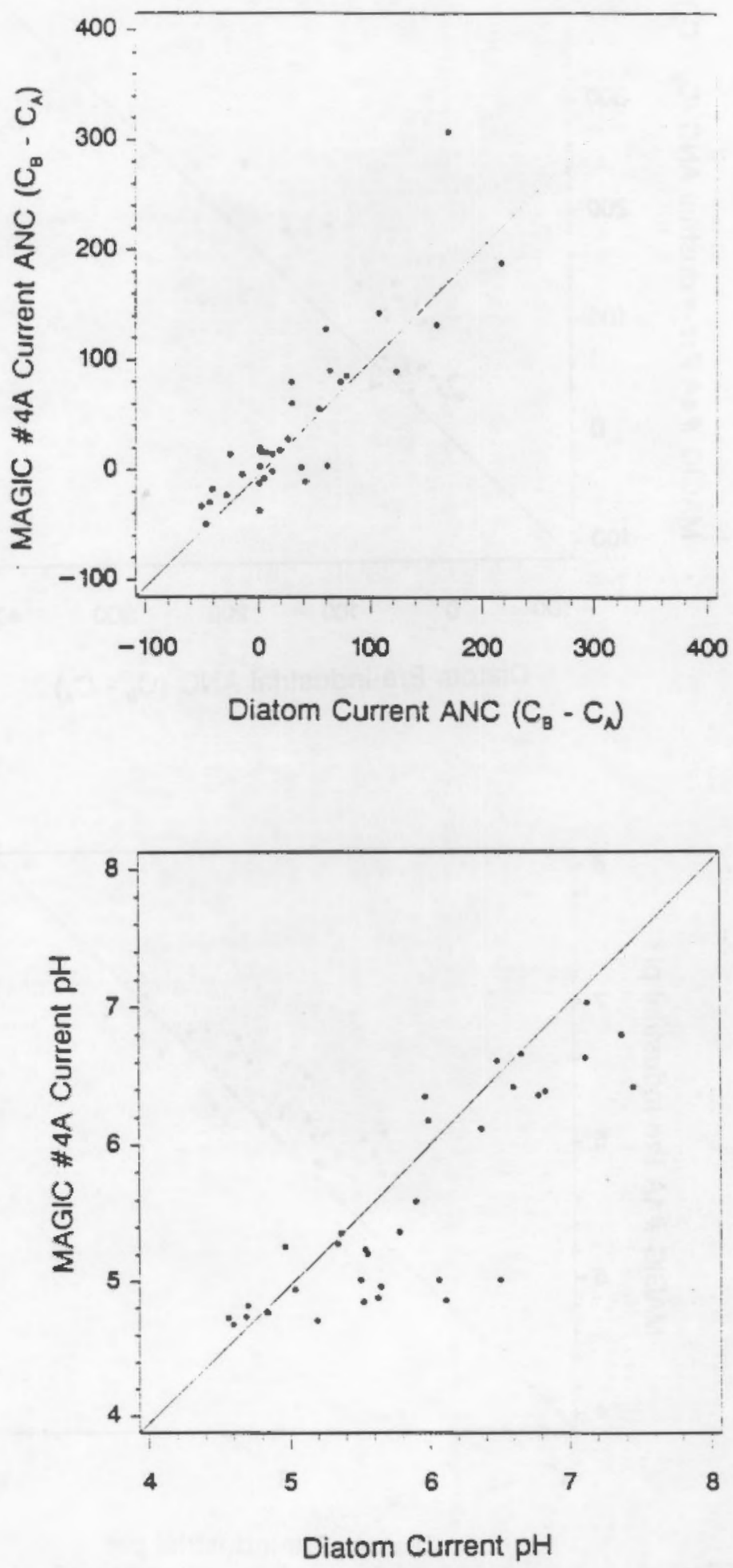

FIGURE A.1. Comparison Plot of (A) Current ANC Estimates Between the MAGIC - Scenario \#4A Simulations of ANC $\left(C_{B}-C_{A}\right)$ and the Diatom Inferences of ANC $\left(C_{B}-C_{A}\right)$ and (B) Current $\mathrm{pH}$ Estimates Between the MAGIC Scenario \#4A Simulations and Diatom Inferences 

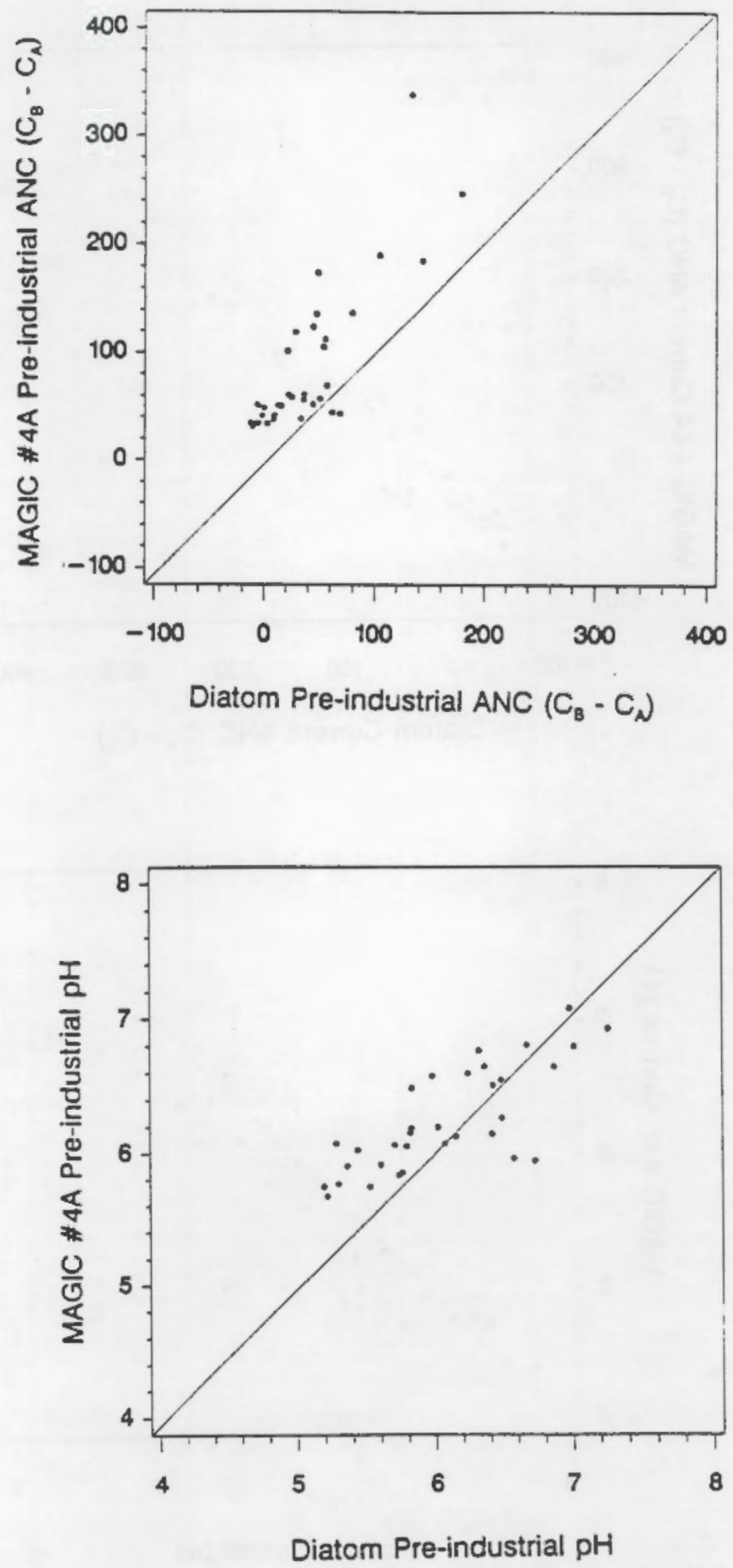

FIGURE A.2. Comparison Plot of (A) Pre-industrial ANC Estimates Between the MAGIC Scenario \#4A Simulations of ANC $\left(C_{B}-C_{A}\right)$ and the Diatom Inferences of $A N C\left(C_{B}-C_{A}\right)$ and $(B)$ Preindustrial $\mathrm{pH}$ Estimates Between the MAGIC Scenario \#4A Simulations and Diatom Inferences

A.8 
(Scenario 4, Figure 3.22). The improvement in agreement between the Diatom and MAGIC estimates of pre-industrial $\mathrm{pH}$ was evident for the low $\mathrm{pH}$ lakes $(\mathrm{pH}<6.0)$. Higher $\mathrm{pH}$ lakes had been in relatively good agreement using MAGIC Scenario 4 , and were not much affected by the inclusion of organic acids in Scenario $4 \mathrm{~A}$ (Figures 3.22 and $\mathrm{A} .2$ ).

The results of MAGIC scenario 44 illustrate that inclusion of a reasonable representation of organic acids in MAGIC can substantially improve the agreement between MAGIC-simulated and diatom-inferred lakewater $\mathrm{pH}$. Quantification of the degree of improvement is uncertain, however, because a rigorous treatment of organic acids, on an individual lake basis, was not performed. Such an analysis could be performed by incorporating a modeled organic representation for each lake, calculated using measured values of DOC and assumed or calibrated values for the charge density and pK distributions of naturally occurring organic acids.

For example, Lam et al. (1989) assumed an organic acid representation using a triprotic acid with three different dissociation constants for observed data from Moose Pit Brook and Mersey River in Mova Scotia. The objective was to determine what specific modifications were needed to calibrate the inorganic Turkey Lakes model to colored water systems having DOC values of $10-40 \mathrm{mg} \mathrm{L^{-1 }}$ and $5-15 \mathrm{mg} \mathrm{L} \mathrm{L}^{-1}$, respectively. They assumed $\mathrm{pK}_{1}=\mathrm{pH}_{1}$ for simplicity reasons, for $\mathrm{pH}$ values between 4.5 and 5.5 . Calibrated values for $\mathrm{pK}_{2}$ and $\mathrm{pK}_{3}$ were 4.8 to 5.0 and 5.0 to 5.2 , respectively for the two stream systems. Calibrated charge densities for DOC in both streams were about $4 \mu \mathrm{eq} \mathrm{mg}^{-1}$. It was found that the assumed charge density of DOC and the assumed $p K_{1}$ value were at least as important as the sulfate loading in influencing the predicted $\mathrm{pH}$. Furthermore, since the organic anions are intimately related to, and also contribute to the acidity of the water, the model results illustrated that simulated increased or decreased sulfate inputs to these two colored stream systems does not cause as large a change in simulated $\mathrm{pH}$ as in clear water systems (Lam et al. 1989).

Driscoll et al. (1990) modeled the organic acidity of lakewaters sampled by the Adirondack Lakes Survey Corporation (Kretser, Gallagher, and Nicolette 1989), using a triprotic organic acid and calibrating the three pk values. Calibrated pk values were 2.6, 5.7, and 5.9. Driscoll et al. (1990) obtained 
a good fit for Adirondack lakes between measured ANC and modeled ANC, including organic acids in the modeled ANC expression. This, or a similar, approach could be coupled to the MAGIC model to produce a more rigorous evaluation of organic influence on the comparison results of pre-industrial $\mathrm{pH}$ between the Diatom and MAGIC models. The results of MAGIC Scenario \#4A

(Figure A.2) suggest that such an approach would be an appropriate next-step in the attempt to rectify the observed discrepancies between model results.

\section{REFERENCES}

Aiken, R. R., D. M. Mcknight, R. L. Wershaw, and P. MacCarthy, eds. 1985. Humic Substances in Soil, Sediment, and Water. Wiley, New York.

Almer, B., W. Dickson, C. Ekstróm, E. Hórnstrón, and U. Miller. 1974. "Effects of Acidification on Swedish Lakes." Ambio 3:30-36.

Anderson, D. S., R. B. Davis, and F. Berge. 1986. "Relationships between Diatom Assemblages in Lake Surface Sediments and Limnological Characteristics in Southern Norway." In: Diatons and Lake Acidity, eds. J. P. Smol, R. W. Battarbee, R. B. Davis, and J. Meriläinen, p. 97. Dr. W. Junk, Dordrecht, The Netherlands.

Cronan, C. S., and G. R. Aiken. 1985. "Chemists and Transport of Soluble Humic Substances in Forested Watersheds of the Adirondack Park. New York." Geochem. Cosmochim. Acta 49: 1697-1705.

Dickson, W. T. 1978. "Some Effects of the Acidification of Swedish Lakes." Verh. Intrn. Verin. Limnol. 20:851 -856.

Driscoll, C. T., M. Lehtinen, R. Munson, and S. A. Gherini. 1990. "The Contribution of Strong Inorganic Acids and Organic Acids in Regulating $\mathrm{H}^{*}$ and Al in Adirondack, NY (USA) Lakes." Presented at the International Conference on Acidic Deposition. Its Nature and Impacts. Glasgow, Scotland, September $16-21$.

Hedin, L. O., G. E. Likens, K. M. Postek, and C. T. Driscoll. 1990. "A Field Experiment to Test Whether Organic Acids Buffer Acid Deposition," Nature $345: 798-800$.

Kramer, J. R., and S. S. Davies. 1988. "Estimation of Non-carbonate Protoytes for Selected Lakes in the Eastern Lake Survey." Environ. Sci. Technol. 22:182-185.

Kramer, J. R., C. S. Cronan, J. P. DePinto, H. F. Hemond, E. M. Perdue, and S. Visser. 1989. Organic Acids and Acidification of Surface Waters. Report to Acid Deposition Comittee, Utility Air Regulatory Group.

Kretser, W., J. Gallagher, and J. Nicolette. 1989. Adirondack Lakes Study 1984-1987. Adirondack Lakes Survey Corporation, Ray Brook, New York. 
Lam, D. C. L., A. G. Bobba, R. A. Bourbonniere, G. D. Howell, and M. E. Thompson. 1989. "Modeling Organic and Inorganic Acidity in Two Nova Scotia Rivers." Woter Air Soil Pollut. 46:277-287.

Lind, C. J., and J. D. Hem. 1975. Effects of Orgonic Solutes on Chemical Reoctions of Aluminum. U.S. Geological Survey Water Supply Paper 1827-G.

Perdue, E. M. 1985. "Acidic Functional Groups of Humic Substances." In: Humic Substances in Soil, Sediment, and Woter, eds. G. R. Aiken, D. M. Mcknight, R.L. Wershaw, and P. MacCarthy, Pp. 493-526. Wiley-lnterscience, NY.

Perdue, E. M., J. H. Reuter, and R. S. Parrish. 1984. "A Statistical Model of Proton Binding by Humus." Geochim. Cosmochim Acto 48:1257-1263.

Taylor, M. C., H. C. Duthie, and S. M. Smith. 1988. "Errors Associated with Diatom-inferred Indices for Predicting $\mathrm{pH}$ in Canadian Shield Lakes." In: Proceedings of the gth International Oiaton Symposium, ed. F. Round, P. 273. Bristol, U.K.

Thurman, E. M. 1985. Organic Geochemistry of Natural Waters. Martinus Nijhoff. Dr. W. Junk, Dordrecht, The Netherlands. 
PNL-7487

UC- -603

\section{DISTRIBUTION}

No. of

Copies

OFFSITE

12 DOE/Office of Scientific and Technical Information

J. A. Bernert

E \& S Environmental Chemistry

1325 NH 9th Street

Corvallis, OR 97330

C. Brandt

Oak Ridge National Laboratory

P.0. Box X

Oak Ridge, TN 37831

0 . Bricker

U.S. Geological Survey

12201 Sunrise Valley Drive

Reston, VA 22092

D. F. Charles

Department of Biology

Indiana University

c/o U.S. Environmental

Protection Agency

200 S.W. 35th St.

Corvallis, OR 97333

M. R. Church

NSI Technology Servies Corporation

c/o U.S. Environmental

Protection Agency

200 S.W. 35th St.

Corvallis, OR 97333
No. of

Copies

J. B. Cosby

Department Forestry

Duke University

Durham, NC 27706

B. F. Cumming

Dept. of Biology

Queen's University

Kingston, Ontario

K7L 3N6

Canada

S. S. Dixit

Dept. of Biology

Queen's University

Kingston, Ontario

K7L 3N6

Canada

E. H. Dolacek

L-383

Lawrence Livermore Laboratory

Livermore, CA 94550

J. M. Eilers

E \& S Environmental Chemistry 1325 NW 9th Street

Corvallis, OR 97330

S. A. Gherini

Tetra Tech, Inc.

$3746 \mathrm{Mt}$. Diablo Blvd.

Suite $: 300$

Lafayette, CA 94549 
PNL-7487

UC -603

G. M. Hornberger

Department Environmental Sciences

University of Virginia

Charlottesville, VI 22903

V. C. Kennedy

U.S. Geological Survey

345 Middlefield Road

Menlo Park, CA 94025

E. C. Krug

Illinois State Water Survey

2204 Griffith Drive

Champaign, IL 61820

R. K. Munson

Tetra Tech, Inc.

2 Bay Road

Hedley, MA 01035

N. P. Nikolaidis

The School of Engineering

UTE Building, Room 376

University of Connecticut

Storrs, CT 06168

S. A. Norton

Geological Sciences Department

110 Boardman Hall

University of Maine

Orono, ME 04469

D. E. Phillips

Argonne National Laboratory

9800 Cass Avenue

Argonne, IL 60439

K. A. Rose

Oak Ridge National Laboratory

P.0. Box 2008

Oak Ridge, TN 37831
J. L. Schnoor

Dept. of Civil Engineering

Madison and Washington Streets

University of Jowa

Iowa City, IA 52242

A. R. Selle

Environmental Protection

Agency

1600 SW Western Blvd.

Corvallis, OR 97333

10 T. J. Sullivan

E \& S Environmental Sciences

$1325 \mathrm{NW}$ 9th Street

Corvallis, OR 97330

R. Turner

Oak Ridge National Laboratory

P.0. Box X

Oak Ridge, TN 37831

K. W. Thorton

FTN Associates Ltd.

3 Innword Circle 220

Little Rock, AK 72211

Wa] ter L. Warnick

Program Integration Analysis

Office of Energy Research

U.S. Department of Energy

ER-32, MS: G-236

19901 Germantown Road

Germantown, MI 20874

P. J. Higington

Environmental Research

Laboratory

Environmental Protection Agency

200 S.W. 35th St.

Corvallis, OR 97333 
PNL -7487

UC -603

ONSITE

DOE Richland Operations Office

P. W. Kruger

Westinghouse Hanford Company

R. 0. Budd

23 Pacific Northwest Laboratory

L. E. Eary

J. W. Falco

J. M. Hales

P. C. Hays

E. A. Jenne (10)

R. L. Skaggs

L. W. VaiT

J. R. Weber

Publishing Coordination

Technical Report Files (5) 


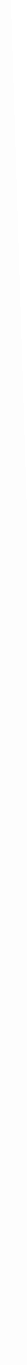

